University of Tennessee Health Science Center

UTHSC Digital Commons

\title{
Oropharyngeal Airway Volume Following Orthodontic Treatment: Premolar Extraction Versus Non-Extraction
}

Thomas Patrick Shannon

University of Tennessee Health Science Center

Follow this and additional works at: https://dc.uthsc.edu/dissertations

Part of the Orthodontics and Orthodontology Commons

\section{Recommended Citation}

Shannon, Thomas Patrick , "Oropharyngeal Airway Volume Following Orthodontic Treatment: Premolar Extraction Versus Non-Extraction" (2012). Theses and Dissertations (ETD). Paper 231. http://dx.doi.org/ 10.21007/etd.cghs.2012.0284.

This Thesis is brought to you for free and open access by the College of Graduate Health Sciences at UTHSC Digital Commons. It has been accepted for inclusion in Theses and Dissertations (ETD) by an authorized administrator of UTHSC Digital Commons. For more information, please contact jwelch30@uthsc.edu. 


\title{
Oropharyngeal Airway Volume Following Orthodontic Treatment: Premolar Extraction Versus Non-Extraction
}

\author{
Abstract \\ Orthodontic correction of tooth size versus arch size discrepancy (TSASD) can be achieved with two \\ distinct methods of treatment. The first involves the extraction of teeth to gain the space needed for tooth \\ alignment. The second relies on arch expansion to gain the space needed for correction. In recent \\ decades, arguments for and against the extraction of teeth for orthodontic purposes have become \\ increasingly important, particularly in regards to oropharyngeal airway size. Purpose: The purpose of this \\ study is to determine whether there is a decrease in oropharyngeal dimensions following the extraction of \\ four premolars and subsequent orthodontic therapy. Methods: Pretreatment and posttreatment CBCT \\ images were taken on 88 healthy, adolescent orthodontic patients ( 27 with 4 premolar extraction, 61 non- \\ extraction). Cephalometric measurements, as well as 3-dimensional analysis of the oropharyx were \\ performed before and after treatment. Results: The extraction group had significantly larger \\ measurements for Anterior Facial Height (AFH), Sella Perpendicular to A Point, SNA, ANB, Facial \\ Convexity, and Y-Axis. The non-extraction group had significantly larger measurements for Sella \\ Perpendicular to B Point. For Sella Perpendicular to L6 Mesial and U6 Mesial, the extraction group had \\ greater mesial movement, which was likely due to Class II treatment mechanics. The measurements that \\ were found to be statistically insignificant between extraction and non-extraction groups were: Atlas \\ Vertebra to Posterior Nasal Spine, Hyoidale to Frankfort Horizontal, Posterior Soft Palate to Posterior \\ Pharyngeal Wall, SNB, Upper Pharyngeal Plane Width, Upper Pharyngeal Plane Area, Middle Pharyngeal \\ Plane Width, Middle Pharyngeal Plane Area, Lower Pharyngeal Plane Width, Lower Pharyngeal Plane Area, \\ Middle Pharyngeal Plane Airway Volume, Inferior Pharyngeal Plane Airway Volume, and Total Pharyngeal \\ Plane Airway Volume. Conclusions: At the level of the posterior nasal spine (PNS), the posterior soft \\ palate, and the tip of the epiglottis, there were net increases in oropharyngeal widths, cross-sectional \\ areas, and oropharyngeal volumes for both treatment groups. There was also no constriction of the \\ oropharyngeal airway during either extraction or non-extraction treatment and there is no quantitative \\ evidence that reducing arch perimeter has any effect on oropharyngeal size.

\section{Document Type} \\ Thesis

\section{Degree Name} \\ Master of Dental Science (MDS)

\section{Program} \\ Orthodontics \\ Research Advisor \\ Edward F. Harris, Ph.D. \\ Keywords \\ Airway, CBCT, Extraction, Oropharynx, Orthodontic, Premolar \\ Subject Categories \\ Dentistry | Medicine and Health Sciences | Orthodontics and Orthodontology
}


OROPHARYNGEAL AIRWAY VOLUME FOLLOWING ORTHODONTIC TREATMENT: PREMOLAR EXTRACTION VERSUS NON-EXTRACTION

\author{
A Thesis \\ Presented for \\ The Graduate Studies Council \\ The University of Tennessee \\ Health Science Center
}

\author{
In Partial Fulfillment \\ Of the Requirements for the Degree \\ Master of Dental Science \\ From The University of Tennessee
}

By

Thomas Patrick Shannon, D.D.S.

May 2012 
Copyright $(92012$ by Thomas Patrick Shannon.

All rights reserved. 


\section{ACKNOWLEDGEMENTS}

I would like to thank Dr. Edward Harris for his expertise, guidance and inspiration. Under his direction, I gained an enthusiasm for the research process and valuable experience that I will apply throughout my career. I would also like to thank Dr. Terry Trojan and Dr. Jere Yates for serving on my thesis committee. Their thoughtful insight and support were invaluable throughout this process. 


\begin{abstract}
Introduction: Orthodontic correction of tooth size versus arch size discrepancy (TSASD) can be achieved with two distinct methods of treatment. The first involves the extraction of teeth to gain the space needed for tooth alignment. The second relies on arch expansion to gain the space needed for correction. In recent decades, arguments for and against the extraction of teeth for orthodontic purposes have become increasingly important, particularly in regards to oropharyngeal airway size. Purpose: The purpose of this study is to determine whether there is a decrease in oropharyngeal dimensions following the extraction of four premolars and subsequent orthodontic therapy.

Methods: Pretreatment and posttreatment CBCT images were taken on 88 healthy, adolescent orthodontic patients (27 with 4 premolar extraction, 61 non-extraction). Cephalometric measurements, as well as 3-dimensional analysis of the oropharyx were performed before and after treatment. Results: The extraction group had significantly larger measurements for Anterior Facial Height (AFH), Sella Perpendicular to A Point, SNA, ANB, Facial Convexity, and Y-Axis. The non-extraction group had significantly larger measurements for Sella Perpendicular to B Point. For Sella Perpendicular to L6 Mesial and U6 Mesial, the extraction group had greater mesial movement, which was likely due to Class II treatment mechanics. The measurements that were found to be statistically insignificant between extraction and non-extraction groups were: Atlas Vertebra to Posterior Nasal Spine, Hyoidale to Frankfort Horizontal, Posterior Soft Palate to Posterior Pharyngeal Wall, SNB, Upper Pharyngeal Plane Width, Upper Pharyngeal Plane Area, Middle Pharyngeal Plane Width, Middle Pharyngeal Plane Area, Lower Pharyngeal Plane Width, Lower Pharyngeal Plane Area, Middle Pharyngeal Plane Airway Volume, Inferior Pharyngeal Plane Airway Volume, and Total Pharyngeal Plane Airway Volume. Conclusions: At the level of the posterior nasal spine (PNS), the posterior soft palate, and the tip of the epiglottis, there were net increases in oropharyngeal widths, cross-sectional areas, and oropharyngeal volumes for both treatment groups. There was also no constriction of the oropharyngeal airway during either extraction or non-extraction treatment and there is no quantitative evidence that reducing arch perimeter has any effect on oropharyngeal size.
\end{abstract}




\section{TABLE OF CONTENTS}

CHAPTER 1. INTRODUCTION ........................................................................................1

CHAPTER 2. REVIEW OF THE LITERATURE ....................................................3

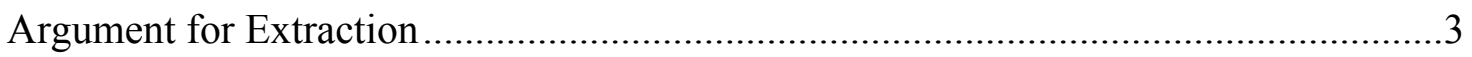

Argument for Expansion..................................................................................... 4

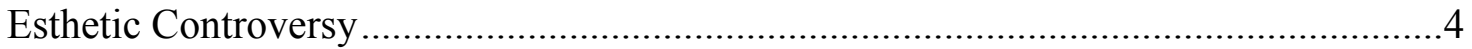

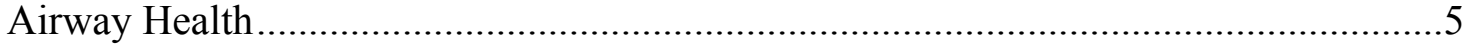

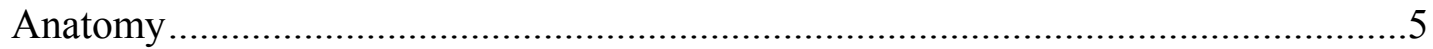

Tooth Extraction and Airway Health ...................................................................... 5

Obstructive Sleep Apnea.................................................................................

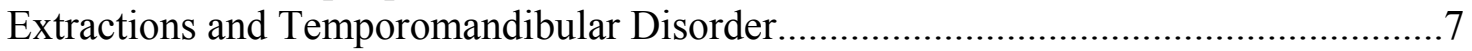

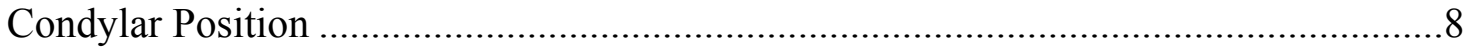

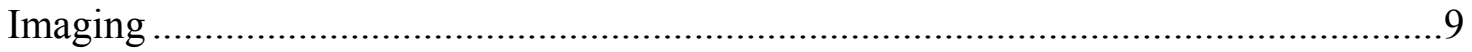

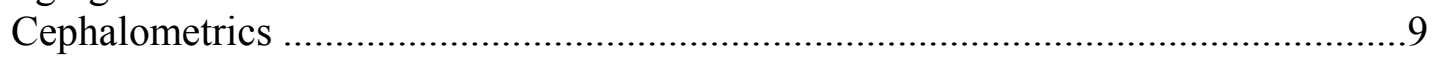

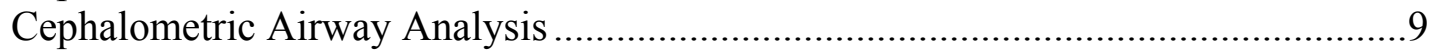

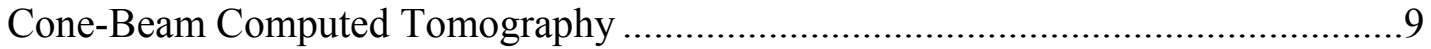

CHAPTER 3. MATERIALS AND METHODS.......................................................11

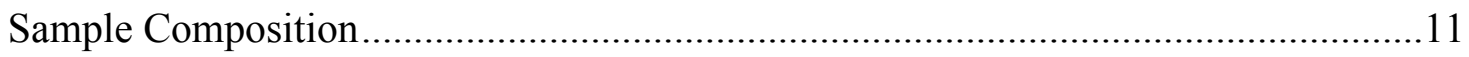

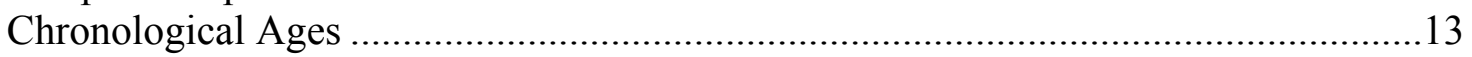

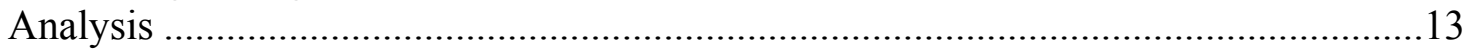

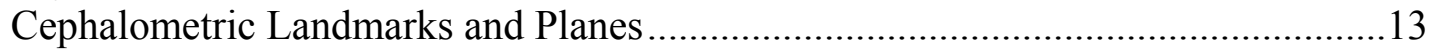

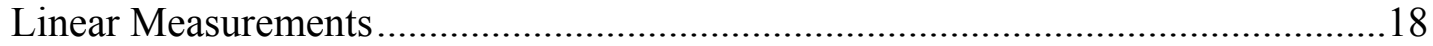

Angular Measurements ...................................................................................... 19

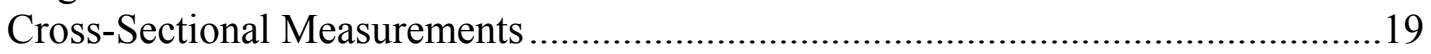

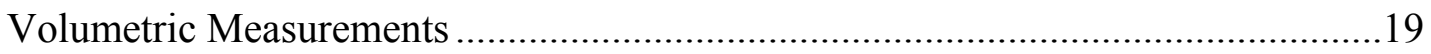

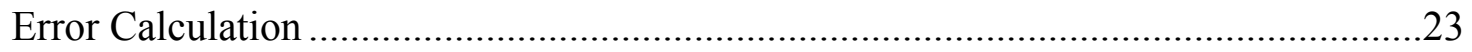

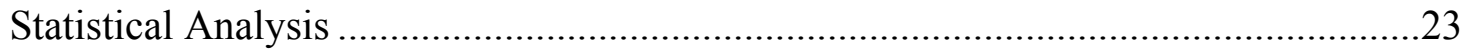

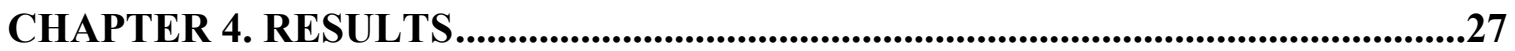

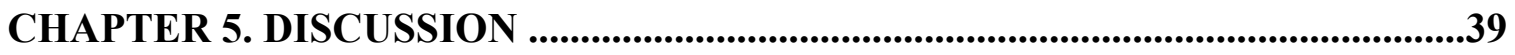

CHAPTER 6. SUMMARY AND CONCLUSIONS............................................45

LIST OF REFERENCES...................................................................................................46

APPENDIX A. ANCOVA TABLES TESTING FOR TREATMENT
DIFFERENCES WHILE CONTROLING FOR AGE AND SEX ............................53

APPENDIX B. RESULTS OF ONE-SAMPLE T-TEST TESTING FOR STATISTICALLY SIGNIFICANT TREATMENT CHANGES..............................76

APPENDIX C. TREATMENT CHANGES .......................................................88 
APPENDIX D. DESCRIPTIVE STATISTICS BY GROUP AND SEX.....................100

APPENDIX E. DESCRIPTIVE STATISTICS BY GROUP ........................................123

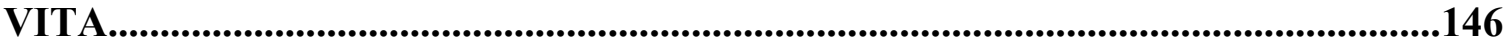




\section{LIST OF TABLES}

Table 1. Descriptive statistics for chronological ages of the samples. .....................12

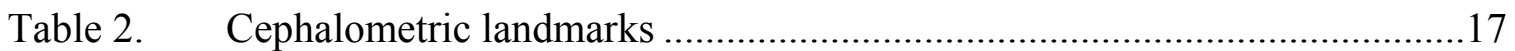

Table 3. Cross-sectional planes of the oropharyngeal airway ................................22

Table 4. Volumetric analysis of the oropharyngeal airway ..................................25 


\section{LIST OF FIGURES}

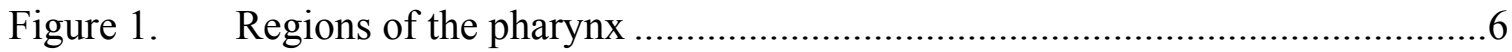

Figure 2. Box plots of the age distributions at the start of treatment, by group ..........14

Figure 3. Box plots of the age distributions at the end of treatment, by group ...........14

Figure 4. Box plots of the time in treatment (years) in the two treatment groups.......15

Figure 5. Cephalometric landmarks identified on unmagnified lateral cephalometric images from CBCT DICOM files ........................................16

Figure 6. Landmark measurements identified on the unmagnified lateral cephalometric images generated from CBCT DICOM files.........................20

Figure 7. Upper pharyngeal plane (Uph plane) ......................................................21

Figure 8. Middle pharyngeal plane (Mph plane) .....................................................21

Figure 9. Lower pharyngeal plane (Lph plane) ....................................................22

Figure 10. Middle pharyngeal airway volume.......................................................24

Figure 11. Inferior pharyngeal airway volume ......................................................24

Figure 12. Total pharyngeal airway volume................................................................25

Figure 13. Plot of the least square means, by sex and extraction pattern, at the start and end of treatment for the variable Sella Perpendicular to B Point...........30

Figure 14. Plot of the least square means, by sex and extraction pattern at the start and end of treatment for the variable Sella Perpendicular to U6 Mesial .....32

Figure 15. Plot of the Y-axis at the start of treatment by chronological age, showing the sex difference that creates a significant age-by-sex interaction for this variable

Figure 16. Plot of the difference in age-progressive changes in middle area depending on extraction treatment at the start of treatment.

Figure 17. Plot of the middle pharyngeal volume at the end of treatment, by extraction group and sex

Figure 18. Plot of total pharyngeal volume against age, depending on extraction mode...... 
Figure 19. Plot of start and end of treatment values for Sella Perpendicular to L6

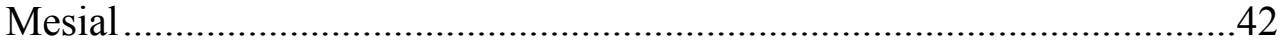

Figure 20. Plot of start and end of treatment values for Sella Perpendicular to U6 Mesial...................................................................................................42

Figure 21. Plot of start and end of treatment values for Y-Axis ..................................43 


\section{CHAPTER 1. INTRODUCTION}

Malocclusion is common in modern society (Kelly and Harvey 1977; Corruccini 1984; Brunelle et al. 1996) and, if untreated, can impair function and esthetics of the dentition. Although malocclusions may result from a variety of environmental or developmental factors (Corruccini 1980; Harris and Smith 1980; Harris and Johnson 1991), a common condition often exists: discrepancy between tooth size and arch size. Orthodontics is primarily concerned with lack of arch space within the alveolus (McDougall et al. 1982; Vaden and Kiser 1996), and there currently are two primary treatments to resolve tooth size versus arch size discrepancy (TSASD). The first involves the extraction of teeth to gain the space needed for tooth alignment. The second relies on arch expansion to gain the space needed for correction.

There is little agreement among orthodontists when it comes to extracting teeth (Han et al. 1991; Stephens et al. 1993). The decision to include extractions in an orthodontic treatment plan depends not only on clinical factors (e.g., facial profile, TSASD), but also on individual clinical preferences (Baumrind et al. 1996). As a result, the majority of orthodontists are not strictly "extractionists" or "non-extractionists" and clinical diagnoses and treatment decisions are arrayed across a continuum (Han et al. 1991). Although extractions have certain disadvantages (e.g., unpleasant for the patient, increased cost of treatment, and increased mean treatment time) (Vig et al. 1990), all treatment options must be assessed in order to provide the best care for the patient (Ribarevski et al. 1996).

Insufficient arch length is a common problem and results in TSASD (Mills 1964; Howe et al. 1983). Arch length deficiency may also worsen over an individual's lifetime (Paquette et al. 1992; Luppanapornlarp and Johnston 1993). In order to treat arch space deficiency, there primarily are two treatment options. The first utilizes extractions to free up arch space for the orthodontic correction. The second focuses on expanding the dental arches to create space.

Premolar extraction is a common treatment option for TSASD because it provides space for subsequent correction. Controversy not only lies with which teeth should be extracted, but also the consequences of space closure. According to extraction opponents, closing extraction spaces reduces the radius of the dental arch (Spahl and Witzig 1987), negatively impacts facial esthetics (Dierkes 1987), and promotes airway deficiency. Through "careless" retraction of the maxilla, the mandibular arch is forced to fit into a maxillary arch that is too small (Hang 2006), which decreases airway volume, increases parafunction, increases the risk of temporomandibular disorder (TMD), and increases chances of obstructive sleep apnea (Hang 2007). Schematically, this argument is intuitive and many websites provide radiographs (Fasttraxortho 2009; Orthotropics 2010), diagrams, and animations (Facefocused 2010) purporting to demonstrate this concept. 
This view that tooth extractions are dangerous is the driving force behind the orthotropic movement. Started nearly a half-century ago by John Mew, an orthodontist, orthotropics is now primarily composed of general dentists who take the non-extraction philosophy to an extreme. According to orthotropists, dental malocclusion can be linked to poor oral posture (Singh et al. 2007), as interpreted from experimental primate studies reported by Harvold et al. (1972, 1981). In addition, weak masticatory musculature, facilitated by a soft modern diet (Kiliaridis and Kalebo 1991), causes the mouth to hang open, resulting in a downward-backward positioning of the mandible and increased vertical growth (Kiliaridis et al. 1989; Mew 2004).

Vertical growth, according to orthotropists, leads to a decrease in airway space, development of malocclusions, and poor facial esthetics (Singh et al. 2007). To "prevent" this, orthotropists use early treatment with removable expansion appliances to protrude the maxillary and mandibular dentition with the intent of enhancing the horizontal growth pattern (Singh et al. 2007). Once a horizontal growth pattern is achieved, the claimed scenario is that malocclusions will resolve (Mew 2007), the airway will open to its full potential, and facial esthetics will improve (Singh et al. 2007).

In recent decades, arguments for and against the extraction of teeth for orthodontic purposes have become increasingly important to the dental community. With the increase in patient and parent awareness, greater access and reliance on internet message boards for dental information, the relationship between extractions and airway health merit scientific assessment. In addition, orthodontists need to be prepared to answer questions that parents and referring dentists develop from scanning websites and internet forums, which provide simplified scenarios and legal advice (Smilepage 2004; Orthodontic-outrage 2008). It is important that the orthodontic community have a clear understanding of the effect on oropharyngeal dimensions and volume following extraction and non-extraction of premolars during orthodontic treatment. Since the potential side effects of tooth extraction focus on claimed constriction of the airway, it must be determined whether or not extractions are responsible.

The purpose of the present study is to determine whether there is a decrease in oropharyngeal dimensions following the extraction of four premolars and subsequent orthodontic therapy. This issue merits study to ensure that clinicians will be aware of any airway consequences of orthodontic treatment, as claimed by orthotropists. The results will shed some light on this debated topic and help orthodontists provide the best care for their patients. 


\section{CHAPTER 2. REVIEW OF THE LITERATURE}

The arguments for and against extractions are as old as the orthodontic specialty, but continue to spark debate (Weintraub et al. 1989; Proffit 1994).

\section{Argument for Extraction}

Proponents of orthodontic extractions contend that functional limits of arch size are genetically predetermined (Tweed 1963). Consequently, extracting teeth is necessary for orthodontic correction in order to respect the limits of the dentition (Tweed 1944; 1963; Strang 1949; Pearson 1986; Richardson 1989) and achieve proper esthetics, health of the dental tissue and occlusal stability (Tweed 1944, 1963; Strang 1949). This argument rests on the premise that teeth are confined to biologically-determined spacial boundaries and should not be moved beyond the limits of supporting alveolar bone (Tweed 1944). Brodie et al. (1938) determined that, although teeth are moved to resolve malocclusions, the movement must be confined to the existing dental arch.

For many clinicians, expanding the dentition beyond the basal bone violates this fundamental orthodontic principle of respecting the limits of the dentition. According to Vaden and Kiser (1996), orthodontists must be mindful of the physiological limits of tooth movement. They state that, in order to achieve proper esthetics, health, function, and stability, the anterior, posterior, vertical, and lateral dimensions must be respected.

According to Vaden and Kiser (1996), the anterior dimension of occlusion is vital to facial balance, as well as occlusal stability. Tweed argued that uprighted mandibular incisors were the cornerstone of this stability (1944). Although patients with high Frankfort mandibular plane angles require more mandibular incisor uprighting, even those with low Frankfort mandibular plane angles should not have protruded mandibular incisors (Vaden and Kiser 1996). In a patient with normal muscular balance, extractions are often necessary in the presence of anterior crowding and/or protrusion (Tweed 1944; Vaden and Kiser 1996).

The posterior dimension of occlusion is largely disregarded by clinicians, and teeth are commonly retracted into a space that is inadequate (Vaden and Kiser 1996). In many non-extraction cases, these writers contend that second molars may be impacted due to retraction into space-deficient posterior arch segments. After premolar and third molar extraction, proper function and eruption of the second molar can be restored in such cases (Vaden and Kiser 1996).

The third dimension in Vaden and Kiser's paper (1996) deals with the vertical limitis of occlusion. The authors state that if the vertical dimension is increased in the posterior, a longer face and gingival excess is created. For every $1 \mathrm{~mm}$ of vertical increase in the molar area, there is a $1.3 \mathrm{~mm}$ increase in anterior facial height (Merrifield 1970). Patients treated without extractions are often expanded vertically (Vaden and 
Kiser 1996). If stability and facial balance are treatment goals, the vertical dimension must be preserved and extractions may be necessary.

The lateral dimension of occlusion deals with mediolateral expansion of the dental arch. Lateral expansion frequently results in violation of anterior and posterior limits of the dentition (Vaden and Kiser 1996), as well as high levels of relapse (Little et al. 1981). In patients treated with expansion and non-extraction, downward and backward rotation of the mandible occurred and, due to expansion of anterior, posterior, vertical and lateral segments, lower lip eversion and soft tissue imbalance developed (Vaden and Kiser 1996).

\section{Argument for Expansion}

Historically, opponents of tooth extractions commonly cite man's natural, evolutionary condition (Angle 1907). Depending on morphological characteristics and position of the teeth, associated soft and hard tissue structures will develop to the proper dimensions (Hellman 1944). Supporters of this view contend that the physiologic function of the dentofacial complexes determine their form and, in many cases, a "full complement of teeth" is necessary for proper growth and development (Angle 1907:63).

More recent opponents of orthodontic extractions contend that arch size is not immutable and that dental crowding may result from incomplete jaw development (McDougall et al. 1982). It is proposed that environmental conditions may predispose individuals to underdeveloped skeletal structures that are too small to accommodate the teeth. This has lead to an alternative method of gaining arch space, namely expansion of the dental arches. Dental arch expansion is achieved in both lateral and sagittal dimensions with palatal expansion (Haas 1961; Fränkel 1969) and functional appliances (McDougall et al. 1982). Through expansion, full development of the dental arch is possible (McDougall et al. 1982), increasing arch perimeter. This allows for teeth to be orthodontically repositioned within the enhanced alveolar processes, eliminating the need for the removal of permanent teeth in many cases.

\section{Esthetic Controversy}

There is ongoing debate about the long-term esthetic consequences of extractions as a means for orthodontic correction. Extraction opponents argue that extracting premolars can cause negative profile changes (Caplan and Shivapuja 1997). Luppanapornlarp and Johnston (1993) studied the esthetic effects of premolar extraction and non-extraction in patients with "clear-cut" treatment plans. They found that nonextraction therapy had little effect on denture position in these cases, while extraction of the premolars had a larger impact (1993). In patients with protrusive profiles, extracting premolars improved esthetics; patients treated with extractions had "full, pleasing profiles," whereas initially-retrusive patients treated without extractions had "concave faces." 
Bowman and Johnston (2000) found that the esthetic impact of premolar extraction depends on initial protrusion of the profile. In their study, premolar extractions decreased facial convexity an average of $1.8 \mathrm{~mm}$. This decrease was beneficial in cases where the objective was to reduce lip procumbency, but it worsened the profiles of patients whose lips were initially 2 to $3 \mathrm{~mm}$ behind the E-Plane.

\section{Airway Health}

\section{Anatomy}

The primary area of concern for airway health is the pharynx, specifically the oropharynx. The pharynx is located immediately dorsal to the oral and nasal cavities, and superior to the esophagus, larynx, and trachea (Netter 2006). The pharynx is a tubeshaped structure and continues to grow into adulthood (Tsai 2007; Sheng et al. 2009). As displayed in Figure 1, the pharynx is divided into three components: the nasopharynx, laryngopharynx, and oropharynx.

The nasopharynx, also known as the epipharynx, lies dorsal to the nasal cavity and extends cranially from the soft palate to the nasal passages (Netter 2006). The laryngopharynx, also known as the hypopharynx, is the region of the pharynx below the cranial edge of the epiglottis, opening into the larynx and esophagus at the level of the hyoid bone (Netter 2006). The oropharynx lies dorsal of the oral cavity, superior to the laryngopharynx and inferior to the nasopharynx, extending from the soft palate to the epiglottis (Netter 2006). Airway constriction in the oropharyngeal region can lead to breathing problems (Ozbek et al. 1998; Singh et al. 2007).

\section{Tooth Extraction and Airway Health}

One prominent concern for non-extraction advocates is the maintenance of adequate airway volume (Hang 2006). Some clinicians theorize that a decrease in airway volume may occur after teeth are extracted. They maintain that, by closing extraction spaces, the maxilla and the mandible retrude (Hang 2006), causing a retrognathic mandibular position and consequent constriction of the oropharyngeal airway (Ozbek et al. 1998; Singh et al. 2007).

A retruded mandibular position may be associated with airway constriction via the lingual musculature and its attachment to the hyoid bone (Tsai et al. 2009). According to orthotropists, a retrusive mandibular position results in excessive vertical facial growth, due to a downward, backward positioning of the mandible (Kiliaridis et al. 1989; Mew 2004). As the mandible shifts downward and backward, there is an increase in lower facial height and in the gonial angle (Tsai et al. 2009). When these increases are combined with the lingual muscular attachment to the hyoid bone, the result is a hyoid bone that is positioned both dorsally and inferiorly. An inferior displacement of the 


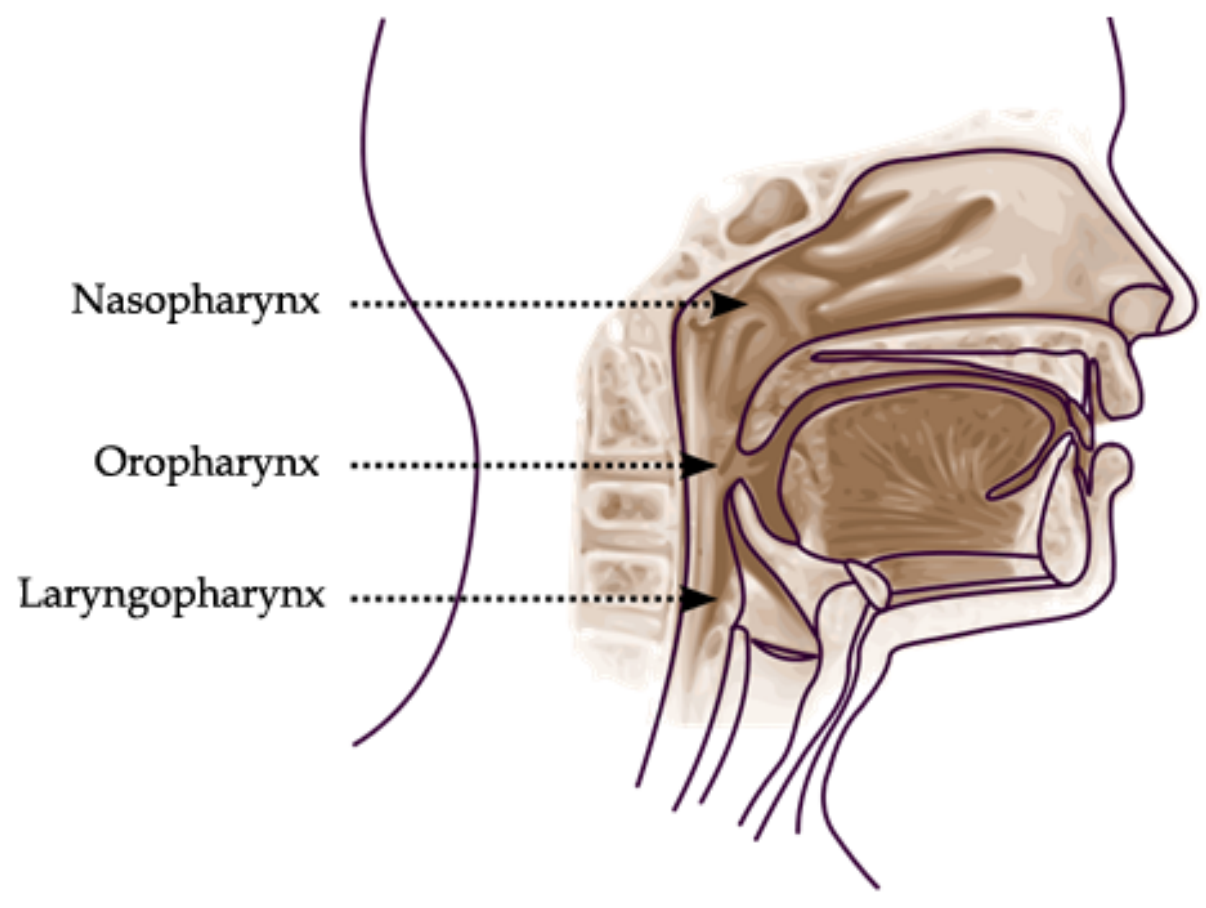

Figure 1. Regions of the pharynx. Wikimedia Commons. Author: Sémhur. Permission to modify. http://upload.wikimedia.org/wikipedia/commons/thumb/6/61/ Pharynx_diagram-fr.svg/800px-Pharynx_diagram-fr.svg.png. Date of accession: 12/07/09. 
hyoid bone and increased lower facial height are predisposing factors for upper airway obstruction (Lowe et al. 1986). Reduction of oropharyngeal airway volume due to extractions and subsequent skeletal changes may lead to serious breathing disorders, including obstructive sleep apnea (Facefocused 2010).

\section{Obstructive Sleep Apnea}

Obstructive sleep apnea (OSA) is a common breathing disorder characterized by recurrent episodes of cessation of airflow during sleep (McNamara 1993). Individuals with OSA have a decreased pharyngeal cross-sectional area (McNamara 1993), caused by the constriction of the upper airway at the level of the pharynx (Hudgel 1992). Constriction of the airway can lead to adverse clinical symptoms including daytime sleepiness, cognitive dysfunction and memory loss, hypertension, and even increased risk of stroke, angina, and myocardial infarction (Phillipson 1993). According to a study by Young et al. (1993), OSA is a notable public health concern and currently 4 percent of women and 9 percent of men experience 15 or more apnea episodes per hour of sleep.

Constriction of the oropharyngeal airway may occur in one or more anatomic locations (Battagel et al. 1999). In studies involving airflow dynamics, constriction most frequently occurs in the retropalatal and retroglossal regions (Launois et al. 1993; Morrison et al. 1993), with a majority occurring in the oropharynx (Lowe et al. 1986). Since OSA has been shown to be associated with constricted oropharyngeal airways (Lowe et al. 1986; Bacon et al. 1990; Ono et al. 2000), it is relevant to determine if there is a decrease in oropharyngeal linear dimensions or volume following dental extractions for orthodontic treatment.

\section{Extractions and Temporomandibular Disorder}

In the past two decades, the orthodontic community has faced criticism regarding the alleged relationship between orthodontic treatment, particularly in cases of premolar extraction, and increased risk of temporomandibular disorder (TMD) (e.g., Kremenak et al. 1992; Profitt 1994). In 1987, the American Association of Orthodontists (AAO) established a committee to oversee research in this area, and studies focused on common orthodontic treatment methods and health of the tempormandibular joint (Behrents 1992).

Luecke and Johnston (1992) used cephalometric superimpositions to study mandibular position following orthodontic treatment where there was extraction of two maxillary premolars. This study was conducted to determine whether the mandible becomes "trapped" following maxillary retraction to close extraction spaces. The results were that the majority of the mandibles underwent a mesial displacement, which is associated with mesial movement of the buccal segments, not retraction of the incisors.

In a two-part study, Kremenak et al. (1992) first looked at premolar extractions as a risk factor for TMD. Using data from a longitudinal study begun in 1983, TMD records 
were collected before the initiation of orthodontic treatment, between 0 and 12 months after debanding, and 12 to 24 months after debanding. Results showed no clinical difference in TMD incidence between the premolar extraction and non-extraction groups. This study agrees with previous reports (Larsson and Ronnerman 1981; Sadowsky et al. 1991) and argues that extractions should not be considered a risk factor for TMJ pathology.

\section{Condylar Position}

Mechanistic inferences can be made about premolar extractions and subsequent orthodontic retraction. According to Gianelly et al. (1991), a superficial understanding is predicated on the maxillary incisors "entrapping" the mandibular arch and forcing the mandible dorsally. Although this mechanism is obscure, anecdotal, and not supported by controlled group studies (Luppanapornlarp and Johnston 1993), various claims are found on many websites that cater to the public.

One claim is that condyles are displaced posteriorly following extraction of premolars and orthodontic retraction. In their study, Farrar and McCarty (1983) concluded that displacement of the condyles may lead to internal joint derangements and TMD. This conclusion was not universally accepted, however. A later investigation by Årtun et al. (1992) found that posterior displacement of the condyles does not cause TMD, but is associated with temporomandibular clicking. In his paper, though, he is quick to mention that posteriorly-located condyles were not exclusive to patients treated with premolar extractions, and subjects with posteriorly-located condyles did not always experience condylar clicking.

Supported by a long-term cephalometric study, Paquette et al. (1992) found no evidence linking distal displacement to extraction or non-extraction treatment. In addition, Paquette concluded that ventral displacement of the chin and condyles occur in both treatments. Also, Gianelly et al. found no empirical evidence to support the claim that premolar extractions displace the condyles and concluded that the dimensions surrounding the condyles within the glenoid fossae do not change following either extraction or non-extraction orthodontic treatment (1991).

In a related study, Luppanapornlarp and Johnston (1993) found that there was no significant difference in TMD between premolar extraction cases and non-extraction cases. They also found that in cases with premolar extractions, the condyles had a significantly more mesial position when compared to the non-extraction group. 


\section{Imaging}

\section{Cephalometrics}

Radiographic cephalometry represents one of the most significant technological advancements in orthodontic diagnosis and treatment planning. For the past 75 years (Lamichane et al. 2009), cephalometric imaging has been the gold standard for assessing relationships among all areas of the craniofacial complexes (Berco et al. 2009). Although 2-dimensional cephalometry has limitations that are well-established in the literature, it remains a mainstay in orthodontic diagnosis because it evaluates the spatial relationships of both skeletal and dental structures with high resolution (Mah and Hatcher 2005). Some of the disadvantages are horizontal and vertical distortion of anatomical structures, imperfect superimposition of right and left sides, image distortion due to improper patient positioning, inaccurate landmark location or identification, and inconsistent calibration of source-to-film distances (Lamichane 2009).

\section{Cephalometric Airway Analysis}

Two-dimensional lateral cephalometry has traditionally represented the gold standard in the analysis of airway dimensions (Malkoc et al. 2005). Although useful for analyzing airway size in the sagittal plane, 3-dimensional anatomical measurements are not imaged (Abramson et al. 2010). Research has revealed many limitations of 2dimensional radiographs (Lowe et al. 1986; Finkelstein et al. 2001), particularly the inability to view the transverse dimension (Hanggi et al. 2008). Previous studies using 2-dimensional cephalometric analyses to determine airway dimensions were obliged to draw major inferences from the narrowest anteroposterior points in the airway. Simply measuring the narrowest constriction of a 2-dimensional image cannot fully quantify the spatial relationships between the two structures (Lowe et al. 1986).

\section{Cone-Beam Computed Tomography}

Cone-beam computed tomography (CBCT), also known as cone-beam volumetric tomography (CBVT) records maxillofacial structures in three dimensions, providing a volumetric analysis of the oropharyngeal airway. CBCT differs from medical computed tomography in many ways, including the type of imaging source detector complex and method of data acquisition. According to Mah and Hatcher (2004), the x-ray source for medical CT is a high output rotating anode generator. CBCT, on the other hand, uses a low-energy fixed anode, similar to ones used in dental panoramic machines. CT incorporates a fan-shaped $\mathrm{x}$-ray beam and data are recorded on solid-state image detectors arranged $360^{\circ}$ around the patient. Conversely, CBCT uses a cone-shaped x-ray beam with a specialized image intensifier. The radiographic image is then captured on a solid-state sensor or an amorphous silicon plate (Mah and Hatcher 2004). 
There also are differences between medical CT and CBCT in mode of image capture. Medical CT images use a series of axial plane slices to image patients. CBCT is similar to panoramic radiography and only uses one rotation around the patient, collecting complete maxillofacial volume on a small region of interest (Mah and Hatcher 2004). In addition, CBCT does not require patients to be supine. Patients can be seated in a natural, upright position, which is important when imaging physiologic hard and soft tissue relationships. CBCT is also the preferred method for airway volume measurement, due to its relatively low cost, ease of access, availability to dentists, and lower effective absorbed dose, when compared to CT (Ogawa et al. 2007). 


\section{CHAPTER 3. MATERIALS AND METHODS}

This is a retrospective study of orthodontic patients, all of whom were treated with comprehensive fully-banded appliances. This study was HIPAA compliant, and final review board approval was obtained from the University of Tennessee Health Science Center (UTHSC IRB\# 11-01239-XM).

\section{Sample Composition}

Orophayrngeal structures were studied in 88 healthy patients (27 extraction, 61 non-extraction) treated orthodontically in private practices in Jackson, Tennessee, and Green Bay, Wisconsin. These subjects had no missing teeth (ignoring third molars) and no developmental defects or abnormalities affecting the craniofacial region. The nonextraction group was composed of 30 males and 31 females who were treated orthodontically without the removal of any teeth, excluding third molars. The extraction group consisted of 11 males and 16 females who each had four premolars removed as part of their orthodontic treatment. One CBCT DICOM file was obtained from each patient at the start and end of treatment.

At the start of orthodontic treatment, the mean age of the non-extraction group was 13.2 years old $(\mathrm{sd}=1.95)$ and the extraction group was 13.5 years old $(\mathrm{sd}=2.87)$. At the end of orthodontic treatment, the mean age of the non-extraction group was 14.9 years old $(\mathrm{sd}=1.92)$ and the extraction group was 15.6 years old $(\mathrm{sd}=2.81)$. The mean treatment time for the non-extraction group was 1.6 years $(\mathrm{sd}=0.31)$ and 2.2 years $(\mathrm{sd}=$ 0.36 ) for the extraction group. The sample characteristics for this study are presented in Table 1.

The research protocol for this study was developed to measure the structural responses of the hard and soft tissues surrounding the oropharynx during orthodontic treatment. To facilitate this analysis, pretreatment and posttreatment cone-beam computed tomographs (CBCTs) were analyzed with Dolphin Imagining ${ }^{\circledR}$ software, Version 11.0 (Dolphin Imaging \& Management Solutions, Chatsworth, CA). The 3D scans were generated using an iCAT CBCT machine (Imagine Sciences International, Hatfield, PA) with a 12 inch field of view to include the craniofacial anatomy.

Each 3D scan was analyzed to assess any change in skeletal relationships or oropharyngeal volume during orthodontic treatment. In addition, 2D cephalometric images were also generated from the 3D scans. Dolphin Imaging ${ }^{\circledR}$ software version 11.0 (Dolphin Imaging \& Management Solutions, Chatsworth, CA) was used to determine all linear and angular measurements, cross-sectional areas, and volumes for this study. 
Table 1. Descriptive statistics for chronological ages of the samples.

\begin{tabular}{lcr}
\hline \multicolumn{1}{c}{ Statistic } & Non-Ext & Extraction \\
\hline & Age at Start of Treatment & \\
Mean & 13.22 & 13.46 \\
Std Dev & 1.95 & 2.87 \\
Std Err Mean & 0.25 & 0.55 \\
Upper 95\% Mean & 13.72 & 14.60 \\
Lower 95\% Mean & 12.72 & 12.32 \\
Sample Size & 61 & 27 \\
& & \\
Mean & Age at End of Treatment & \\
Std Dev & 14.86 & 15.62 \\
Std Err Mean & 1.92 & 2.81 \\
Upper 95\% Mean & 0.25 & 0.54 \\
Lower 95\% Mean & 15.35 & 16.73 \\
Sample Size & 14.36 & 14.51 \\
& 61 & 27 \\
Mean & & \\
Std Dev & Time in Treatment & \\
Std Err Mean & 1.63 & 2.16 \\
Upper 95\% Mean & 0.31 & 0.36 \\
Lower 95\% Mean & 0.04 & 0.07 \\
Sample Size & 1.71 & 2.30 \\
\hline
\end{tabular}




\section{Chronological Ages}

Ages at the start of orthodontic treatment ranged from late childhood into early adulthood (Figure 2). By $\mathrm{t}$-test, there is no difference in initial age between groups $(\mathrm{t}=$ $0.46 ; \mathrm{df}=86 ; \mathrm{P}=0.6482$ ).

Ages at the end of treatment are plotted in Figure 3. Again, the means do not differ between groups $(\mathrm{t}=1.48 ; \mathrm{df}=86 ; \mathrm{P}=0.1424)$.

Treatment averaged 1.8 years overall (Figure 4), but it was significantly longer $(\bar{x}=2.03 \mathrm{yrs})$ in the extraction group compared to the non-extraction group $(\overline{\mathrm{x}}=1.63$ $\mathrm{yr})$. By $\mathrm{t}$-test the difference is significant $(\mathrm{t}=6.9 ; \mathrm{df}=86 ; \mathrm{P}<0.0001)$.

\section{Analysis}

Volumetric measurements, as well as cephalometric radiographs were generated from CBCT scans at two time points, the pretreatment examination (T1) and at completion of orthodontic treatment (T2).

\section{Cephalometric Landmarks and Planes}

A total of 19 landmarks and planes were identified on each cephalometric image (Figure 5). Points were located on a computer screen and not traced on acetate. The following alphabetical listing provides definitions of the cephalometric landmarks used in this study:

A Point A (Subspinale): the most posterior point on the exterior ventral curve of the maxilla between the anterior nasal spine and Supradentale.

Aa Atlas vertebra: the most ventral point on the vertebral atlas.

B Point B (Supramentale): the most posterior point on the bony curvature of the mandible between Infradentale and Pogonion.

Et Tip of epiglottis: the most superior point of the epiglottis.

FH Frankfort Horizontal: a horizontal plane drawn from porion to orbitale, with patient in natural head position.

Gn Gnathion (anatomic): the most anterior-inferior point of the mandibular symphysis.

Hy Hyoidale: the most superior and anterior point on the body of the hyoid bone.

L6 L6 mesial: the most mesial point on the height of contour of lower first molar. 


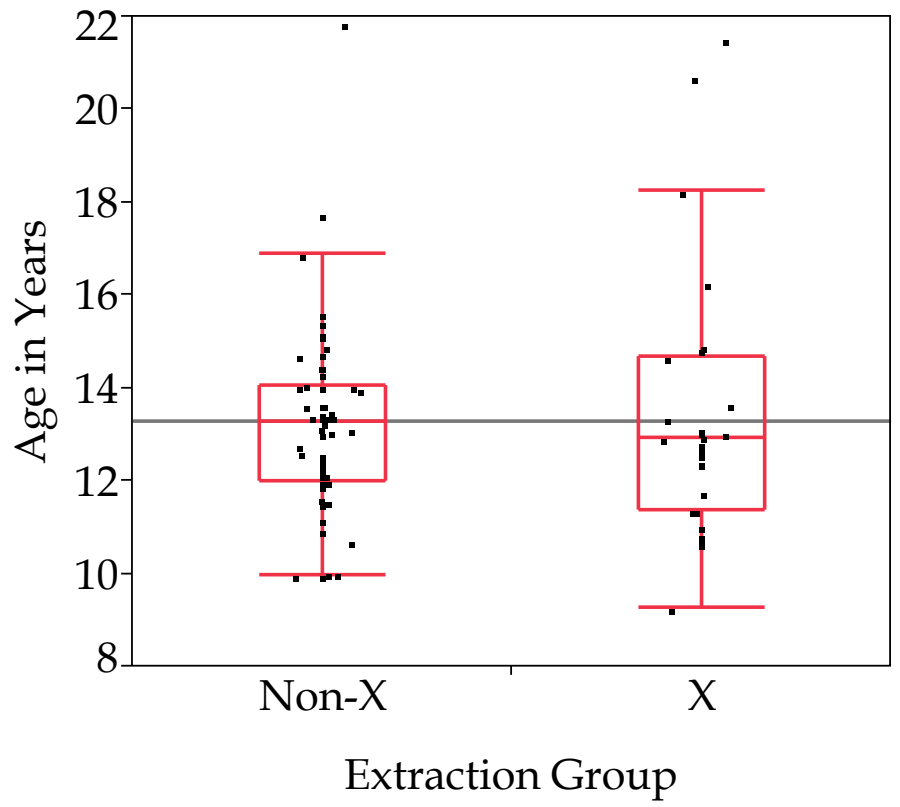

Figure 2. Box plots of the age distributions at the start of treatment, by group.

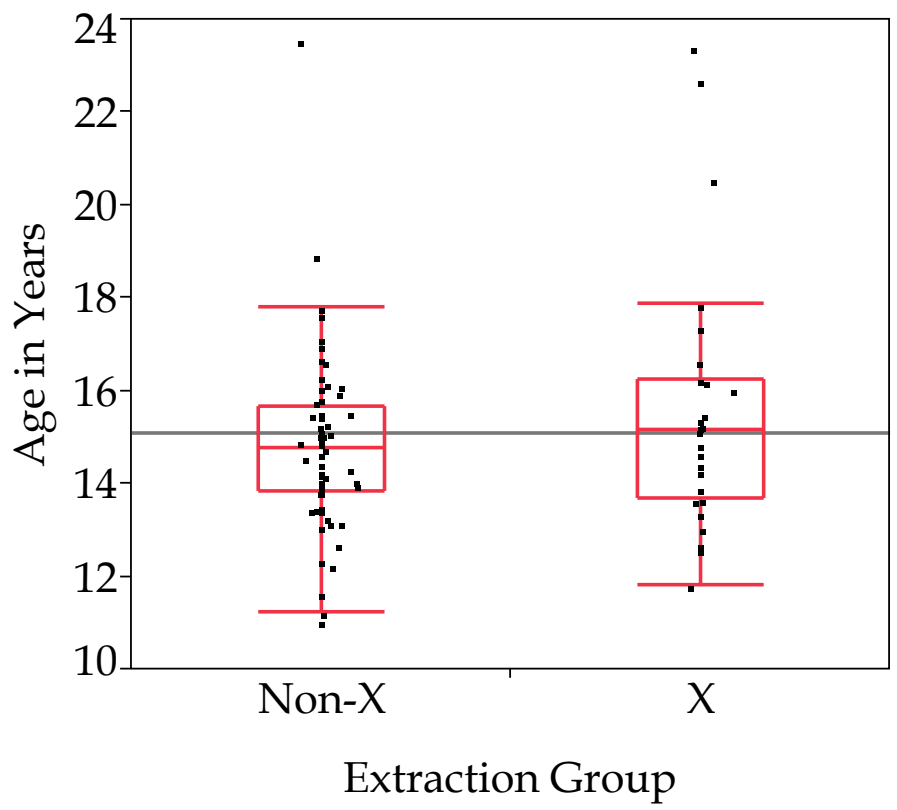

Figure 3. Box plots of the age distributions at the end of treatment, by group. 


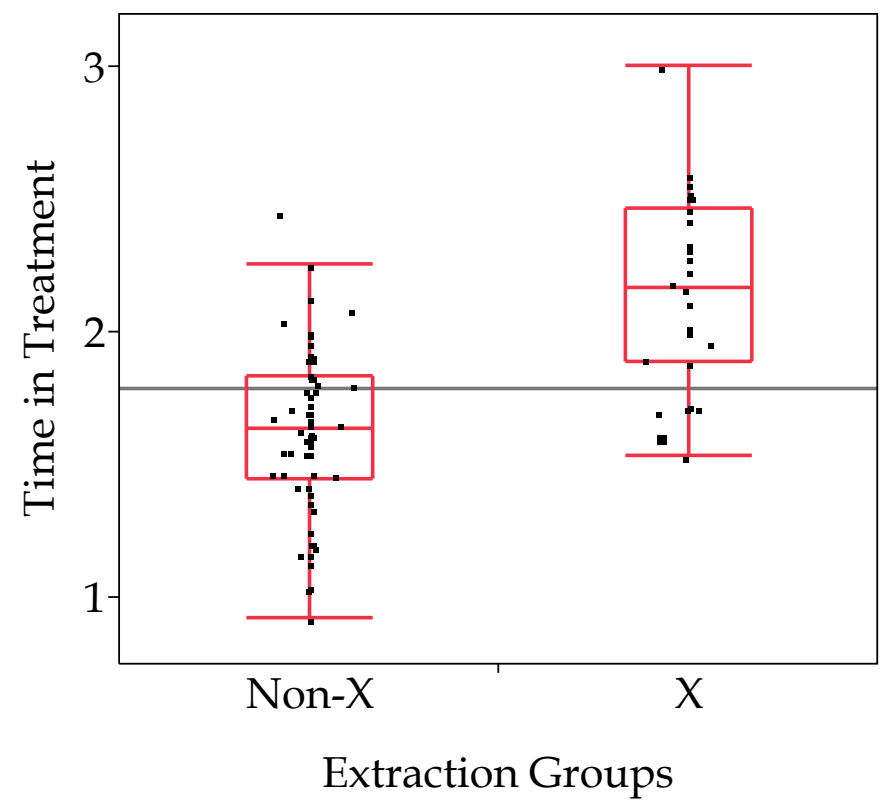

Figure 4. Box plots of the time in treatment (years) in the two treatment groups. 


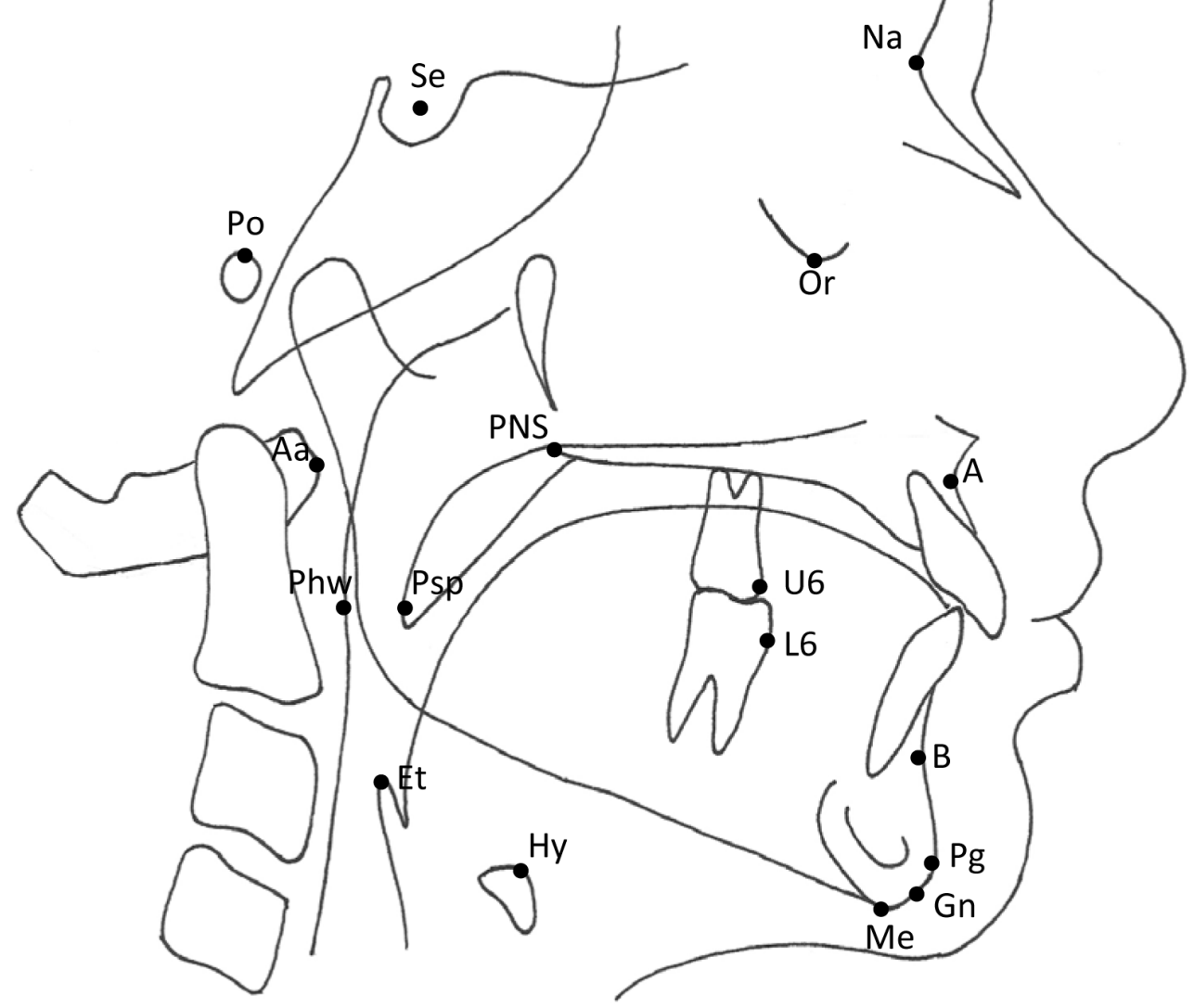

Figure 5. Cephalometric landmarks identified on unmagnified lateral cephalometric images generated from CBCT DICOM files. For definitions, refer to Table 2. 
Table 2. Cephalometric landmarks.

\begin{tabular}{|c|c|}
\hline Landmark & Definition \\
\hline A & $\begin{array}{l}\text { Point A (Subspinale): the most posterior point on the exterior ventral } \\
\text { curve of the maxilla between the anterior nasal spine and Supradentale. }\end{array}$ \\
\hline $\mathrm{Aa}$ & Atlas vertebra: \\
\hline B & $\begin{array}{l}\text { Supramentale: the most posterior point on the bony curvature of the } \\
\text { mandible between Infradentale and Pogonion. }\end{array}$ \\
\hline Et & Tip of epiglottis: the most superior point of the epiglottis. \\
\hline FH & $\begin{array}{l}\text { Frankfort horizontal: a horizontal plane drawn from porion to orbitale, } \\
\text { with patient in natural head position. }\end{array}$ \\
\hline Gn & $\begin{array}{l}\text { Gnathion (anatomic): the most anterior-inferior point of the mandibular } \\
\text { symphysis. }\end{array}$ \\
\hline Нy & $\begin{array}{l}\text { Hyoidale: the most superior and anterior point on the body of the hyoid } \\
\text { bone. }\end{array}$ \\
\hline L6 & L6 mesial: the most mesial point on the lower first molar. \\
\hline $\mathrm{Me}$ & Menton: the most inferior point on the symphysis of the mandible. \\
\hline $\mathrm{Na}$ & $\begin{array}{l}\text { Nasion: the anterior point of the intersection between the nasal and } \\
\text { frontal bones. }\end{array}$ \\
\hline Or & $\begin{array}{l}\text { Orbitale: the most inferior point on the lower margin of the bony } \\
\text { orbit. }\end{array}$ \\
\hline $\mathrm{Pg}$ & $\begin{array}{l}\text { Pogonion: the most anterior point on the anterior contour of the bony } \\
\text { chin below B point and above Gnathion. }\end{array}$ \\
\hline $\mathrm{Phw}$ & Posterior pharyngeal wall at the level of the Psp. \\
\hline PNS & $\begin{array}{l}\text { Posterior Nasal Spine: the most posterior point at the midsagittal plane } \\
\text { on the bony hard palate. }\end{array}$ \\
\hline Po & $\begin{array}{l}\text { Porion: the midpoint on the superior aspect of the rim of the external } \\
\text { auditory meatus. }\end{array}$ \\
\hline Psp & Posterior soft palate: the most superior-posterior point of the soft palate. \\
\hline $\mathrm{Se}$ & $\begin{array}{l}\text { Sella turcica: the center of the hypophyseal fossa, determined by } \\
\text { inspection. }\end{array}$ \\
\hline S-P & Sella-Perpendicular: line through Sella, perpendicular to FH \\
\hline U6 & U6 mesial: the most mesial point on the upper first molar. \\
\hline
\end{tabular}


Me Menton: the most inferior point on the symphysis of the mandible.

$\mathrm{Na}$ Nasion: the anterior point of the intersection between the nasal and frontal bones.

Or Orbitale: the most inferior point on the lower margin of the bony orbit.

Pg Pogonion: the most anterior point on the anterior contour of the bony chin below B Point and above Gnathion.

Phw Posterior pharyngeal wall: point on posterior pharyngeal wall at the level of Psp, parallel to FH.

PNS Posterior Nasal Spine: the most posterior point on the hard palate.

Psp Posterior soft palate: the most posterior point of the soft palate.

Po Porion: the midpoint on the superior aspect of the rim of the external auditory meatus.

Se Sella turcica: the center of the hypophyseal fossa, determined by inspection.

Se- $\perp$ Sella-Perpendicular: line through Sella, perpendicular to FH.

U6 U6 mesial: the most mesial point on the height of contour of the upper first molar.

\section{Linear Measurements}

A total of 8 linear measurements were used (Figure 6). The following alphabetical listing provides definitions of the linear measurements analyzed in this study:

AFH Anterior Facial Height: linear measurement from $\mathrm{FH}$ to $\mathrm{Me}$, perpendicular to $\mathrm{FH}$.

Aa to PNS Linear measurement from Aa to PNS.

Hy to $\mathrm{FH} \quad$ Linear measurement from $\mathrm{Hy}$ to $\mathrm{FH}$, perpendicular to $\mathrm{FH}$.

Psp to Phw Linear measurement from Psp to Phw.

Se $-\perp$ to A Linear measurement from Sella perpendicular to A Point.

Se- $\perp$ to B Linear measurement from Sella perpendicular to B Point. 
Se- $\perp$ to L6 Linear measurement from Sella perpendicular to the most mesial point on the lower first molar.

Se- $\perp$ to U6 Linear measurement from Sella perpendicular to the most mesial point on the upper first molar.

\section{Angular Measurements}

A total of 5 angular measurements (Figure 6) were obtained from each cephalometric image, generated by Dolphin 11.0 (Dolphin Imaging \& Management Solutions, Chatsworth, CA). The following alphabetical listing provides definitions of the angular measurements analyzed in this study:

ANB The difference between the SNA and SNB angles

NAP Facial convexity: Na-A Point-Pg angle.

SNA Sella-Nasion-A Point: the posterior-inferior angle formed by the intersection of the two lines formed by Sella-Nasion and Nasion-A Point.

SNB Sella-Nasion-B Point: the posterior-inferior angle formed by the intersection of the two lines formed by Sella-Nasion and Nasion-B Point.

Y-Axis Anterior-inferior angle formed at the intersection of a line from Sella to Nasion and a line from Sella to Gnathion.

\section{Cross-Sectional Measurements}

Three cross-sectional planes were generated for 3D analysis of the pharyngeal airway (Figures 7, 8, and 9). The cross-sectional width and area was taken at the level of each of these planes, parallel to Frankfort Horizontal. Frankfort Horizontal was used as a reference to standardize each plane orientation.

The three cross-sectional planes were: (1) Upper pharyngeal plane (Uph plane), which is the axial plane parallel to FH, passing through PNS; (2) Middle pharyngeal plane (Mph plane), which is the axial plane parallel to FH, passing through Psp; and (3) Lower pharyngeal plane (Lph plane), which is the axial plane parallel to $\mathrm{FH}$, passing through the tip of the epiglottis.

\section{Volumetric Measurements}

Oropharyngeal volumetric renderings of the subjects' CBCT scans were generated with Dolphin, Version 11.0 (Dolphin Imaging and Management Solutions, 


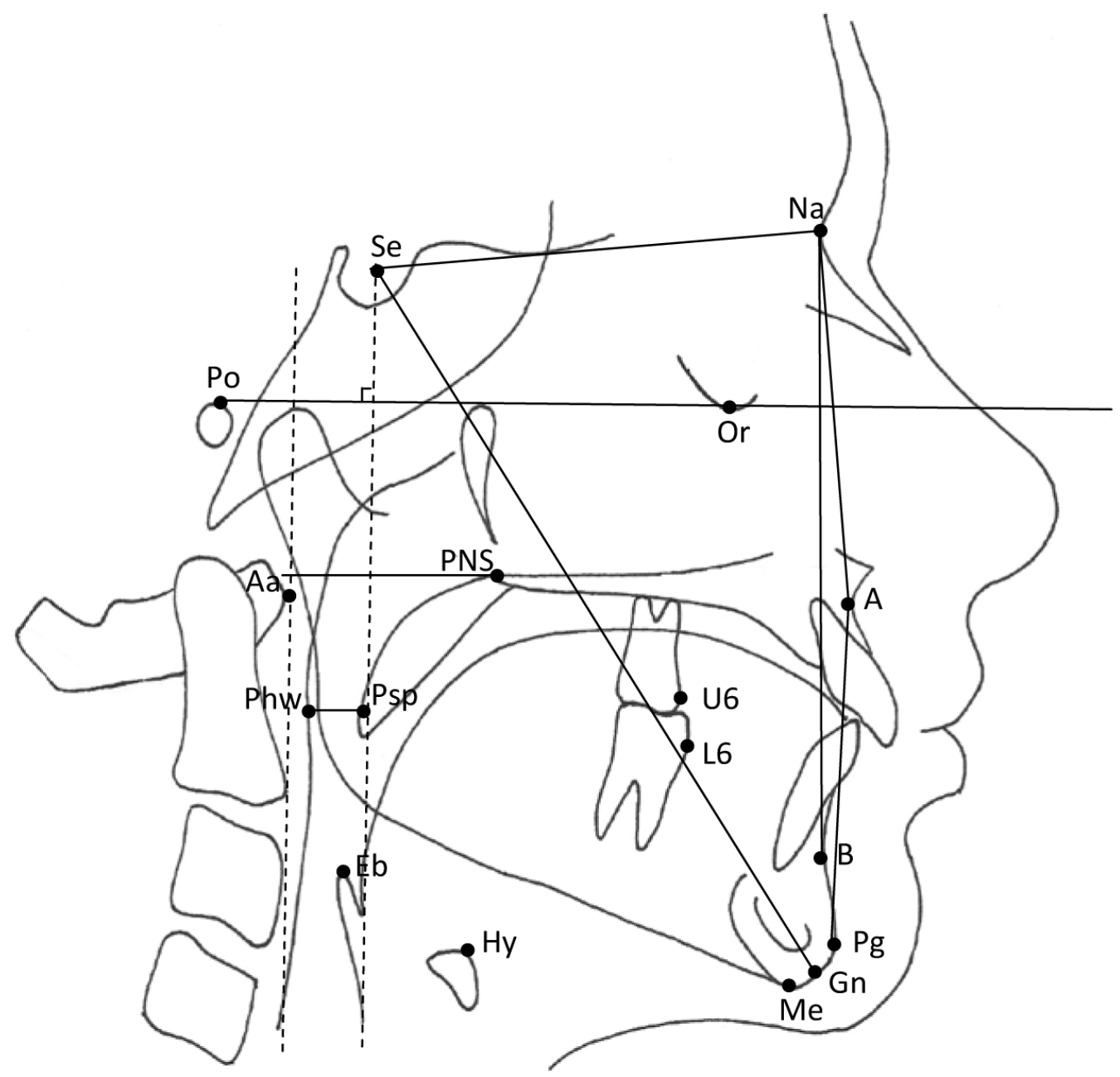

Figure 6. Landmark measurements identified on the unmagnified lateral cephalometric images generated from CBCT DICOM files. 


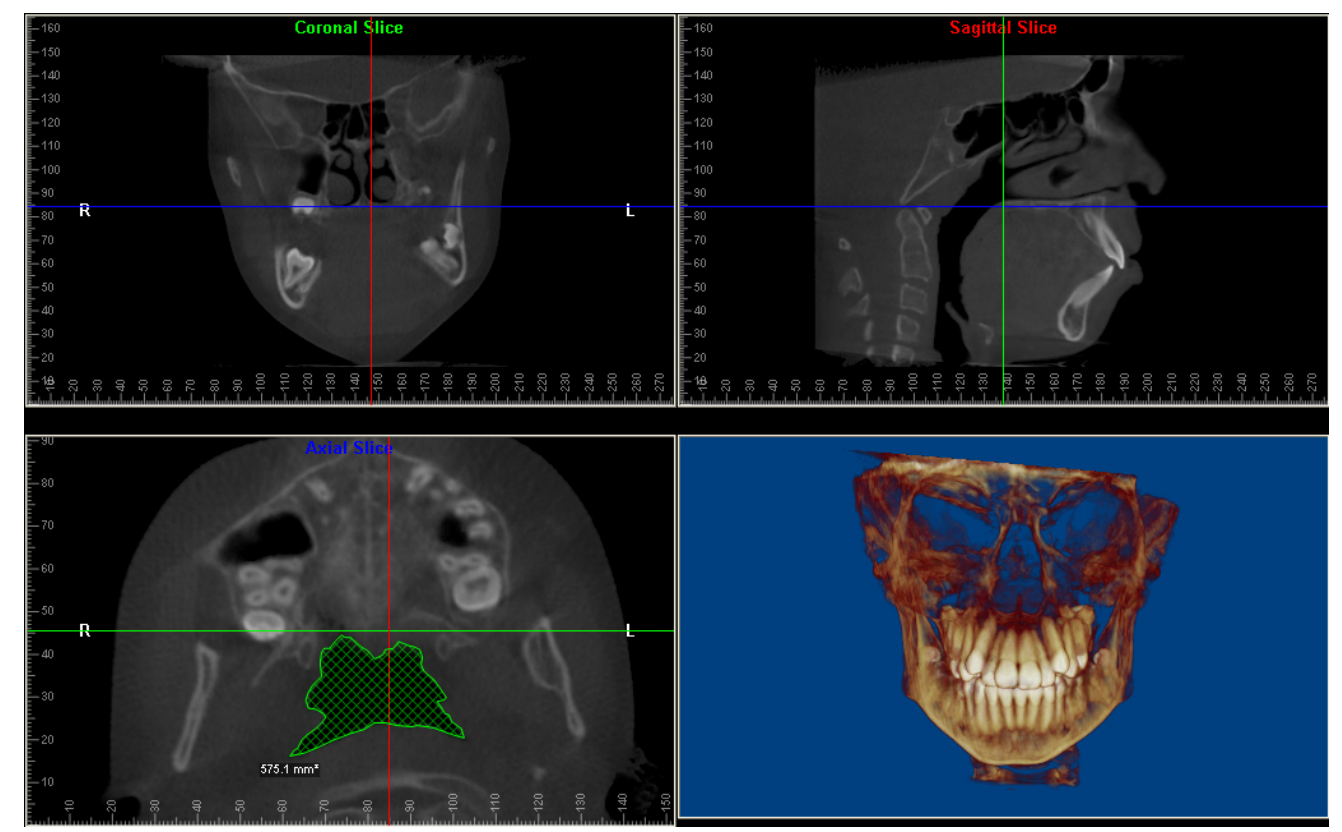

Figure 7. Upper pharyngeal plane (Uph plane); definition in Table 3.

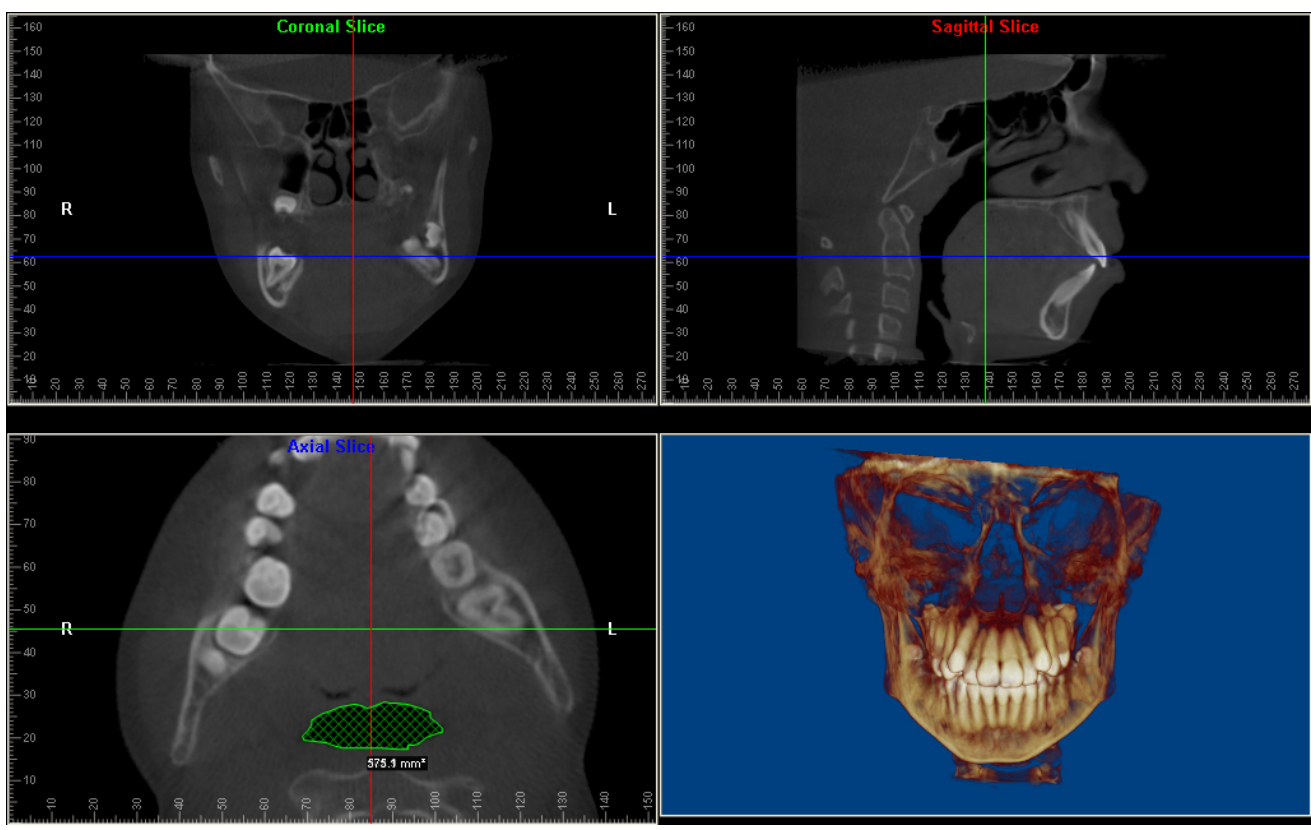

Figure 8. Middle pharyngeal plane (Mph plane); definition in Table 3. 


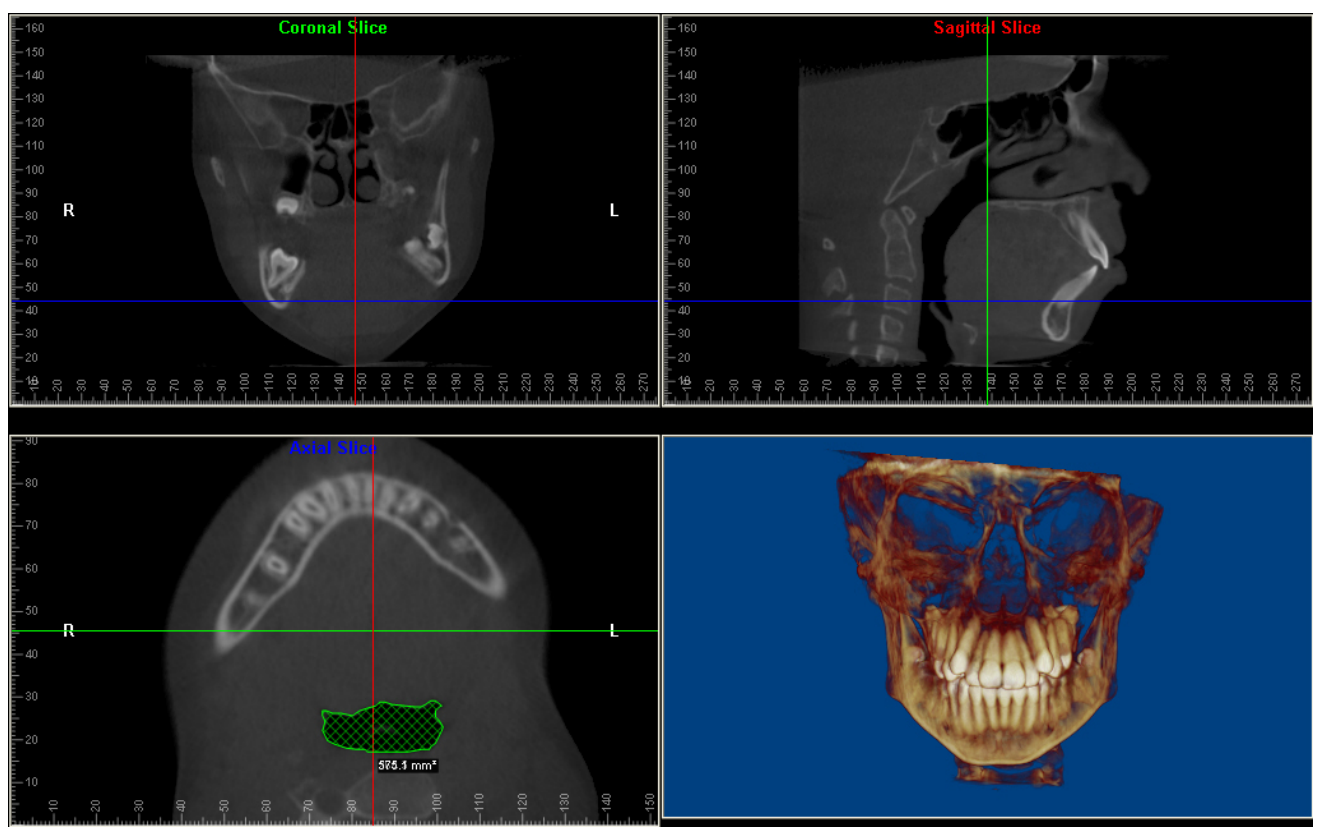

Figure 9. Lower pharyngeal plane (Lph plane); definition in Table 3.

\section{Table 3. Cross-sectional planes of the oropharyngeal airway.}

\begin{tabular}{ll}
\hline \multicolumn{1}{c}{ Measure } & \multicolumn{1}{c}{ Definition } \\
\hline Upper pharyngeal plane (Uph plane) & $\begin{array}{l}\text { An axial plane parallel to the FH plane, } \\
\text { passing through PNS }\end{array}$ \\
Middle pharyngeal plane (Mph plane) & $\begin{array}{l}\text { An axial plane parallel to the FH plane, } \\
\text { passing through Psp }\end{array}$ \\
Lower pharyngeal plane (Lph plane) & $\begin{array}{l}\text { An axial plane parallel to the FH plane, } \\
\text { passing through the tip of the epiglottis }\end{array}$ \\
\hline
\end{tabular}


Chatsworth, CA). This 3-dimensional imaging software functioned by detecting large differences in $\mathrm{x}$-ray attenuation between air in the pharynx and the high water content of the surrounding tissues, resulting in a visualization of the airway in 3 dimensions. Threshold values were adjusted to eliminate imaging artifacts and to refine the region of the selected airway and volume was then calculated in cubic millimeters.

The volumetric measurements taken of the two regions of the oropharyngeal airway were: (1) Middle Pharyngeal Airway Volume (Figure 10), which is the airway formed by the upper and middle pharyngeal planes; (2) Inferior Pharyngeal Airway Volume (Figure 11), which is the airway formed by the middle and lower pharyngeal planes; and (3) Total Pharyngeal Airway Volume (Figure 12), which is the airway that extends from the upper to lower pharyngeal planes.

\section{Error Calculation}

Fifteen CBCT scans were randomly selected and their cephalometric variables, as well as airway dimensions were re-measured 2 weeks after the initial measurements by the same investigator. The results of the original and re-measured groups were compared, a repeatability index was calculated (Dahlberg 1940), and error was found to be statistically insignificant. The remaining subjects were then analyzed according to the established protocol.

\section{Statistical Analysis}

Data were collated into an Excel ${ }^{\circledR}$ spreadsheet (Microsoft Corporation, Redmond, WA) then transferred to the JMP ${ }^{\circledR}$ statistical package version 9 (SAS Institute Inc., Cary, NC). Exploratory data analysis (Tukey 1977) was performed, searching for outliers; those due to technical errors were corrected. Descriptive statistics (Woolf 1968; Sokal and Rohlf 1995) were computed, including arithmetic mean $(\bar{x})$, standard deviation (sd), standard error of mean (sem), upper and lower $95 \%$ confidence limit $\left(\mathrm{L}_{1}, \mathrm{~L}_{2}\right)$, sample size $(\mathrm{n})$, sample variance $\left(\mathrm{s}^{2}\right)$, skewness $\left(\mathrm{g}_{1}\right)$, kurtosis $\left(\mathrm{g}_{2}\right)$, coefficient of variation $(\mathrm{cv})$, number of cases missing, maximum value, median value (50th percentile), and minimum value.

The major focus in the study was whether the dimensions changed differently in the two treatment groups, namely whether cases were treated with or without premolar extractions. The inferential statistic employed here was analysis of covariance (ANCOVA) because preliminary analyses showed that (A) patient's chronological age and (B) patient's sex often had a significant influence on trait size. In other words, age and sex are "nuisance" variables that need to be included in the model to account for these major - and predictable - sources of variability. The common situation is that boys are statistically larger than girls of because steroid-mediated growth differences,

particularly after the onset of adolescence (e.g., Tanner 1962). Patient's age has two effects on size: One, older adolescents are bigger than younger adolescents as a 


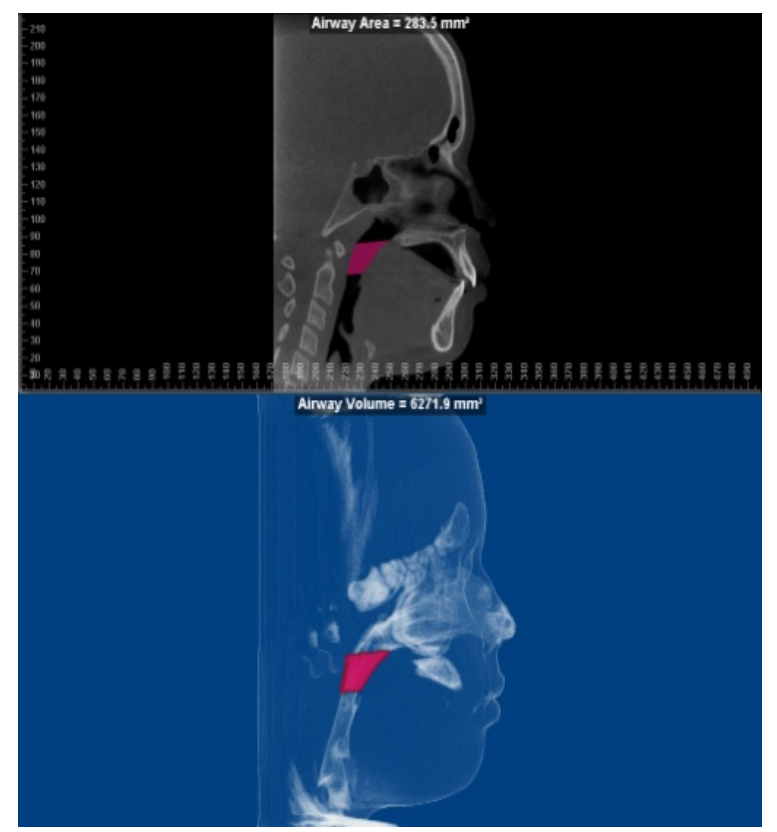

Figure 10. Middle pharyngeal airway volume; definition in Table 4.

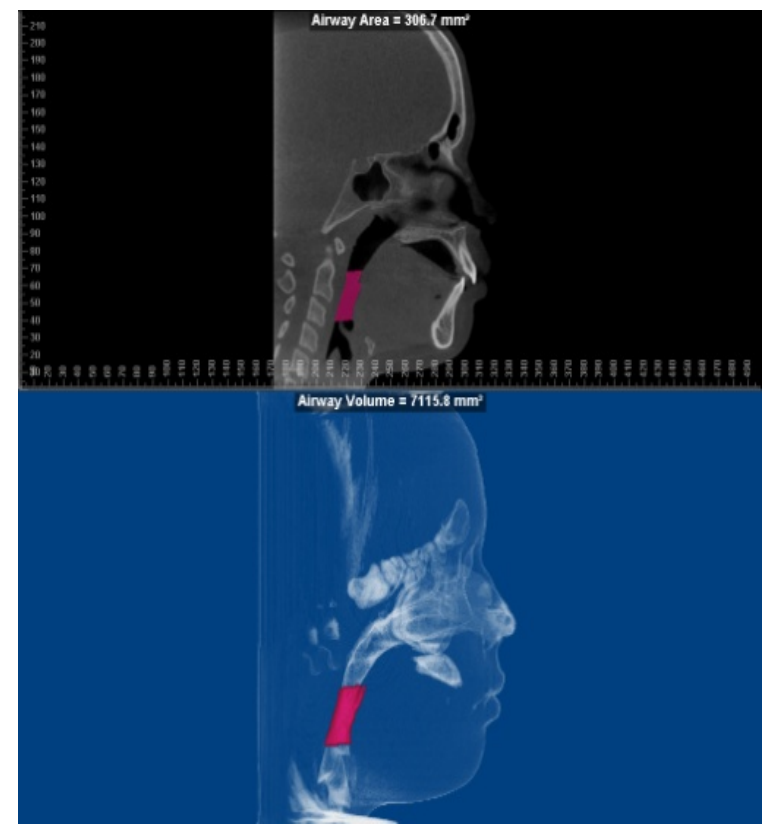

Figure 11. Inferior pharyngeal airway volume; definition in Table 4. 


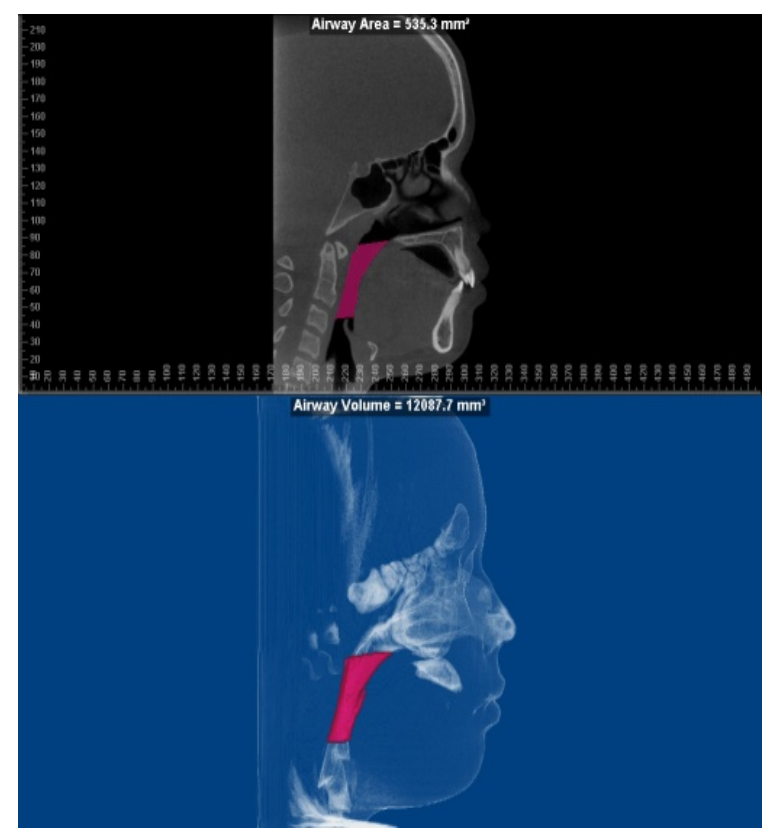

Figure 12. Total pharyngeal airway volume; definition in Table 4.

Table 4. Volumetric analysis of the oropharyngeal airway.

\begin{tabular}{ll}
\hline \multicolumn{1}{c}{ Measure } & \multicolumn{1}{c}{ Definition } \\
\hline Middle pharyngeal airway volume & $\begin{array}{l}\text { Airway volume extending from the Uph } \\
\text { plane to the Mph plane }\end{array}$ \\
Inferior pharyngeal airway volume & $\begin{array}{l}\text { Airway volume extending from the Mph } \\
\text { plane to the Lph plane }\end{array}$ \\
Total pharyngeal airway volume & $\begin{array}{l}\text { Airway volume extending from the Uph } \\
\text { plane to the Lph plane }\end{array}$ \\
\hline
\end{tabular}


statistical average, and since there is variability in the age at onset of treatment (and at end of treatment), it is relevant to account for this variability in the statistical model rather than let the differences be hidden in the treatment effects. Two, adolescents obviously grow larger as they grow older, and orthodontic treatment in this sample averaged roughly 2 years. Consequently, it is predictable that size of a dimension will increase across time independently of treatment changes.

The ANCOVA model (Winer et al. 1991) was used to test (A) status at the start of treatment, (B) status at the end of treatment, and (C) the in-treatment changes. The key main factor is "treatment" (whether the case was treated with or without extractions), and "sex" and "age" were included to control for these sources of variance. With these three main effects, there are three first-order interaction terms, namely treatment-by-sex, treatment-by-age, and sex-by-age. There also is one second-order term in the full model, treatment-by-sex-by-age. All terms are factorial rather than repeated measures. All tests were evaluated as two-tail conditions, and the same level of alpha was used throughout $($ alpha $=0.05)$ despite the multiple comparisons.

This ANCOVA model discloses whether the effects achieve statistical significance, but it does not provide information about the nature of the differences. The sample was partitioned by treatment (and by sex) in order to calculate descriptive statistics for each group itself. In addition, for each of the in-treatment changes, onesample (two-tail) t-tests (Sokal and Rohlf 1995) were used to calculate whether that change differed significantly from zero. For example, for several variables, there is no treatment difference in trait size at the start or end of treatment, but inspection shows that both groups changed significantly but comparably, and these t-tests disclose this. 


\section{CHAPTER 4. RESULTS}

The sample consisted of pre- and post-treatment pairs of CBCT DICOM files of 88 patients who had been treated orthodontically. The DICOM files were collected from two orthodontic practices, one in Jackson, Tennessee and the other in Green Bay, Wisconsin. Cases were divided into two groups: 61 patients were treated without extractions, and 27 patients had 4 premolars extracted as part of orthodontic treatment. The non-extraction sample consisted of 30 boys and 31 girls, and the extraction group consisted of 11 boys and 16 girls.

For the present study, 13 cephalometric measurements, 3 cross-sectional pharyngeal planes (Table 3), and 3 pharyngeal volumes (Table 4) were measured. An ANCOVA model that tested for a group difference while controlling for age and sex was generated for each variable (Appendix A, Tables A-1 through A-22). The reader will see that there actually are 3 timepoints associated with each variable, namely a test of the dimension at the start of treatment, secondly a test of the dimension at the end of treatment, and thirdly a test of the posttreatment-minus-pretreatment change in the size of the dimension. These tests evaluated whether the two treatment groups are comparable (while controlling for age and sex). To explore the changes in more detail, each group was divided by sex and then tested as to whether its in-treatment changes achieved statistical significance; this analysis was evaluated with one-sample t-tests interpreted as two-tail tests (Appendix B, Tables B-1 through B-22). In Appendix C (Figures C-1 through C-22), treatment changes for all groups are expressed in graphical format. Appendix D (Tables D-1 through D-22) shows descriptive statistics by group and sex for pretreatment, posttreatment, and during treatment. Appendix E (Tables E-1 through E-22) shows descriptive statistics by group for pretreatment, posttreatment, and during treatment.

For Anterior Facial Height, there was a difference between extraction and nonextraction groups (Table A-1). Prior to treatment, the only significant initial variable was age $(\mathrm{P}=0.0024)$, where, as expected, older subjects had larger facial heights than younger subjects. Following treatment, the extraction sample had a significantly larger Anterior Facial Height than the non-extraction sample $(\mathrm{P}=0.0341)$. Also, boys had a larger Anterior Facial Height than girls at the end of treatment $(\mathrm{P}=0.0160)$. For change during treatment, the extraction sample displayed a larger increase in Anterior Facial Height than non-extraction patients $(\mathrm{P}=0.0032)$. Also, males had a larger increase in Anterior Facial Height than females during treatment $(\mathrm{P}<0.0001)$ and Anterior Facial Height increased significantly with age. According to the one-sample t-tests (Table B-1), all treatment groups experienced significant increases in Anterior Facial Height during treatment, ranging from $2.2 \mathrm{~mm}$ for nonextraction girls up to $6.5 \mathrm{~mm}$ for extraction boys.

For the distance from Anterior Vertebra to Posterior Nasal Spine, there was no significant difference between groups at the initial or final examination (Table A-2). There also was no significant difference in Anterior Vertebra to Posterior Nasal Spine dimensions between non-extraction and extraction samples during treatment (Table A-2). 
This distance remained unchanged statistically (Table B-2) and there is no significant movement of the maxilla (or consequent infringement of the oropharyngeal airway) during extraction or non-extraction orthodontic treatment.

For the distance from Hyoidale to Frankfort Horizontal, there was no significant group difference. Incidentally, the two significant initial covariates in the ANCOVA table (Table A-3) were sex and age. Boys had a larger Hyoidale to Frankfort Horizontal dimension than girls at the start of treatment $(\mathrm{P}=0.0042)$. Also, older patients had a larger dimension than younger patients at the start of treatment $(\mathrm{P}<0.0001)$. Following treatment, boys had a larger Hyoidale to Frankfort Horizontal dimension than girls $(\mathrm{P}=$ $0.0102)$, and older patients had a larger dimension than younger patients $(\mathrm{P}=0.0452)$. The one-sample t-tests (Table B-3) disclosed a significant increase in the Hyoidale to Frankfort horizontal dimension for non-extraction girls $(\mathrm{P}=0.0376)$ and non-extraction boys $(\mathrm{P}=0.0282)$, but no significant change for extraction boys or girls. This is mainly an effect of sample size (small samples of extraction cases) because the actual amounts of change - on the order of 3 to $4 \mathrm{~mm}$ - are the same between groups.

For the Posterior Soft Palate to Posterior Pharyngeal Wall distance, there was no significant difference between groups at the start of treatment (Table A-4). At the end of treatment, older patients had a larger dimension than younger patients $(\mathrm{P}=0.0042)$. Likewise, results of the ANCOVA showed that there was no significant difference in Posterior Soft Palate to Posterior Pharyngeal Wall dimensions between groups during treatment (Table A-4). These findings argue that there was no constriction of the oropharynx during extraction or non-extraction orthodontic treatment. In raw terms, all groups grew slightly during treatment (Table B-4), with means ranging from 0.1 to 1.2 $\mathrm{mm}$. Of them, just the non-extraction boys exhibited a significant increase $(\bar{x}=1.2 \mathrm{~mm})$. The one-sample t-test found a significant increase of $1 \mathrm{~mm}$ for Posterior Soft Palate to Posterior Pharyngeal Wall distance in non-extraction boys during treatment.

For the distance from Sella Perpendicular to A Point, the covariate of sex showed that males had larger dimensions at both initial and final time points (Table A-5; $\mathrm{P}=$ 0.0290 and $\mathrm{P}=0.0079$, respectively). For change during treatment, non-extraction patients increased their Sella Perpendicular to A Point dimension by $0.6 \mathrm{~mm}$ and extraction patients decreased by $0.2 \mathrm{~mm}$ (Table E-5). This difference is likely due to Class II treatment mechanics; cases requiring premolar extractions benefit from retraction of the anterior segment. According to the one-sample t-tests, only the non-extraction boys displayed a significant change in this dimension during treatment $(\mathrm{P}=0.0010)$, and this averaged only $1.1 \mathrm{~mm}$ of forward growth.

For Sella Perpendicular to B Point distance, non-extraction patients had significantly larger dimensions at the start of treatment (Table A-6; P =0.0131). This dimension of mandibular length is 2 to $3 \mathrm{~mm}$ longer in the non-extraction group (Table E-6). Also, older patients had larger dimensions than younger patients $(P=0.0129)$. At the end of treatment, non-extraction patients still had larger Sella Perpendicular to B Point dimensions than the extraction group $(\mathrm{P}=0.0047)$. According to the ANCOVA 
results for change during treatment (Table A-6), older patients experienced smaller changes in the Sella to B Point dimension $(\mathrm{P}=0.0039)$ probably because they were biologically more mature. When evaluated by sex, non-extraction boys differed from extraction boys during treatment $(\mathrm{P}=0.0021)$. As shown in Figure 13, non-extraction boys had a significant increase in Sella Perpendicular to B Point dimensions, while extraction boys experienced little change. Based on the one-sample t-tests, only the nonextraction boys had a significant change in Sella Perpendicular to B Point during treatment $(\mathrm{P}<0.0001)$.

For Sella Perpendicular to L6 Mesial, there was no difference between the two groups at the start or end of treatment. Inspection of the covariates showed that older patients had larger dimensions than younger patients (Table A-7) at the start of treatment $(\mathrm{P}=0.0007)$. At the final time point, though, there was no significant difference in any of the ANCOVA factors (Table A-7). For change during treatment, there was a significant difference between non-extraction and extraction patients $(\mathrm{P}<0.0001)$. L6 Mesial shifted significantly during treatment in both groups, but (A) the extraction group experienced significantly more change $(\sim 4 \mathrm{~mm})$ than the non-extraction group $(\sim 2 \mathrm{~mm})$, and (B) all changes were to the mesial, so the teeth moved ventrally, away from the pharynx. This larger value for the extraction group is likely due to reciprocal closure of extraction spaces during Class II correction. There were also significant differences during treatment between older and younger patients $(\mathrm{P}<0.0001)$, as well as between non-extraction and extraction patients when controlled for sex $(\mathrm{P}=0.0003)$. Also during treatment, age and Sella Perpendicular to L6 Mesial distance had a negative relationship because, predictably, older patients grew less. The treatment-by-sex interaction also was significant because there was a greater increase in this distance in extraction girls than non-extraction girls $(\mathrm{P}=0.0003)$. Once again, this was likely due to loss of molar anchorage during Class II correction. According to one-sample t-tests, there were significant changes in all treatment groups during treatment (Table B-7).

For Sella Perpendicular to U6 Mesial, the only significant covariate in the ANCOVA model at the initial time point was age (Table A-8). Older patients had a greater Sella Perpendicular to U6 Mesial distance than younger patients $(\mathrm{P}=0.0023)$ at the start of treatment. Following treatment, the extraction and non-extraction groups were different. The ANCOVA results show that the extraction sample had a larger Sella Perpendicular to U6 Mesial dimension than non-extraction sample $(\mathrm{P}=0.0352)$, and the descriptive statistics (Table B-8) show (A) that this distance increased in all groups, but more so in the extraction group, and (B) these changes moved the dentition ventrally, away from the pharynx. Also, older patients had a larger Sella Perpendicular to U6 Mesial distance $(\mathrm{P}=0.0345)$, probably because they had experienced more growth. For change during treatment, extraction patients had a greater increase in Sella Perpendicular to U6 Mesial dimension $(\mathrm{P}=0.0010)$. This is likely due to burning anchorage to close unused extraction spaces. Also, older patients displayed a negative relationship with Sella Perpendicular to U6 Mesial distance $(\mathrm{P}=0.0323)$. The treatment-by-sex interaction also was significant because extraction girls had a signficant increase in Sella Perpendicular to U6 Mesial dimension, while non-extraction girls experienced virtually 


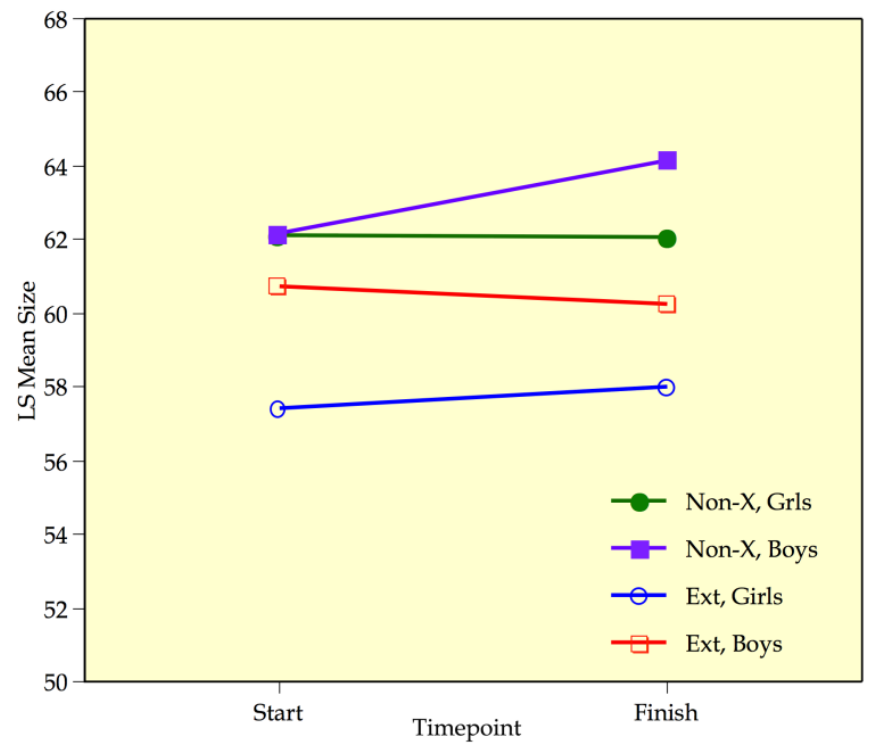

Figure 13. Plot of the least square means, by sex and extraction pattern, at the start and end of treatment for the variable Sella Perpendicular to B Point. 
no change, which is shown in Figure 14. This result was likely due to intentional molar anchorage loss during reciprocal closure of upper extraction space. According to the one-sample t-tests (Table B-8), all treatment groups except non-extraction girls showed significant increases during treatment.

For the Facial Convexity ANCOVA (Table A-9), the extraction/non-extraction factor was significantly different at the start of treatment $(\mathrm{P}=0.0004)$. At the initial examination, extraction patients had a mean Facial Convexity of 9 degrees, while nonextraction patients had a mean of 3 degrees. This greater mandibular retrognathia probably influenced the decision to extract teeth. Following treatment, this difference between groups was still significant $(\mathrm{P}=0.0048)$, where the extraction group had a mean Facial Convexity of 6 degrees, while non-extraction mean was 2 degrees. It is interesting that each treatment group's Facial Convexity was decreased by roughly one third (Table E-9). There also was a significant interaction between extraction/non-extraction and age. Although both treatment groups showed a decrease in facial convexity during treatment, the extraction group had a greater decrease $(\mathrm{P}=0.0028)$. Also, younger patients experienced a greater decrease in Facial Convexity during treatment than older patients $(\mathrm{P}=0.0013)$. According to the one-sample t-tests (Table B-9), all treatment groups showed a significant decrease in Facial Convexity during treatment.

For SNA (Table A-10), the two groups were significant at the start of treatment $(\mathrm{P}=0.0242)$ and it is likely that the maxillary excess in the extraction group influenced the decision to remove teeth. Before treatment, extraction patients had a mean SNA of 82 , while non-extraction patients had a mean of 80 . This difference disappeared during treatment, and was not significant at the end-of-treatment examination (Table A-10). For the change during treatment (Table A-10), non-extraction and extraction groups were once again significant $(\mathrm{P}=0.0006)$ because the extraction sample had a greater decrease in SNA than non-extraction patients. According to the one-sample t-tests, the extraction cases changed significantly (to reduce maxillary prominence), while the non-extraction group had only a slight, nonsignificant decrease.

For SNB (Table A-11), there was no difference between the two groups at the initial or final treatment examinations. For change during treatment, though, the groups were significantly different. SNB increased very slightly (and not significantly) in the non-extraction group (Table B-11), while SNB decreased in the extraction group. This decrease was not significant (Table B-11), but the slight increase in the non-extraction group, coupled with a decrease averaging 0.5 degrees in the extraction group, was significant in the ANCOVA model. The ANCOVA table also shows that older patients changed less during treatment than younger patients.

For ANB, the ANCOVA model (Table A-12) shows that differences between extraction and non-extraction groups were significant at the start of treatment $(\mathrm{P}=$ 0.0022). As seen with SNA and SNB, the extraction group had a significantly greater jaw discrepancy $\left(\mathrm{ANB} \sim 5^{\circ}\right.$ ) compared to the non-extraction group (ANB $\sim 3^{\circ}$ ). Following treatment, this same ANB difference persisted between groups $(\mathrm{P}=0.0051$; Table A-10). Extraction patients were left with a mean ANB angle of 3.5 degrees, while 


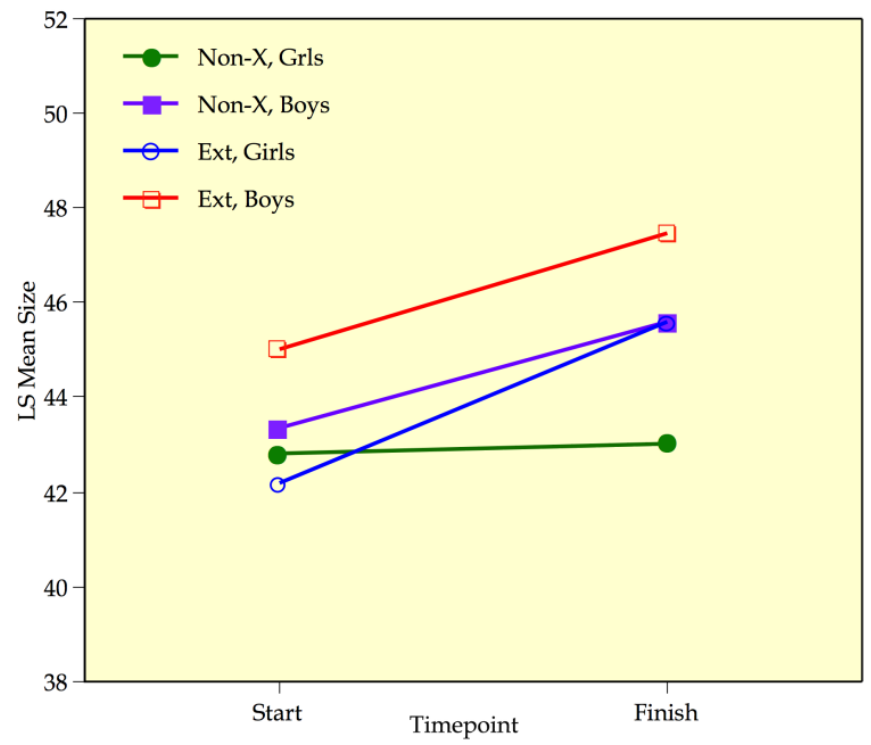

Figure 14. Plot of the least square means, by sex and extraction pattern at the start and end of treatment for the variable Sella Perpendicular to U6 Mesial. 
non-extraction patients had a mean of 2 degrees. Treatment (Table A-12) were not significant $(\mathrm{P}=0.09)$ because both groups experienced some reduction of ANB. Inspecting the covariates, older patients tended to have a positive ANB angle during treatment, while younger patients tended to have a negative ANB angle. According to the one-sample t-tests (Table B-12), all treatment groups displayed significant decreases in ANB during treatment, except for non-extraction girls.

The Y-Axis was comparable in the two groups at the start of treatment (Table A13). The ANCOVA table does disclose a significant sex-by-age interaction of marginal significance $(\mathrm{P}=0.0458)$. This occurred because girls exhibited no association between Y-Axis and age, but in boys, Y-Axis decreased significantly with increasing age, as shown in Figure 15. Following treatment, there was a significant treatment difference $(\mathrm{P}$ $=0.0059$ ). Extraction patients had a mean Y-Axis that was 2 degrees larger than nonextraction patients at the end of treatment (Table E-13). For change during treatment, there was significantly greater change in the extraction sample. Extraction patients had a mean increase in Y-Axis of almost 1 degree, while the Y-Axis of non-extraction patients remained virtually unchanged (Table E-13). According to the one-sample t-tests (Table $\mathrm{B}-13)$, the one group with a significant change during treatment was extraction boys $(\mathrm{P}=$ 0.0233).

For Upper Pharyngeal Plane Width, the two treatment groups are comparable at the start and the end of treatment (Table A-14). Among the covariates, older patients had a larger dimension than younger patients at both time points $(\mathrm{P}=0.0008 ; \mathrm{P}=0.0026)$. Also, girls had a larger Upper Pharyngeal Plane Width than boys at the end of treatment $(\mathrm{P}=0.0187)$. For change during treatment (Table A-14), there was no significant difference between groups for Upper Pharyngeal Plane Width. From the one-sample ttests, one can see that the mean changes were all positive, on the order of a 1-to- $2 \mathrm{~mm}$ increase. The greater sample sizes of the non-extraction samples causes their changes to be significant by t-test.

For Upper Pharyngeal Plane Area (Table A-15) the groups were comparable at the start of treatment. The one significant covariate at the initial time point was age $(\mathrm{P}=$ 0.0006) because older patients had a larger Upper Pharyngeal Plane Area. At the end of treatment, the groups continued to be comparable (Table A-15). Age remained the one significant covariate $(\mathrm{P}=0.0002)$, and older patients still had a larger Upper Pharyngeal Plane Area. For change during treatment (Table A-15), there was no significant change in this area of the pharynx. According to the one-sample t-tests, the only treatment groups that displayed significant changes in Upper Pharyngeal Plane Width were nonextraction girls $(\mathrm{P}=0.0116)$ and non-extraction boys $(\mathrm{P}=0.0155)$. Also, for all treatment groups, there was a mean increase in Upper Pharyngeal Plane Area during treatment.

For Middle Pharyngeal Plane Width, the two groups were comparable at the start and at the end of treatment (Table A-16). Following treatment, the only significant covariate was age $(\mathrm{P}=0.0167)$ because older patients had a larger Middle Pharyngeal 


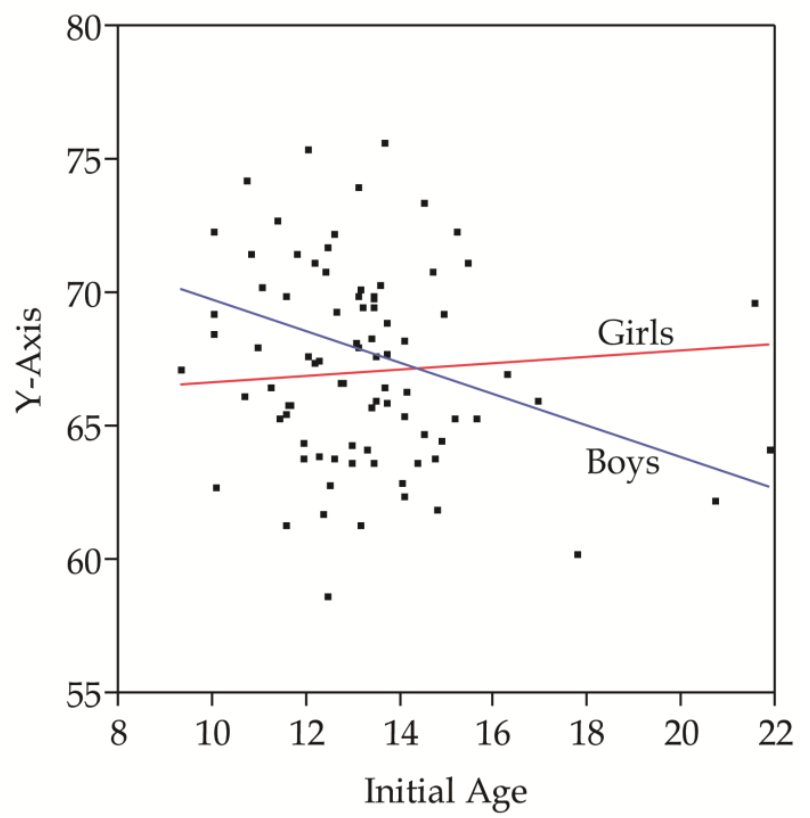

Figure 15. Plot of the $Y$-axis at the start of treatment by chronological age, showing the sex difference that creates a significant age-by-sex interaction for this variable. 
Plane Width than younger patients. The ANCOVA model for change during treatment showed no difference between groups (Table A-16), and inspection of the changes in this width (Table B-16) disclosed that size increased on the order of 2 to $3 \mathrm{~mm}$ in both treatment groups.

Middle Pharyngeal Plane Area responded similarly to the width previously examined: There was no difference between treatment groups at the start or the end of treatment (Table A-17), and the change also was statistically the same in the two groups. This area increased equivalently in both treatments, and the change was on the order of $40 \mathrm{~mm}^{2}$. Due to limited sample sizes in the extraction group (Table B-17), these increases were not significant $(\mathrm{P}>0.05)$, though comparable changes achieved significance in the non-extraction groups $(\mathrm{P}<0.01)$. Older patients had a larger Middle Pharyngeal Plane Area than younger patients and although non-extraction patients had no significant change in Middle Pharyngeal Plane Area with age, extraction patients had a significant increase. This interaction is shown in Figure 16.

For Lower Pharyngeal Plane Width, the two treatments were comparable at the start of orthodontic treatment (Table A-18). Age was the one significant covariate, and this was significant at the initial and the final time points $(\mathrm{P}=0.0077$ and $\mathrm{P}=0.0072$, respectively). Older patients had a larger Lower Pharyngeal Plane Width than younger patients before and after orthodontic treatment. For change during treatment, this width increased comparably in the two groups (Table A-18). The one-sample t-tests (Table B-18) confirmed that all groups displayed significant changes, with increases on the order of $2.5 \mathrm{~mm}$.

For Lower Pharyngeal Plane Area, the two groups were comparable at the start and end of treatment (Table A-19). None of the covariates was significant except, following treatment, age was positively associated with size $(\mathrm{P}=0.0279)$; older patients had a larger area. The comparability of the groups for this area is due to the fact that both groups increased to similar extents during treatment (Table B-19). That is, both treatments increased roughly $50 \mathrm{~mm}^{2}$ across the examinations, which is a significant increase statistically.

Analysis of Middle Pharyngeal Airway Volume is interesting because the treatment groups are not significantly different at the start or end (Table A-20) of treatment, but the levels of probability are suggestive $(0.10>\mathrm{P}>0.05)$ because the nonextraction group tends to be larger (Table D-20; Table E-20). An interesting minor interaction occurred between non-extraction and extraction girls $(\mathrm{P}=0.0405)$. As shown in Figure 17, the Middle Pharyngeal Airway Volume of non-extraction girls remained relatively unchanged with increasing age, while extraction girls had a significant increase. This discrepancy may be due to a small sample size of older patients, but, regardless, the extraction group had a larger volume. Because changes in Middle Pharyngeal Volume during treatment were similar, the in-treatment changes (Table A-20) were not significant $(\mathrm{P}=0.90)$. All four treatment-sex combinations (Table B-20) changed to similar extents $\left(c a .1,000 \mathrm{~mm}^{2}\right)$. Because of smaller sample sizes, though, these differences are not significant statistically in the extraction groups. 


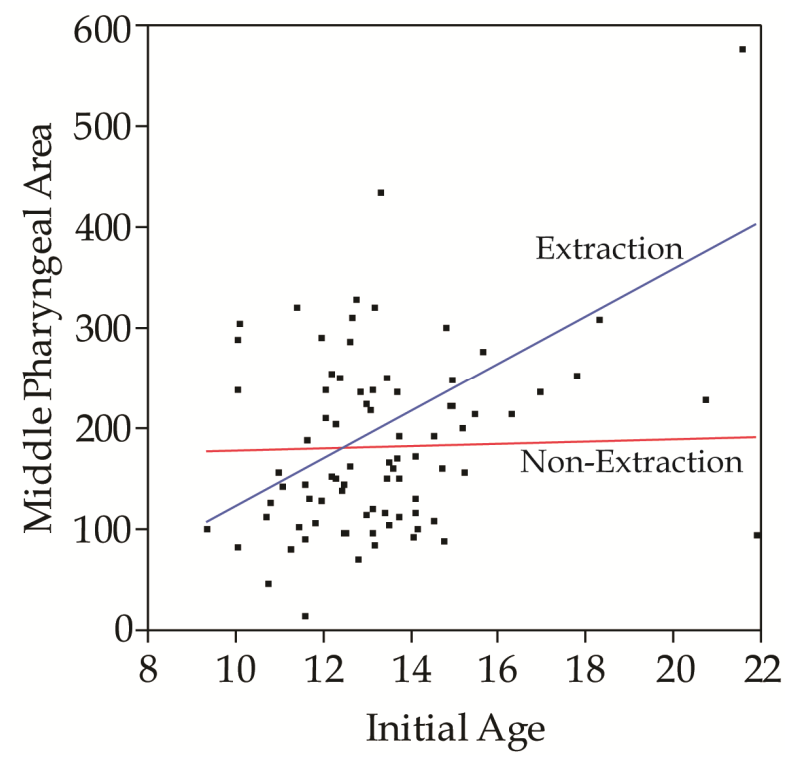

Figure 16. Plot of the difference in age-progressive changes in middle pharyngeal area depending on extraction treatment at the start of treatment.

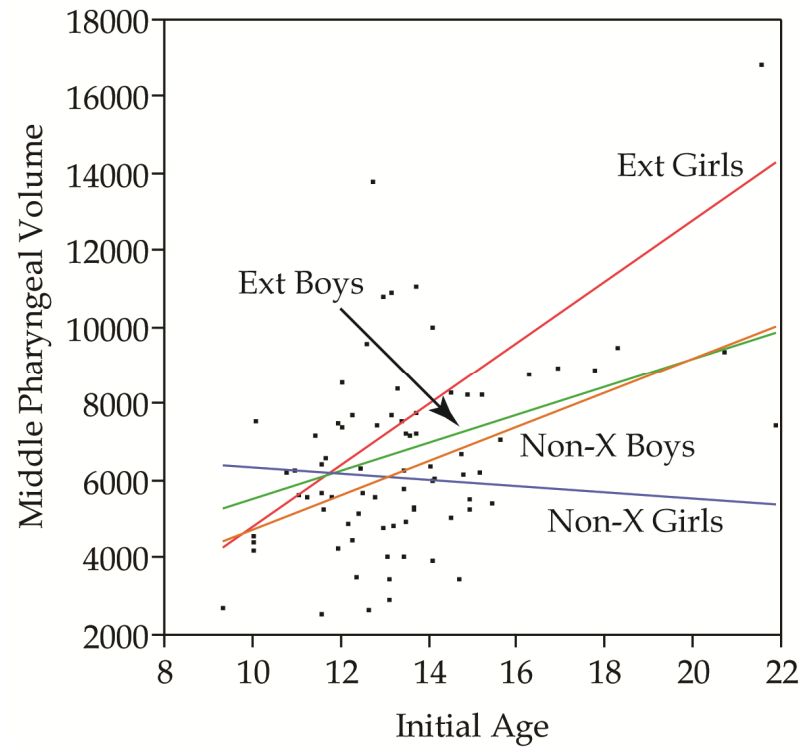

Figure 17. Plot of the middle pharyngeal volume at the end of treatment, by extraction group and sex. 
Inferior Pharyngeal Airway Volume did not differ between groups at the start or the end of treatment, nor for the treatment change (Table A-21). The t-tests (Table B-21) show that volume increased significantly in all groups, so the ANCOVA results show that the changes were comparable across time in the two samples. For Inferior Pharyngeal Airway Volume, age was the one significant covariate at the initial time point. Prior to treatment, older patients had larger Inferior Pharyngeal Airway Volume than younger patients. Following treatment, age continued to be the only significant covariate, and older patients had larger volume than younger patients. For change during treatment, there was no significant factor in the ANCOVA model. According to the one-sample t-tests, all treatment groups displayed significant changes in Inferior Pharyngeal Airway Volume during treatment (Table B-21).

Similar results are seen for Total Pharyngeal Airway Volume. That is, there was no major difference between groups at the start or the end of treatment, nor did the change differ between the treatment groups (Table A-22; $\mathrm{P}=0.91$ ). There was a significant group-by-age interaction at the start of treatment. As shown in Figure 18, Total Pharyngeal Airway Volume increased more with age in the extraction group than in the non-extraction group. The situation is that total volume increased about $2,500 \mathrm{~mm}^{2}$ in both treatments during the course of treatment. These increases - probably due to growth - were unaffected by mode of extraction. 


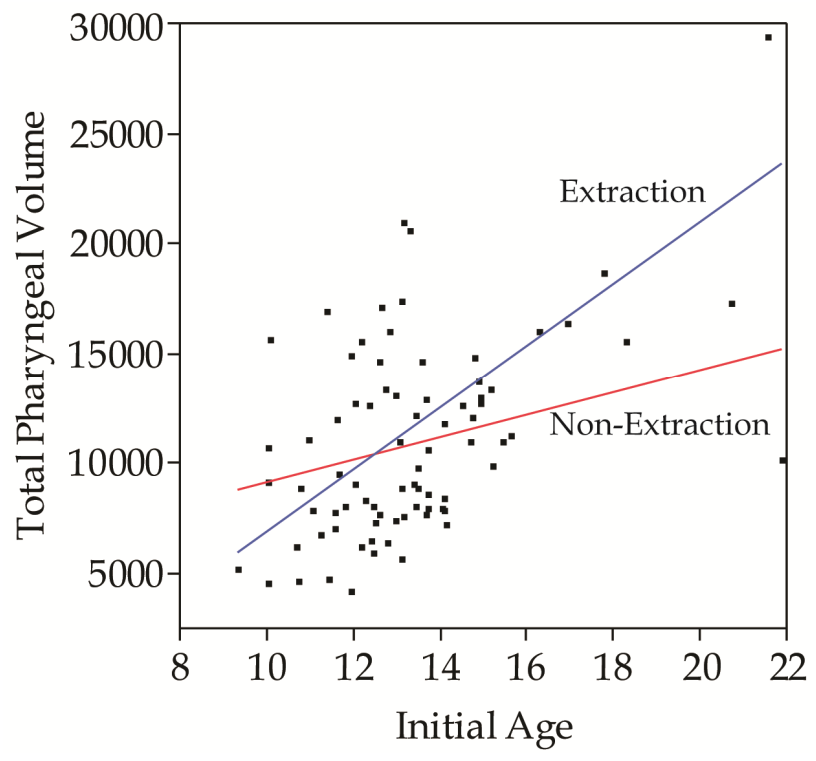

Figure 18. Plot of total pharyngeal volume against age depending on extraction mode. 


\section{CHAPTER 5. DISCUSSION}

The dental, skeletal, and soft tissue effects of extraction and non-extraction treatment continue to be debated in the orthodontic literature, just as they have been for over a century. The decision whether or not to extract premolars is multifaceted, often involving relationships between arch size, occlusion, vertical control, and esthetics. Recently, a segment of the orthodontic (and general dental) community has asserted that airway health should also be a primary consideration before initiating orthodontic treatment with premolar extractions. The contention is that orthodontic treatment can move the denture back in the mouth, reducing oral space and restriction pharyngeal volume. The present study questioned this claim, and analysis shows that the extraction of premolars has no deleterious effect on oropharyngeal volume. There is no pharyngeal size reduction with treatment, and, in the conventional teenage patient, growth causes most dimensions to increase.

The contention of some "non-extraction" orthodontists and orthotropists is that treatment, especially with premolar extractions, causes the retraction of anterior teeth, which decreases oral and pharyngeal space, thus impairing air flow. These arguments are of concern to patients and parents. The long-term effects of oxygen deprivation from "outdated" extraction treatment are alleged to be dire: developmental delays, migraine headaches, and even obstructive sleep apnea. However, the orthotropists' contentions are without documentation - there is only conjecture that pharyngeal size is affected by position of the teeth - but this is addressed in the present study where we quantitatively tested the argument that the pharynx is reduced in size when premolars are extracted. Of note, this study also stresses the points that (1) anatomical structures exist in three dimensions and (2) children grow.

The majority of orthodontic research on airway health is limited because of technological limitations of cephalometric imaging (Abramson et al. 2009; Finkelstein et al. 2001; Hanggi et al. 2008; Lowe et al. 1986). Using 2-dimensional radiography, no reliable conclusions can be made about the effects of orthodontic treatment on airway volume because mediolateral widths are unknown. The advantage of the present study and other current airway studies that capitalize on CBCT technology is that these previously unknown widths, areas, and volumes can now be quantified. To date, this is only the second known study to measure the effects premolar extraction versus nonextraction on oropharyngeal airway volume.

One aspect of orthodontic treatment that cannot be ignored is that the majority of orthodontic patients are growing adolescents. In growing patients, structural dimensions expand as the face grows downward and forward. Claims that orthotropic treatment produces downward-and-forward growth is just taking credit for natural growth trajectories and cannot be attributed to treatment. Growth is a powerful and often underrated component of orthodontic treatment—and it can easily outweigh the effects of treatment mechanics. 
The present study analyzed 88 patients with pretreatment and posttreatment CBCT records from orthodontic practices in Jackson, Tennessee, and Green Bay, Wisconsin. Similar iCAT CBCT machines were used to collect all samples and each scan recorded patients in an upright position, with a 12 inch field of view to include full craniofacial anatomy. Samples were selected from private practices in order to reflect current orthodontic practice in the United States. The present study was approved by the University of Tennessee Health Science Center's Institutional Review Board (IRB\# 11-01239-XM).

Of the 88 patients, 61 were treated without extractions and 27 patients had four premolars extracted as part of orthodontic treatment. The limited number of extraction cases was a concern, but due to time constraints, the sample size had to be accepted. For the 88 cases collected, there was no significant difference between initial $(\mathrm{P}=0.6482)$ or final age $(\mathrm{P}=0.1424)$ between non-extraction and extraction groups.

In addition to 3-dimensional volume of the oropharyngeal airway, cephalometric measurements and cross-sectional areas were also recorded. This identifies associations between common, 2-dimensional cephalometric measurements and the 3-dimensional data. Also, cross-sectional areas measured at the levels of the PNS, posterior soft palate, and tip of the epiglottis, provide important clues about how the oropharygeal airway adapts following premolar extraction.

At the level of the PNS, there was no backward movement of the maxilla or impingement of the oropharyngeal airway with either extraction or non-extraction treatment. This was evident both cephalometrically (Aa to PNS) and 3-dimensionally (Uph plane width and area). Because of growth, these dimensions actually increased. Cephalometrics measured the anteroposterior depth of the pharynx. CBCTs add mediolateral width measurements. Notably, the cross-sectional area at the level of Uph increases in both groups during treatment (Table A-15). Width and area increased the same amounts with and without extractions (Tables E-14 and E-15), showing that the extraction of 4 premolars has no effect on the airway at the level of the PNS.

At the level of the Posterior Soft Palate, both groups increased their pharyngeal size. This was seen cephalometrically (Posterior Soft Palate to Posterior Pharyngeal Wall) and 3-dimensionally (Mph width and area). Since both treatment groups increased comparably in Mph width and area during treatment (Tables E-16; Table E-17), extraction of premolars has no effect on the airway at the level of the Posterior Soft Palate.

At the level of the tip of the epiglottis, there was significant widening of the oropharynx both with extraction and non-extraction treatment. This measurement also was evident 3-dimensionally (Lph width and area) and both groups increased in Lph width and in area during treatment (Tables E-18 and E-19). Premolar extraction has no effect on the airway at the level of the tip of the epiglottis; instead, treatment of tooth positions seems to be independent of pharyngeal growth. 
With regard to total oropharyngeal airway volume, there was no significant difference before,during, or at the end treatment (Table A-22). Even among the oropharyngeal subdivisions, there was no significant difference at any timepoint (Tables A-20 and A-21). Accordingly, it is safe to say that extracting premolars does not affect the size of the oropharyngeal airway.

Evidence that orthodontic treatment can affect airway size is found in the oral surgery literature, where the jaws (not just the teeth) are repositioned, sometimes dramatically. Three-dimensional analysis has shown that airway size increases with maxillomandibular advancement (El et al. 2011, Nout et al. 2010). With mandibular setbacks, although structures move backward following surgery, physiologic deformation occurs to preserve airway volume (Park et al. 2010).

One common assertion is that the extraction of premolars, with subsequent canine retraction, results in constriction of the palate, tongue space, and oropharyngeal airway. In the study published by Valiathan et al. (2010), 40 pretreatment and posttreatment CBCT scans and medical histories were collected from the orthodontic clinic at Case Western Reserve University. Twenty patients were treated with extraction of four premolars and 20 controls were identified. Cephalometric variables were measured and oropharyngeal volumes were analyzed using Dolphin Imaging 11.0. Oropharyngeal airway changes from pretreatment to posttreatment were found to be similar in both groups. Their conclusion was that the extraction of 4 premolars with retraction of incisors does not affect oropharyngeal airway volume.

Another important line of evidence is to look at the positions of the teeth themselves. If premolar extraction is detrimental, the buccal teeth should move backward in the arch, decreasing the distance between the pharynx and the dentition. This distance was measured in this study (Se- $\perp$ to $\mathrm{L} 6, \mathrm{Se}-\perp$ to U6) and the distances actually increased (Figures 19,20).

Part of the increase occurs because the supporting arches are growing forward, but there is also the issue of anchorage loss. Anchorage loss moves the molars mesially when their anchorage is pitted against that of the anteriors. Also, seldom is the entire premolar-extraction space needed to resolve crowding in the anterior segment, so molar positions are allowed to slide forward ("burning anchorage") to close extraction spaces. The cumulative effects of growth, anchorage loss, and intentional mesial molar movement increases the distance of the teeth from the pharynx. This increase typically occurs whether or not the case is treated with extractions.

To answer concerns that extraction treatment increases the vertical component of facial growth, Y-Axis was analyzed for extraction and non-extraction samples. Following treatment, there was a greater increase in Y-Axis for the extraction sample (Table A-13). Although this change was statistically significant by paired t-test $(\mathrm{P}=$ 0.0337 ), it was negligible and clinically trivial at only 0.85 degrees (Table E-13). The change in Y-Axis is shown in Figure 21. 


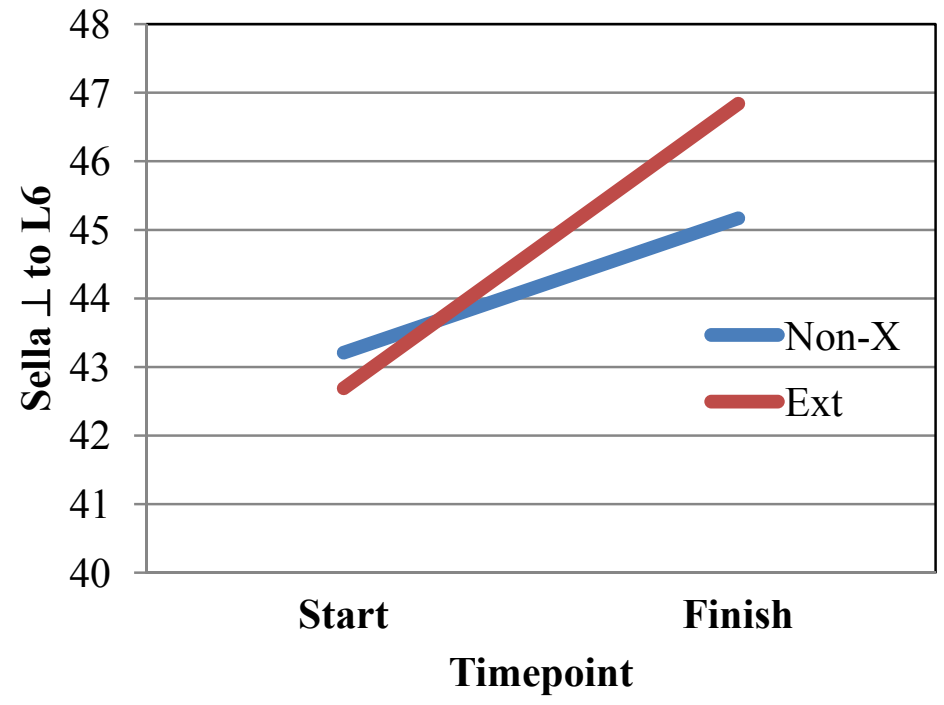

Figure 19. Plot of start and end of treatment values for Sella Perpendicular to L6 Mesial.

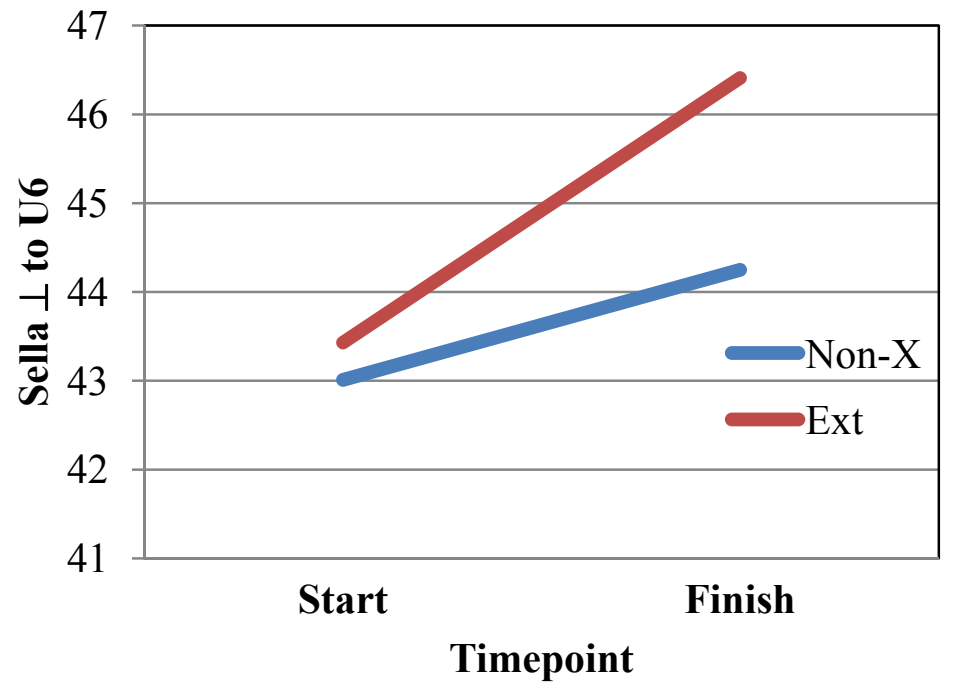

Figure 20. Plot of start and end of treatment values for Sella Perpendicular to U6 Mesial. 


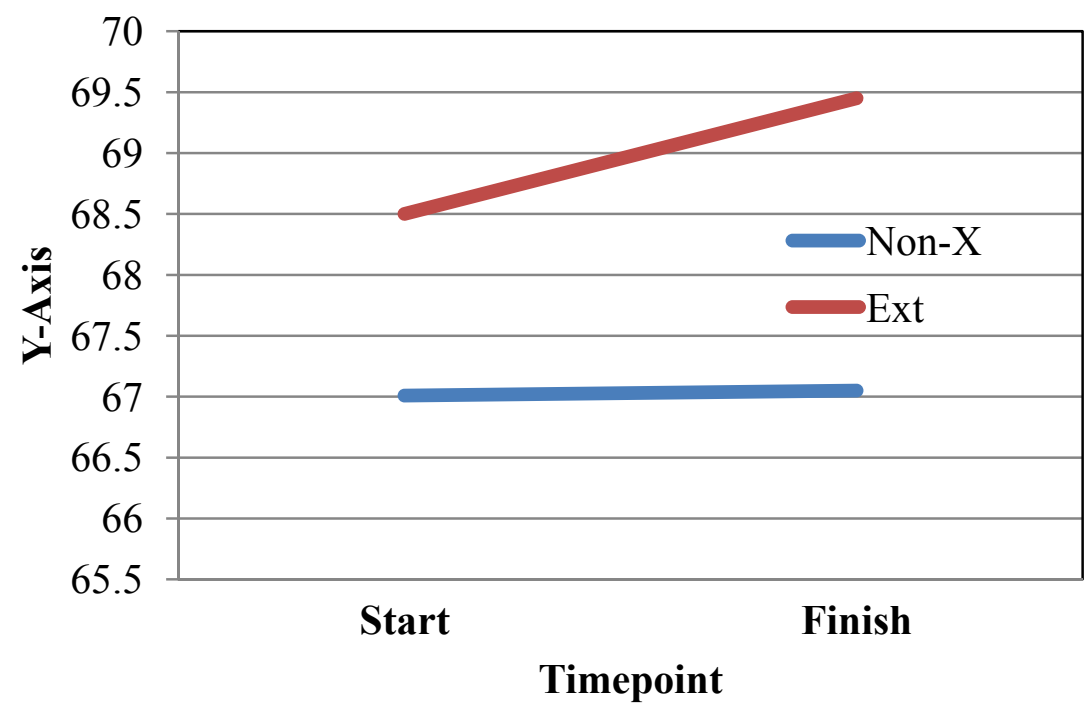

Figure 21. Plot of start and end of treatment values for Y-Axis. 
There are popular misconceptions about orthopedic expansion of the palate and improvement of the airway. In the past, orthopedic expansion of the maxillary suture has been claimed to increase the volume of the nasal airway by expanding the sutures surrounding the nasopharynx (Hershey et al. 1976; White et al. 1989). With 3-dimensional airway studies, rapid palatal expansion is now known to be independent of nasopharyngeal or oropharyngeal volume (Zhao et al. 2010).

One limitation of this study is our small number of extraction cases. Due to time constraints, individual practice preferences, and longer average treatment times, there was not adequate time for us to collect more extraction patients. Although the extraction and non-extraction groups were not significantly different, a larger extraction sample would have increased the power of this study and provided a more convincing result.

Another limitation was that the amount of canine retraction was not recorded. One point of contention between extraction and non-extraction camps is the amount of canine retraction needed to close extraction spaces. Non-extraction practitioners assert that with more canine retraction, there is less room for the tongue, a greater chance for the tongue to impinge on the airway, and a higher probability for a poor esthetic result. Although molar movement was recorded (Tables E-7, E-8), by not measuring the amount of canine retraction, it is unknown how much net canine retraction occurred during space closure.

In both non-extraction and extraction patients, the maxillary and mandibular molars moved anteriorly during treatment (Tables E-7, E-8). This is due to normative downward and forward growth of the jaw bones, and the teeth are carried along with them. In the extraction cases, a greater anterior molar displacement was found because of the addition of anchorage loss during space closure to this normative downward and forward growth. 


\section{CHAPTER 6. SUMMARY AND CONCLUSIONS}

Discrepancy between tooth size and arch size is a common cause of dental malocclusion. For the past century, orthodontists have addressed size discrepancies with two primary treatment options: (1) expansion of the arch perimeter or (2) dental extractions, primarily premolars. For decades, arguments for and against extractions have dealt primarily with esthetics and occlusion. Recently, with the growth of the orthotropic movement (Fasttraxortho 2009; Facefocused 2010; Orthotropics 2010) the effect of premolar extractions on airway volume has again come into question.

According to orthotropists, dental malocclusion is linked to inadequate oropharyngeal volume, resulting from vertical growth and poor oral posture (Mew 2004; Singh et al. 2007). Through the use of removable expansion mechanics, orthotropists claim they can open the airway to its full potential, promoting a horizontal growth pattern and resolution of malocclusions (Mew 2007; Singh et al. 2007). Further, orthotropists contend that extracting premolars exacerbates vertical growth tendencies by forcing the mandible into a retruded position, resulting in downward, backward growth (Hang 2006). Through "careless" retraction of the maxilla, the mandibular arch is forced to fit into a maxillary arch that is purported to be too small, resulting in constriction of the oropharyngeal airway, increased parafunction, poor facial esthetics, increased risk of TMD, and even an increased chance of OSA (Hang 2006).

The purpose of the present, retrospective study was to determine if there is a decrease in oropharyngeal dimensions following the extraction of four premolars and subsequent orthodontic treatment. Oropharyngeal structures were analyzed in 88 healthy teenagers (27 extraction, 61 non-extraction cases) before and after orthodontic treatment. Using CBCT technology, cephalometric variables, as well as transverse and volumetric measurements were analyzed. Major findings are:

(1) Measured at the levels of the PNS (Posterior Nasal Spine), the posterior soft palate, and the tip of the epiglottis, there was no evidence of constriction of the oropharyngeal airway during either extraction or non-extraction treatment.

(2) Instead, at the levels of the PNS, the posterior soft palate, and the tip of the epiglottis, there were net increases in oropharyngeal width, area, and volume for both extraction and non-extraction groups.

(3) The increase in oropharyngeal airway volume during both extraction and nonextraction treatment is due to growth over the roughly two years of treatment, not to a specific treatment.

(4) There is no quantitative evidence that reducing arch perimeter (extracting premolars) has any effect on oropharyngeal size. 


\section{LIST OF REFERENCES}

Abramson ZR, Susarla S, Tagoni JR, Kaban L. Three-dimensional computed tomographic analysis of airway anatomy. J Oral Maxillofac Surg 2010;68:363-71.

Angle E. Treatment of malocclusion of the teeth. Seventh Ed. Philadelphia: S. S. White; 1907.

Årtun J, Hollender LG, Truelove EL. Relationship between orthodontic treatment, condylar position, and internal derangement in the temporomandibular joint. Am J Orthod Dentofacial Orthop 1992;101:48-53.

Battagel JM, Johal A, L'Estrange PR, Croft CB, Kotecha B. Changes in airway and hyoid position in response to mandibular protrusion in subjects with obstructive sleep apnoea (OSA). Eur J Orthod 1999;21:363-76.

Baumrind S, Korn EL, Boyd RL, Maxwell R. The decision to extract: part II. Analysis of clinicians' stated reasons for extraction. Am J Orthod Dentofacial Orthop 1996;109:393-402.

Behrents RG, White RA. TMJ research: responsibility and risk. Am J Orthod Dentofacial Orthop 1992;101:1-3.

Berco M, Rigali PH, Miner RM, DeLuca S, Anderson NK, Will LA. Accuracy and reliability of linear cephalometric measurements from cone-beam computed tomography scans of a dry human skull. Am J Orthod Dentofacial Orthop 2009;136:17.e1-17.e9.

Bowman SJ, Johnston LE Jr. The esthetic impact of extraction and nonextraction treatments on Caucasian patients. Angle Orthod 2000;70:3-10.

Brodie AG, Downs WB, Goldstein A, Myer E. Cephalometric appraisal of orthodontic results - a preliminary report. Angle Orthod 1938;8:261-329.

Brunelle JA, Bhat M, Lipton JA. Prevalence and distribution of selected occlusal characteristics in the US population, 1988-1991. J Dent Res 1996;75:706-13.

Caplan MJ, Shivapuja PK. The effect of premolar extractions on the soft-tissue profile in adult African American females. Angle Orthod 1997;67:129-36.

Corruccini RS. An epidemiologic transition in dental occlusion in world populations. Am J Orthod 1984;86:419-26.

Corruccini RS, Potter RH. Genetic analysis of occlusal variation in twins. Am J Orthod 1980;78:140-54. 
Dahlberg G. Statistical methods for medical and biological students. New York: Interscience; 1940.

Dierkes JM. The beauty of the face: an orthodontic perspective. J Am Dent Assoc 1987;(Special Issue):89E-95E.

El AS, El H, Palomo JM, Baur DA. A 3-dimensional airway analysis of an obstructive sleep apnea surgical correction with cone beam computed tomography. J Oral Maxillofac Surg 2011;69:2424-36.

Facefocused. Face focused orthodontics and dentofacial orthopedics ${ }^{\circledR}$ for children and adults. Date of accession: 12/7/09. http://www.facefocused.com/indexb.html/

Farrar WB, McCarty WL. A clinical outline of temporomandibular joint diagnosis and treatment. Montgomeray, AL: Walker Printing; 1983.

Fasttraxortho. Fast Trax Orthodontics. Date of accession: 12/8/09. Updated 3/10/2009. http://www.fasttraxortho.com/

Finkelstein Y, Wexler D, Horowitz E, Berger G, Nachmani A, Shapiro-Feinberg M, Ophir D. Frontal and lateral cephalometry in patients with sleep-disordered breathing. Laryngoscope 2001;111:634-41.

Fränkel R. The treatment of Class II, Division 1 malocclusion with functional correctors. Am J Orthod 1969;55:265-75.

Gianelly AA, Anderson CK, Boffa J. Longitudinal evaluation of condylar position in extraction and nonextraction treatment. Am J Orthod Dentofacial Orthop 1991;100:416-20.

Gianelly AA, Cozzani M, Boffa J. Condylar position and maxillary first premolar extraction. Am J Orthod Dentofacial Orthop 1991;99:473-6.

Haas AJ. Rapid expansion of the maxillary dental arch and nasal cavity by opening of the midpalatal suture. Angle Orthod 1961;31:73-90.

Han UK, Vig KW, Weintraub JA, Vig PS, Kowalski CJ. Consistency of orthodontic treatment decisions relative to diagnostic records. Am J Orthod Dentofacial Orthop 1991;100:212-9.

Hänggi MP, Teuscher UM, Roos M, Peltomäki TA. Long-term changes in pharyngeal airway dimensions following activator-headgear and fixed appliance treatment. Eur J Orthod 2008;30:598-605.

Hang WM. Obstructive sleep apnea: dentistry's unique role in longevity enhancement. J Am Ortho Soc 2007;7:28-32. 
Hang WM. "How many years must a profession exist...?” Cranio 2006;24:73-5.

Harris EF, Smith RJ. A study of occlusion and arch widths in families. Am J Orthod 1980;78:155-63.

Harris EF, Johnson MG. Heritability of craniometric and occlusal variables: a longitudinal sib analysis. Am J Orthod Dentofacial Orthop 1991;99:258-68.

Harvold EP, Chierici G, Vargervik K. Experiments on the development of dental malocclusion. Am J Orthod 1972;61:38-44.

Harvold EP, Tomer BS, Vargervik K, Chierici G. Primate experiments on oral respiration. Am J Orthod 1981;79:359-72.

Hellman M. Fundamental principles and expedient compromises in orthodontic procedures. Am J Orthod Oral Surg 1944;30:429-36.

Hershey HG, Stewart BL, Warren DW. Changes in nasal airway resistance associated with rapid maxillary expansion. Am J Orthod. 1976;69:274-84.

Howe RP, McNamara JA Jr, O'Connor KA. An examination of dental crowding and its relationship to tooth size and arch dimension. Am J Orthod 1983;83:363-73.

Hudgel DW. The role of upper airway anatomy and physiology in obstructive sleep apnea. Clin Chest Med 1992;13:383-398.

Kelly JE, Harvey CR. An assessment of the occlusion of youths 12-17 years. Vital Health Stat 11 1977;162:1-65.

Kiliaridis S, Kalebo P. Masseter muscle thickness measured by ultrasonography and its relation to muscle morphology. J Dent Res 1991;70:1262-5.

Kiliaridis S, Mejersjo C, Thilander B. Muscle function and cranio-facial morphology: a clinical study in patients with myotonic dystrophy. Eur J Orthod 1989;11:131-8.

Kremenak CR, Kinser DD, Harman HA, Menard CC, Jakobsen JR. Orthodontic risk factors for temporomandibular disorders (TMD). I: Premolar extractions. Am J Orthod Dentofacial Orthop 1992;101:13-20.

Lamichane M, Anderson NK, Rigali PH, Seldin EB, Will LA. Accuracy of reconstructed images from cone-beam computed tomography scans. Am J Orthod Dentofacial Orthop 2009;136:156.e1-156.e6.

Larsson E, Roonnerman A. Mandibular dysfunction symptoms in orthodontically treated patients ten years after completion of treatment. Eur J Orthod 1981;3:89-94. 
Launois SH, Feroah TR, Campbell WN, Issa FG, Morrison D, Whitelaw WA, Isono S, Remmers JE. Site of pharyngeal narrowing predicts outcome of surgery for obstructive sleep apnea. Am Rev Respir Dis 1993;147:182-9.

Little RM, Wallen TR, Riedel RA. Stability and relapse of mandibular anterior alignment-first premolar extraction cases treated by traditional edgewise orthodontics. Am J Orthod Dentofac Orthop 1981;80:349-65.

Lowe AA, Gionhaku N, Takeuchi K, Fleetham JA. Three-dimensional CT reconstructions of tongue and airway in adult subjects with obstructive sleep apnea. Am J Orthod Dentofacial Orthop 1986;90:364-74.

Lowe AA, Santamaria JD, Fleetham JA, Price C. Facial morphology and obstructive sleep apnea. Am J Orthod Dentofacial Orthop 1986;90:484-91.

Luecke PE 3rd, Johnston LE Jr. The effect of maxillary first premolar extraction and incisor retraction on mandibular position: testing the central dogma of "functional orthodontics". Am J Orthod Dentofacial Orthop 1992;101:4-12.

Luppanapornlarp S, Johnston LE Jr. The effects of premolar-extraction: a long-term comparison of outcomes in "clear-cut" extraction and nonextraction Class II patients. Angle Orthod 1993;63:257-72.

Mah J, Hatcher D. Three-dimensional craniofacial imaging. Am J Orhod Dentofacial Orthop 2004;126:308-9.

Mah J, Hatcher D. Craniofacial imaging in orthodontics. In: Graber TM, Vanarsdall RL, Vig KWL, editors. Orthodontics, current principles and techniques. $4^{\text {th }}$ edition. St. Louis: Mosby; 2005.

McDougall PD, McNamara JA Jr, Dierkes JM. Arch width development in class II patients treated with the Fränkel appliance. Am J Orthod 1982;82:10-22.

McNamara SG, Grunstein RR, Sullivan CE. Obstructive sleep apnoea. Thorax 1993;48:754-64.

Merrifield LL, Cross JJ. Directional force. Am J Orthod 1970;57:435-64.

Mew JR. The postural basis of malocclusion: a philosophical overview. Am J Orthod Dentofacial Orthop 2004;126:729-38.

Mew JR. Facial changes in identical twins treated by different orthodontic techniques. World J Orthod 2007;8:174-88.

Mills LF. Arch width, arch length, and tooth size in young males. Angle Orthod 1964;34:124-9. 
Morrison DL, Launois SH, Isono S, Feroah TR, Whitelaw WA, Remmers JE. Pharyngeal narrowing and closing pressures in patients with obstructive sleep apnea. Am Rev Respir Dis 1993;148:606-11.

Netter F. Atlas of human anatomy, 4th Ed. Philadelphia: Saunders; 2006.

Nout E, Bouw FP, Veenland JF, Hop WC, van der Wal KG, Mathijssen IM, Wolvius EB. Three-dimensional airway changes after Le Fort III advancement in syndromic craniosynostosis patients. Plast Reconstr Surg 2010;126:564-71.

Ogawa T, Enciso R, Shintaku WH, Clark GT. Evaluation of cross-section airway configuration of obstructive sleep apnea. Oral Surg Oral Med Oral Pathol Oral Radiol Endod 2007;103:102-8.

Ono T, Otsuka R, Kuroda T, Honda E, Sasaki T. Effects of head and body position on two- and three-dimensional configurations of the upper airway. J Dent Res 2000;79:1879-84.

Orthodontic-outrage. Orthodontic outrage. Date of accession: 12/13/09. Updated 4/16/2008. http://www.orthodonic-outrage.com/

Orthotropics. Orthodontics alternative: official site for natural growth guidance. Date of accession: 12/8/09. Updated 1/5/2010. http://www.orthotropics.com/

Ozbek MM, Memikoglu TU, Gögen H, Lowe AA, Baspinar E. Oropharyngeal airway dimensions and functional-orthopedic treatment in skeletal class II cases. Angle Orthod 1998;68:327-36.

Paquette DE, Beattie JR, Johnston LE Jr. A long-term comparison of nonextraction and premolar extraction edgewise therapy in "borderline" class II patients. Am J Orthod Dentofacial Orthop 1992;102:1-14.

Park JW, Kim NK, Kim JW, Kim MJ, Chang YI. Volumetric, planar, and linear analyses of pharyngeal airway change on computed tomography and cephalometry after mandibular setback surgery. Am J Orthod Dentofacial Orthop 2010;138:292-9.

Pearson LE. Vertical growth in fully-banded orthodontic treatment. Angle Orthod 1986;43:132-40.

Phillipson EA. Sleep apnea - a major public health problem. N Engl J Med 1993;328:1271-3.

Proffit WR. Forty-year review of extraction frequencies at a university orthodontic clinic. Angle Orthod 1994;64:407-14. 
Ribarevski R, Vig P, Vig KD, Weyant R, O'Brien K. Consistency of orthodontic extraction decisions. Eur J Orthod 1996;18:77-80.

Richardson ME. The effect of the mandibular first premolar extraction on third molar space. Angle Orthod 1989;52:291-4.

Sadowsky C, Theisen TA, Sakols EI. Orthodontic treatment and temporomandibular joint sounds: a longitudinal study. Am J Orhod Dentofac Orthop 1991;99:441-7.

Sheng CM, Lin LH, Su Y, Tsai HH. Developmental changes in pharyngeal airway depth and hyoid bone position from childhood to young adulthood. Angle Orthod 2009;79:484-90.

Singh GD, Garcia-Motta AV, Hang WM. Evaluation of the posterior airway space following Biobloc therapy: geometric morphometrics. Cranio 2007;25:84-9.

Smilepage. Advancing the health benefits of fuctional jaw orthopedics (FJO). Date of accession: 12/17/2009. http://www.smilepage.com/

Sokal RR, Rohlf FJ. Biometry: the principles and practice of statistics in biological research, 3rd ed. San Francisco: WH Freeman and Company, 1995.

Spahl TJ, Witzig JW. The clinical management of basic maxillofacial orthopedic appliances. Vol. 1. Mechanics. Littleton, Massachusetts: PSG Publishing Co., 1987.

Stephens CD, Drage KJ, Richmond S, Shaw WC, Roberts CT, Andrews M. Consultant opinion on orthodontic treatment plans used by dental practitioners: a pilot study. J Dent 1993;21:355-9.

Strang RHW. The fallacy of denture expansion as a treatment procedure. Angle Orhod 1949;19:12-7.

Tsai HH. Developmental changes of pharyngeal airway structures from young to adult persons. J Clin Pediatr Dent 2007;31:219-21.

Tukey JW. Exploratory data analysis. Reading, Mass: Addision-Wesley, 1977.

Tweed CH. Indications for the extraction of teeth in orthodontic procedures. Am J Orthod Oral Surg 1944;30:405-28.

Tweed $\mathrm{CH}$. Treatment planning and therapy in the mixed dentition. Am J Orthod 1963;49:881-906.

Vaden JL, Kiser HE. Straight talk about extraction and nonextraction: a differential diagnostic decision. Am J Orthod Dentofacial Orthop 1996;109:445-52. 
Valiathan M, El H, Hans MG, Palomo MJ. Effects of extraction versus non-extraction treatment on oropharyngeal airway volume. Angle Orthod 2010;80:1068-74.

Weintraub JA, Vig PS, Brown C, Kowalski CJ. The prevalence of orthodontic extractions. Am J Orthod Dentofacial Orthop 1989;96:462-66.

White BC, Woodside DG, Cole P. The effect of rapid maxillary expansion on nasal airway resistance. J Otolaryngol 1989;18:137-43.

Winer BJ, Brown DR, Michels KM. Statistical principles in experimental design, 3rd ed. New York: McGraw-Hill Book Company, 1991.

Woolf CM. Principles of biometry. Princeton, NJ: D Van Nostrand Company, Inc, 1968.

Young T, Palta M, Dempsey J, Skatrud J, Weber S, Badr S. The occurrence of sleepdisordered breathing among middle-aged adults. N Engl J Med 1993;328:12301235.

Zhao Y, Nguyen M, Gohl E, Mah JK, Sameshima G, Enciso R. Oropharyngeal airway changes after rapid palatal expansion evaluated with cone-beam computed tomography. Am J Orthod Dentofacial Orthop 2010;137:S71-8. 


\section{APPENDIX A. ANCOVA TABLES TESTING FOR TREATMENT DIFFERENCES WHILE CONTROLLING FOR AGE AND SEX}


Table A-1. ANCOVA results of testing for difference in treatment (extraction versus nonextraction) while controlling for the patient's age and sex: Anterior Facial Height.

\begin{tabular}{|c|c|c|c|c|}
\hline Source & df & SSQ & F ratio & P value \\
\hline \multicolumn{5}{|c|}{ Start of Treatment } \\
\hline Ext-NonExt & 1 & 36.74 & 1.28 & 0.2620 \\
\hline Sex & 1 & 38.35 & 1.33 & 0.2519 \\
\hline Age & 1 & 282.66 & 9.82 & 0.0024 \\
\hline Ext-NonExt-x-Sex & 1 & 2.79 & 0.10 & 0.7564 \\
\hline Ext-NonExt-x-Age & 1 & 8.36 & 0.29 & 0.5915 \\
\hline Sex-x-Age & 1 & 10.10 & 0.35 & 0.5553 \\
\hline Ext-NonExt-x-Sex-X-Age & 1 & 6.58 & 0.23 & 0.6339 \\
\hline \multicolumn{5}{|c|}{ End of Treatment } \\
\hline Ext-NonExt & 1 & 133.94 & 4.66 & 0.0341 \\
\hline Sex & 1 & 174.50 & 6.07 & 0.0160 \\
\hline Age & 1 & 46.72 & 1.62 & 0.2064 \\
\hline Ext-NonExt-x-Sex & 1 & 5.88 & 0.20 & 0.6524 \\
\hline Ext-NonExt-x-Age & 1 & 23.11 & 0.80 & 0.3729 \\
\hline Sex-x-Age & 1 & 3.94 & 0.14 & 0.7124 \\
\hline Ext-NonExt-x-Sex-X-Age & 1 & 10.91 & 0.38 & 0.5398 \\
\hline \multicolumn{5}{|c|}{ In-Treatment Change } \\
\hline Ext-NonExt & 1 & 50.44 & 9.27 & 0.0032 \\
\hline Sex & 1 & 112.49 & 20.68 & $<0.0001$ \\
\hline Age & 1 & 71.08 & 13.06 & 0.0005 \\
\hline Ext-NonExt-x-Sex & 1 & 4.35 & 0.80 & 0.3738 \\
\hline Ext-NonExt-x-Age & 1 & 0.79 & 0.14 & 0.7047 \\
\hline Sex-X-Age & 1 & 6.98 & 1.28 & 0.2608 \\
\hline Ext-NonExt-x-Sex-X-Age & 1 & 0.09 & 0.02 & 0.8989 \\
\hline
\end{tabular}


Table A-2. ANCOVA results of testing for difference in treatment (extraction versus nonextraction) while controlling for the patient's age and sex: Atlas Vertebra to Posterior Nasal Spine.

\begin{tabular}{|c|c|c|c|c|}
\hline Source & df & SSQ & F ratio & $P$ value \\
\hline \multicolumn{5}{|c|}{ Start of Treatment } \\
\hline Ext-NonExt & 1 & 1.56 & 0.13 & 0.7179 \\
\hline Sex & 1 & 3.01 & 0.25 & 0.6165 \\
\hline Age & 1 & 6.86 & 0.58 & 0.4499 \\
\hline Ext-NonExt-x-Sex & 1 & 2.47 & 0.21 & 0.6502 \\
\hline Ext-NonExt-x-Age & 1 & 6.33 & 0.53 & 0.4681 \\
\hline Sex-x-Age & 1 & 2.16 & 0.18 & 0.6712 \\
\hline Ext-NonExt-x-Sex-x-Age & 1 & 13.54 & 1.14 & 0.2895 \\
\hline \multicolumn{5}{|c|}{ End of Treatment } \\
\hline Ext-NonExt & 1 & 10.98 & 0.81 & 0.3711 \\
\hline Sex & 1 & 13.70 & 1.01 & 0.3182 \\
\hline Age & 1 & 5.94 & 0.44 & 0.5103 \\
\hline Ext-NonExt-x-Sex & 1 & 3.17 & 0.23 & 0.6305 \\
\hline Ext-NonExt-x-Age & 1 & 0.58 & 0.04 & 0.8364 \\
\hline Sex-x-Age & 1 & 6.37 & 0.47 & 0.4953 \\
\hline Ext-NonExt-X-Sex-X-Age & 1 & 5.62 & 0.41 & 0.5218 \\
\hline \multicolumn{5}{|c|}{ In-Treatment Change } \\
\hline Ext-NonExt & 1 & 4.26 & 1.30 & 0.2570 \\
\hline Sex & 1 & 3.87 & 1.18 & 0.2799 \\
\hline Age & 1 & 0.03 & 0.01 & 0.9196 \\
\hline Ext-NonExt-x-Sex & 1 & 0.04 & 0.01 & 0.9084 \\
\hline Ext-NonExt-x-Age & 1 & 10.75 & 3.29 & 0.0734 \\
\hline Sex-x-Age & 1 & 1.11 & 0.34 & 0.5614 \\
\hline Ext-NonExt-x-Sex-X-Age & 1 & 1.71 & 0.52 & 0.4711 \\
\hline
\end{tabular}


Table A-3. ANCOVA results of testing for difference in treatment (extraction versus nonextraction) while controlling for the patient's age and sex: Hyoidale to Frankfort Horizontal.

\begin{tabular}{|c|c|c|c|c|}
\hline Source & df & SSQ & F ratio & $P$ value \\
\hline \multicolumn{5}{|c|}{ Start of Treatment } \\
\hline Ext-NonExt & 1 & 5.64 & 0.16 & 0.6945 \\
\hline Sex & 1 & 316.06 & 8.71 & 0.0042 \\
\hline Age & 1 & 790.38 & 21.79 & $<0.0001$ \\
\hline Ext-NonExt-x-Sex & 1 & 59.39 & 1.64 & 0.2047 \\
\hline Ext-NonExt-x-Age & 1 & 47.94 & 1.32 & 0.2540 \\
\hline Sex-x-Age & 1 & 22.58 & 0.62 & 0.4327 \\
\hline Ext-NonExt-x-Sex-x-Age & 1 & 14.96 & 0.41 & 0.5228 \\
\hline \multicolumn{5}{|c|}{ End of Treatment } \\
\hline Ext-NonExt & 1 & 36.90 & 0.53 & 0.4691 \\
\hline Sex & 1 & 488.64 & 7.03 & 0.0102 \\
\hline Age & 1 & 290.35 & 4.18 & 0.0452 \\
\hline Ext-NonExt-x-Sex & 1 & 0.08 & 0.00 & 0.9730 \\
\hline Ext-NonExt-x-Age & 1 & 71.08 & 1.02 & 0.3159 \\
\hline Sex-x-Age & 1 & 158.34 & 2.28 & 0.1363 \\
\hline Ext-NonExt-x-Sex-x-Age & 1 & 108.16 & 1.56 & 0.2170 \\
\hline \multicolumn{5}{|c|}{ In-Treatment Change } \\
\hline Ext-NonExt & 1 & 0.17 & 0.00 & 0.9587 \\
\hline Sex & 1 & 42.51 & 0.66 & 0.4186 \\
\hline Age & 1 & 80.66 & 1.26 & 0.2664 \\
\hline Ext-NonExt-x-Sex & 1 & 19.40 & 0.30 & 0.5842 \\
\hline Ext-NonExt-x-Age & 1 & 9.45 & 0.15 & 0.7023 \\
\hline Sex-x-Age & 1 & 8.58 & 0.13 & 0.7157 \\
\hline Ext-NonExt-x-Sex-x-Age & 1 & 29.01 & 0.45 & 0.5036 \\
\hline
\end{tabular}


Table A-4. ANCOVA results of testing for difference in treatment (extraction versus nonextraction) while controlling for the patient's age and sex: Posterior Soft Palate to Posterior Pharyngeal Wall.

\begin{tabular}{|c|c|c|c|c|}
\hline Source & df & SSQ & F ratio & $P$ value \\
\hline \multicolumn{5}{|c|}{ Start of Treatment } \\
\hline Ext-NonExt & 1 & 13.64 & 2.03 & 0.1585 \\
\hline Sex & 1 & 3.71 & 0.55 & 0.4598 \\
\hline Age & 1 & 19.45 & 2.89 & 0.0931 \\
\hline Ext-NonExt-x-Sex & 1 & 0.04 & 0.01 & 0.9391 \\
\hline Ext-NonExt-x-Age & 1 & 1.73 & 0.26 & 0.6135 \\
\hline Sex-x-Age & 1 & 1.63 & 0.24 & 0.6237 \\
\hline Ext-NonExt-x-Sex-x-Age & 1 & 0.83 & 0.12 & 0.7260 \\
\hline \multicolumn{5}{|c|}{ End of Treatment } \\
\hline Ext-NonExt & 1 & 5.57 & 0.93 & 0.3382 \\
\hline Sex & 1 & 1.62 & 0.27 & 0.6050 \\
\hline Age & 1 & 52.49 & 8.77 & 0.0042 \\
\hline Ext-NonExt-x-Sex & 1 & 5.79 & 0.97 & 0.3286 \\
\hline Ext-NonExt-x-Age & 1 & 0.66 & 0.11 & 0.7414 \\
\hline Sex-x-Age & 1 & 9.47 & 1.58 & 0.2127 \\
\hline Ext-NonExt-x-Sex-x-Age & 1 & 3.64 & 0.61 & 0.4380 \\
\hline \multicolumn{5}{|c|}{ In-Treatment Change } \\
\hline Ext-NonExt & 1 & 6.11 & 1.43 & 0.2359 \\
\hline Sex & 1 & 4.93 & 1.15 & 0.2865 \\
\hline Age & 1 & 10.95 & 2.56 & 0.1141 \\
\hline Ext-NonExt-x-Sex & 1 & 0.01 & 0.00 & 0.9625 \\
\hline Ext-NonExt-x-Age & 1 & 0.12 & 0.03 & 0.8650 \\
\hline Sex-x-Age & 1 & 1.02 & 0.24 & 0.6273 \\
\hline Ext-NonExt-x-Sex-x-Age & 1 & 0.08 & 0.02 & 0.8907 \\
\hline
\end{tabular}


Table A-5. ANCOVA results of testing for difference in treatment (extraction versus nonextraction) while controlling for the patient's age and sex: Sella Perpendicular to A Point.

\begin{tabular}{|c|c|c|c|c|}
\hline Source & df & SSQ & F ratio & P value \\
\hline \multicolumn{5}{|c|}{ Start of Treatment } \\
\hline Ext-NonExt & 1 & 11.44 & 0.64 & 0.4258 \\
\hline Sex & 1 & 88.28 & 4.94 & 0.0290 \\
\hline Age & 1 & 50.19 & 2.81 & 0.0975 \\
\hline Ext-NonExt-x-Sex & 1 & 19.05 & 1.07 & 0.3048 \\
\hline Ext-NonExt-x-Age & 1 & 3.12 & 0.17 & 0.6772 \\
\hline Sex-x-Age & 1 & 8.97 & 0.50 & 0.4805 \\
\hline Ext-NonExt-x-Sex-x-Age & 1 & 9.07 & 0.51 & 0.4780 \\
\hline \multicolumn{5}{|c|}{ End of Treatment } \\
\hline Ext-NonExt & 1 & 40.84 & 2.21 & 0.1415 \\
\hline Sex & 1 & 137.45 & 7.42 & 0.0079 \\
\hline Age & 1 & 21.59 & 1.17 & 0.2835 \\
\hline Ext-NonExt-x-Sex & 1 & 6.53 & 0.35 & 0.5542 \\
\hline Ext-NonExt-x-Age & 1 & 4.24 & 0.23 & 0.6337 \\
\hline Sex-X-Age & 1 & 5.71 & 0.31 & 0.5803 \\
\hline Ext-NonExt-x-Sex-X-Age & 1 & 3.27 & 0.18 & 0.6755 \\
\hline \multicolumn{5}{|c|}{ In-Treatment Change } \\
\hline Ext-NonExt & 1 & 9.05 & 4.90 & 0.0298 \\
\hline Sex & 1 & 5.42 & 2.93 & 0.0906 \\
\hline Age & 1 & 5.94 & 3.22 & 0.0766 \\
\hline Ext-NonExt-x-Sex & 1 & 3.27 & 1.77 & 0.1872 \\
\hline Ext-NonExt-x-Age & 1 & 0.09 & 0.05 & 0.8299 \\
\hline Sex-X-Age & 1 & 0.37 & 0.20 & 0.6570 \\
\hline Ext-NonExt-x-Sex-X-Age & 1 & 1.45 & 0.79 & 0.3783 \\
\hline
\end{tabular}


Table A-6. ANCOVA results of testing for difference in treatment (extraction versus nonextraction) while controlling for the patient's age and sex: Sella Perpendicular to B Point.

\begin{tabular}{|c|c|c|c|c|}
\hline Source & df & SSQ & F ratio & P value \\
\hline \multicolumn{5}{|c|}{ Start of Treatment } \\
\hline Ext-NonExt & 1 & 171.07 & 6.44 & 0.0131 \\
\hline Sex & 1 & 52.68 & 1.98 & 0.1629 \\
\hline Age & 1 & 171.91 & 6.47 & 0.0129 \\
\hline Ext-NonExt-x-Sex & 1 & 48.47 & 1.82 & 0.1805 \\
\hline Ext-NonExt-x-Age & 1 & 1.91 & 0.07 & 0.7894 \\
\hline Sex-X-Age & 1 & 21.32 & 0.80 & 0.3729 \\
\hline Ext-NonExt-x-Sex-x-Age & 1 & 43.65 & 1.64 & 0.2035 \\
\hline \multicolumn{5}{|c|}{ End of Treatment } \\
\hline Ext-NonExt & 1 & 286.86 & 8.47 & 0.0047 \\
\hline Sex & 1 & 87.76 & 2.59 & 0.1114 \\
\hline Age & 1 & 47.76 & 1.41 & 0.2385 \\
\hline Ext-NonExt-x-Sex & 1 & 0.11 & 0.00 & 0.9553 \\
\hline Ext-NonExt-x-Age & 1 & 0.58 & 0.02 & 0.8961 \\
\hline Sex-x-Age & 1 & 31.47 & 0.93 & 0.3379 \\
\hline Ext-NonExt-x-Sex-X-Age & 1 & 21.97 & 0.65 & 0.4229 \\
\hline \multicolumn{5}{|c|}{ In-Treatment Change } \\
\hline Ext-NonExt & 1 & 14.88 & 3.43 & 0.0678 \\
\hline Sex & 1 & 4.45 & 1.02 & 0.3144 \\
\hline Age & 1 & 38.45 & 8.85 & 0.0039 \\
\hline Ext-NonExt-x-Sex & 1 & 44.02 & 10.14 & 0.0021 \\
\hline Ext-NonExt-x-Age & 1 & 0.38 & 0.09 & 0.7673 \\
\hline Sex-X-Age & 1 & 0.98 & 0.23 & 0.6353 \\
\hline Ext-NonExt-x-Sex-X-Age & 1 & 3.69 & 0.85 & 0.3597 \\
\hline
\end{tabular}


Table A-7. ANCOVA results of testing for difference in treatment (extraction versus nonextraction) while controlling for the patient's age and sex: Sella Perpendicular to L6 Mesial.

\begin{tabular}{|c|c|c|c|c|}
\hline Source & df & SSQ & F ratio & P value \\
\hline \multicolumn{5}{|c|}{ Start of Treatment } \\
\hline Ext-NonExt & 1 & 2.82 & 0.13 & 0.7229 \\
\hline Sex & 1 & 78.44 & 3.52 & 0.0642 \\
\hline Age & 1 & 279.10 & 12.53 & 0.0007 \\
\hline Ext-NonExt-x-Sex & 1 & 57.36 & 2.58 & 0.1124 \\
\hline Ext-NonExt-x-Age & 1 & 0.00 & 0.00 & 0.9949 \\
\hline Sex-X-Age & 1 & 5.66 & 0.25 & 0.6154 \\
\hline Ext-NonExt-x-Sex-X-Age & 1 & 29.87 & 1.34 & 0.2502 \\
\hline \multicolumn{5}{|c|}{ End of Treatment } \\
\hline Ext-NonExt & 1 & 56.42 & 2.48 & 0.1190 \\
\hline Sex & 1 & 83.57 & 3.68 & 0.0587 \\
\hline Age & 1 & 58.28 & 2.56 & 0.1132 \\
\hline Ext-NonExt-x-Sex & 1 & 0.06 & 0.00 & 0.9601 \\
\hline Ext-NonExt-x-Age & 1 & 1.66 & 0.07 & 0.7876 \\
\hline Sex-X-Age & 1 & 14.32 & 0.63 & 0.4297 \\
\hline Ext-NonExt-x-Sex-X-Age & 1 & 6.21 & 0.27 & 0.6026 \\
\hline \multicolumn{5}{|c|}{ In-Treatment Change } \\
\hline Ext-NonExt & 1 & 84.47 & 19.82 & $<0.0001$ \\
\hline Sex & 1 & 0.08 & 0.02 & 0.8904 \\
\hline Age & 1 & 82.30 & 19.31 & $<0.0001$ \\
\hline Ext-NonExt-x-Sex & 1 & 61.04 & 14.32 & 0.0003 \\
\hline Ext-NonExt-x-Age & 1 & 1.74 & 0.41 & 0.5247 \\
\hline Sex-x-Age & 1 & 1.97 & 0.46 & 0.4985 \\
\hline Ext-NonExt-x-Sex-X-Age & 1 & 8.84 & 2.07 & 0.1537 \\
\hline
\end{tabular}


Table A-8. ANCOVA results of testing for difference in treatment (extraction versus nonextraction) while controlling for the patient's age and sex: Sella Perpendicular to U6 Mesial.

\begin{tabular}{|c|c|c|c|c|}
\hline Source & df & SSQ & F ratio & P value \\
\hline \multicolumn{5}{|c|}{ Start of Treatment } \\
\hline Ext-NonExt & 1 & 4.96 & 0.29 & 0.5912 \\
\hline Sex & 1 & 51.99 & 3.05 & 0.0845 \\
\hline Age & 1 & 169.09 & 9.92 & 0.0023 \\
\hline Ext-NonExt-x-Sex & 1 & 24.25 & 1.42 & 0.2364 \\
\hline Ext-NonExt-x-Age & 1 & 2.74 & 0.16 & 0.6895 \\
\hline Sex-X-Age & 1 & 3.15 & 0.18 & 0.6685 \\
\hline Ext-NonExt-x-Sex-X-Age & 1 & 5.99 & 0.35 & 0.5550 \\
\hline \multicolumn{5}{|c|}{ End of Treatment } \\
\hline Ext-NonExt & 1 & 89.73 & 4.59 & 0.0352 \\
\hline Sex & 1 & 90.45 & 4.62 & 0.0345 \\
\hline Age & 1 & 70.16 & 3.59 & 0.0619 \\
\hline Ext-NonExt-x-Sex & 1 & 1.91 & 0.10 & 0.7553 \\
\hline Ext-NonExt-x-Age & 1 & 4.47 & 0.23 & 0.6341 \\
\hline Sex-x-Age & 1 & 3.66 & 0.19 & 0.6665 \\
\hline Ext-NonExt-x-Sex-X-Age & 1 & 2.67 & 0.14 & 0.7126 \\
\hline \multicolumn{5}{|c|}{ In-Treatment Change } \\
\hline Ext-NonExt & 1 & 52.51 & 11.64 & 0.0010 \\
\hline Sex & 1 & 5.29 & 1.17 & 0.2820 \\
\hline Age & 1 & 21.41 & 4.75 & 0.0323 \\
\hline Ext-NonExt-x-Sex & 1 & 39.79 & 8.82 & 0.0039 \\
\hline Ext-NonExt-x-Age & 1 & 0.21 & 0.05 & 0.8299 \\
\hline Sex-x-Age & 1 & 0.02 & 0.00 & 0.9482 \\
\hline Ext-NonExt-x-Sex-X-Age & 1 & 0.66 & 0.15 & 0.7032 \\
\hline
\end{tabular}


Table A-9. ANCOVA results of testing for difference in treatment (extraction versus nonextraction) while controlling for the patient's age and sex: Facial Convexity.

\begin{tabular}{|c|c|c|c|c|}
\hline Source & df & SSQ & F ratio & P value \\
\hline \multicolumn{5}{|c|}{ Start of Treatment } \\
\hline Ext-NonExt & 1 & 574.68 & 13.85 & 0.0004 \\
\hline Sex & 1 & 5.12 & 0.12 & 0.7264 \\
\hline Age & 1 & 40.97 & 0.99 & 0.3236 \\
\hline Ext-NonExt-x-Sex & 1 & 51.59 & 1.24 & 0.2684 \\
\hline Ext-NonExt-x-Age & 1 & 1.76 & 0.04 & 0.8376 \\
\hline Sex-X-Age & 1 & 59.61 & 1.44 & 0.2345 \\
\hline Ext-NonExt-x-Sex-X-Age & 1 & 18.54 & 0.45 & 0.5059 \\
\hline \multicolumn{5}{|c|}{ End of Treatment } \\
\hline Ext-NonExt & 1 & 280.41 & 8.43 & 0.0048 \\
\hline Sex & 1 & 25.34 & 0.76 & 0.3854 \\
\hline Age & 1 & 1.39 & 0.04 & 0.8383 \\
\hline Ext-NonExt-x-Sex & 1 & 9.63 & 0.29 & 0.5921 \\
\hline Ext-NonExt-x-Age & 1 & 3.37 & 0.10 & 0.7512 \\
\hline Sex-x-Age & 1 & 49.69 & 1.49 & 0.2253 \\
\hline Ext-NonExt-x-Sex-X-Age & 1 & 17.73 & 0.53 & 0.4675 \\
\hline \multicolumn{5}{|c|}{ In-Treatment Change } \\
\hline Ext-NonExt & 1 & 39.46 & 9.59 & 0.0028 \\
\hline Sex & 1 & 1.03 & 0.25 & 0.6186 \\
\hline Age & 1 & 45.80 & 11.13 & 0.0013 \\
\hline Ext-NonExt-x-Sex & 1 & 17.63 & 4.28 & 0.0421 \\
\hline Ext-NonExt-x-Age & 1 & 0.74 & 0.18 & 0.6737 \\
\hline Sex-x-Age & 1 & 1.38 & 0.34 & 0.5637 \\
\hline Ext-NonExt-x-Sex-X-Age & 1 & 0.16 & 0.04 & 0.8427 \\
\hline
\end{tabular}


Table A-10. ANCOVA results of testing for difference in treatment (extraction versus nonextraction) while controlling for the patient's age and sex: Sella-NasionA Point angle.

\begin{tabular}{|c|c|c|c|c|}
\hline Source & df & SSQ & F ratio & P value \\
\hline \multicolumn{5}{|c|}{ Start of Treatment } \\
\hline Ext-NonExt & 1 & 59.87 & 5.29 & 0.0242 \\
\hline Sex & 1 & 0.96 & 0.08 & 0.7719 \\
\hline Age & 1 & 24.48 & 2.16 & 0.1455 \\
\hline Ext-NonExt-x-Sex & 1 & 3.48 & 0.31 & 0.5809 \\
\hline Ext-NonExt-x-Age & 1 & 0.08 & 0.01 & 0.9331 \\
\hline Sex-X-Age & 1 & 6.40 & 0.57 & 0.4543 \\
\hline Ext-NonExt-x-Sex-X-Age & 1 & 25.44 & 2.25 & 0.1380 \\
\hline \multicolumn{5}{|c|}{ End of Treatment } \\
\hline Ext-NonExt & 1 & 0.17 & 0.02 & 0.9011 \\
\hline Sex & 1 & 8.87 & 0.79 & 0.3767 \\
\hline Age & 1 & 14.64 & 1.31 & 0.2567 \\
\hline Ext-NonExt-x-Sex & 1 & 6.74 & 0.60 & 0.4407 \\
\hline Ext-NonExt-x-Age & 1 & 1.34 & 0.12 & 0.7301 \\
\hline Sex-x-Age & 1 & 10.53 & 0.94 & 0.3356 \\
\hline Ext-NonExt-x-Sex-X-Age & 1 & 16.53 & 1.47 & 0.2284 \\
\hline \multicolumn{5}{|c|}{ In-Treatment Change } \\
\hline Ext-NonExt & 1 & 21.79 & 13.02 & 0.0006 \\
\hline Sex & 1 & 0.04 & 0.02 & 0.8823 \\
\hline Age & 1 & 0.23 & 0.14 & 0.7143 \\
\hline Ext-NonExt-x-Sex & 1 & 1.34 & 0.80 & 0.3732 \\
\hline Ext-NonExt-x-Age & 1 & 0.00 & 0.00 & 0.9639 \\
\hline Sex-x-Age & 1 & 0.33 & 0.20 & 0.6574 \\
\hline Ext-NonExt-x-Sex-X-Age & 1 & 0.01 & 0.01 & 0.9398 \\
\hline
\end{tabular}


Table A-11. ANCOVA results of testing for difference in treatment (extraction versus nonextraction) while controlling for the patient's age and sex: Sella-Nasion$B$ Point angle.

\begin{tabular}{|c|c|c|c|c|}
\hline Source & df & SSQ & F ratio & P value \\
\hline \multicolumn{5}{|c|}{ Start of Treatment } \\
\hline Ext-NonExt & 1 & 0.08 & 0.01 & 0.9364 \\
\hline Sex & 1 & 2.14 & 0.18 & 0.6748 \\
\hline Age & 1 & 28.50 & 2.37 & 0.1281 \\
\hline Ext-NonExt-x-Sex & 1 & 20.36 & 1.69 & 0.1974 \\
\hline Ext-NonExt-x-Age & 1 & 0.93 & 0.08 & 0.7814 \\
\hline Sex-x-Age & 1 & 23.99 & 1.99 & 0.1622 \\
\hline Ext-NonExt-x-Sex-x-Age & 1 & 9.85 & 0.82 & 0.3687 \\
\hline \multicolumn{5}{|c|}{ End of Treatment } \\
\hline Ext-NonExt & 1 & 34.17 & 2.54 & 0.1153 \\
\hline Sex & 1 & 1.89 & 0.14 & 0.7090 \\
\hline Age & 1 & 8.82 & 0.66 & 0.4207 \\
\hline Ext-NonExt-x-Sex & 1 & 11.05 & 0.82 & 0.3676 \\
\hline Ext-NonExt-x-Age & 1 & 0.58 & 0.04 & 0.8365 \\
\hline Sex-X-Age & 1 & 28.56 & 2.12 & 0.1494 \\
\hline Ext-NonExt-x-Sex-X-Age & 1 & 4.57 & 0.34 & 0.5616 \\
\hline \multicolumn{5}{|c|}{ In-Treatment Change } \\
\hline Ext-NonExt & 1 & 8.28 & 5.04 & 0.0278 \\
\hline Sex & 1 & 0.22 & 0.14 & 0.7136 \\
\hline Age & 1 & 10.86 & 6.62 & 0.0122 \\
\hline Ext-NonExt-x-Sex & 1 & 0.43 & 0.26 & 0.6101 \\
\hline Ext-NonExt-x-Age & 1 & 0.17 & 0.10 & 0.7478 \\
\hline Sex-X-Age & 1 & 0.57 & 0.35 & 0.5584 \\
\hline Ext-NonExt-x-Sex-X-Age & 1 & 1.38 & 0.84 & 0.3631 \\
\hline
\end{tabular}


Table A-12. ANCOVA results of testing for difference in treatment (extraction versus nonextraction) while controlling for the patient's age and sex: A PointNasion-B Point angle.

\begin{tabular}{|c|c|c|c|c|}
\hline Source & df & SSQ & F ratio & P value \\
\hline \multicolumn{5}{|c|}{ Start of Treatment } \\
\hline Ext-NonExt & 1 & 64.24 & 10.06 & 0.0022 \\
\hline Sex & 1 & 0.23 & 0.04 & 0.8489 \\
\hline Age & 1 & 0.15 & 0.02 & 0.8773 \\
\hline Ext-NonExt-x-Sex & 1 & 7.01 & 1.10 & 0.2982 \\
\hline Ext-NonExt-x-Age & 1 & 0.47 & 0.07 & 0.7876 \\
\hline Sex-x-Age & 1 & 5.60 & 0.88 & 0.3518 \\
\hline Ext-NonExt-x-Sex-x-Age & 1 & 3.63 & 0.57 & 0.4531 \\
\hline \multicolumn{5}{|c|}{ End of Treatment } \\
\hline Ext-NonExt & 1 & 39.22 & 8.33 & 0.0051 \\
\hline Sex & 1 & 2.57 & 0.55 & 0.4622 \\
\hline Age & 1 & 0.73 & 0.16 & 0.6943 \\
\hline Ext-NonExt-x-Sex & 1 & 0.53 & 0.11 & 0.7377 \\
\hline Ext-NonExt-x-Age & 1 & 0.16 & 0.03 & 0.8544 \\
\hline Sex-X-Age & 1 & 4.41 & 0.94 & 0.3366 \\
\hline Ext-NonExt-x-Sex-X-Age & 1 & 3.71 & 0.79 & 0.3774 \\
\hline \multicolumn{5}{|c|}{ In-Treatment Change } \\
\hline Ext-NonExt & 1 & 3.21 & 3.00 & 0.0874 \\
\hline Sex & 1 & 0.08 & 0.07 & 0.7874 \\
\hline Age & 1 & 7.96 & 7.44 & 0.0080 \\
\hline Ext-NonExt-x-Sex & 1 & 3.30 & 3.08 & 0.0833 \\
\hline Ext-NonExt-x-Age & 1 & 0.22 & 0.21 & 0.6491 \\
\hline Sex-X-Age & 1 & 1.77 & 1.65 & 0.2025 \\
\hline Ext-NonExt-x-Sex-X-Age & 1 & 1.16 & 1.08 & 0.3019 \\
\hline
\end{tabular}


Table A-13. ANCOVA results of testing for difference in treatment (extraction versus nonextraction) while controlling for the patient's age and sex: Y-Axis.

\begin{tabular}{|c|c|c|c|c|}
\hline Source & df & SSQ & F ratio & P value \\
\hline \multicolumn{5}{|c|}{ Start of Treatment } \\
\hline Ext-NonExt & 1 & 39.78 & 3.19 & 0.0780 \\
\hline Sex & 1 & 5.36 & 0.43 & 0.5139 \\
\hline Age & 1 & 22.36 & 1.79 & 0.1844 \\
\hline Ext-NonExt-x-Sex & 1 & 10.52 & 0.84 & 0.3611 \\
\hline Ext-NonExt-x-Age & 1 & 4.01 & 0.32 & 0.5725 \\
\hline Sex-x-Age & 1 & 51.39 & 4.12 & 0.0458 \\
\hline Ext-NonExt-x-Sex-X-Age & 1 & 0.00 & 0.00 & 0.9908 \\
\hline \multicolumn{5}{|c|}{ End of Treatment } \\
\hline Ext-NonExt & 1 & 102.49 & 8.04 & 0.0059 \\
\hline Sex & 1 & 9.88 & 0.77 & 0.3817 \\
\hline Age & 1 & 8.82 & 0.69 & 0.4083 \\
\hline Ext-NonExt-x-Sex & 1 & 4.71 & 0.37 & 0.5453 \\
\hline Ext-NonExt-x-Age & 1 & 4.25 & 0.33 & 0.5653 \\
\hline Sex-x-Age & 1 & 32.18 & 2.52 & 0.1164 \\
\hline Ext-NonExt-x-Sex-X-Age & 1 & 1.87 & 0.15 & 0.7031 \\
\hline \multicolumn{5}{|c|}{ In-Treatment Change } \\
\hline Ext-NonExt & 1 & 9.81 & 4.69 & 0.0337 \\
\hline Sex & 1 & 0.15 & 0.07 & 0.7902 \\
\hline Age & 1 & 7.87 & 3.76 & 0.0564 \\
\hline Ext-NonExt-x-Sex & 1 & 2.37 & 1.13 & 0.2912 \\
\hline Ext-NonExt-x-Age & 1 & 0.00 & 0.00 & 0.9699 \\
\hline Sex-X-Age & 1 & 0.24 & 0.11 & 0.7367 \\
\hline Ext-NonExt-x-Sex-X-Age & 1 & 1.65 & 0.79 & 0.3780 \\
\hline
\end{tabular}


Table A-14. ANCOVA results of testing for difference in treatment (extraction versus nonextraction) while controlling for the patient's age and sex: Upper Pharyngeal Plane Width.

\begin{tabular}{|c|c|c|c|c|}
\hline Source & df & SSQ & F ratio & P value \\
\hline \multicolumn{5}{|c|}{ Start of Treatment } \\
\hline Ext-NonExt & 1 & 35.66 & 1.89 & 0.1731 \\
\hline Sex & 1 & 47.34 & 2.51 & 0.1172 \\
\hline Age & 1 & 230.79 & 12.26 & 0.0008 \\
\hline Ext-NonExt-x-Sex & 1 & 37.75 & 2.00 & 0.1611 \\
\hline Ext-NonExt-x-Age & 1 & 13.84 & 0.74 & 0.3941 \\
\hline Sex-x-Age & 1 & 19.11 & 1.01 & 0.3172 \\
\hline Ext-NonExt-x-Sex-x-Age & 1 & 0.67 & 0.04 & 0.8510 \\
\hline \multicolumn{5}{|c|}{ End of Treatment } \\
\hline Ext-NonExt & 1 & 4.53 & 0.20 & 0.6526 \\
\hline Sex & 1 & 128.28 & 5.79 & 0.0187 \\
\hline Age & 1 & 216.44 & 9.77 & 0.0026 \\
\hline Ext-NonExt-x-Sex & 1 & 27.08 & 1.22 & 0.2726 \\
\hline Ext-NonExt-x-Age & 1 & 5.22 & 0.24 & 0.6289 \\
\hline Sex-x-Age & 1 & 16.69 & 0.75 & 0.3884 \\
\hline Ext-NonExt-x-Sex-X-Age & 1 & 29.27 & 1.32 & 0.2542 \\
\hline \multicolumn{5}{|c|}{ In-Treatment Change } \\
\hline Ext-NonExt & 1 & 13.32 & 0.98 & 0.3259 \\
\hline Sex & 1 & 26.92 & 1.98 & 0.1640 \\
\hline Age & 1 & 0.02 & 0.00 & 0.9703 \\
\hline Ext-NonExt-x-Sex & 1 & 0.42 & 0.03 & 0.8612 \\
\hline Ext-NonExt-x-Age & 1 & 0.30 & 0.02 & 0.8826 \\
\hline Sex-X-Age & 1 & 0.59 & 0.04 & 0.8359 \\
\hline Ext-NonExt-x-Sex-X-Age & 1 & 17.05 & 1.25 & 0.2668 \\
\hline
\end{tabular}


Table A-15. ANCOVA results of testing for difference in treatment (extraction versus nonextraction) while controlling for the patient's age and sex: Upper Pharyngeal Plane Area.

\begin{tabular}{|c|c|c|c|c|}
\hline Source & df & SSQ & F ratio & P value \\
\hline \multicolumn{5}{|c|}{ Start of Treatment } \\
\hline Ext-NonExt & 1 & 52195.50 & 2.81 & 0.0981 \\
\hline Sex & 1 & 2412.07 & 0.13 & 0.7197 \\
\hline Age & 1 & 239569.78 & 12.89 & 0.0006 \\
\hline Ext-NonExt-x-Sex & 1 & 3234.12 & 0.17 & 0.6778 \\
\hline Ext-NonExt-x-Age & 1 & 30164.37 & 1.62 & 0.2068 \\
\hline Sex-X-Age & 1 & 2363.35 & 0.13 & 0.7224 \\
\hline Ext-NonExt-x-Sex-X-Age & 1 & 8365.23 & 0.45 & 0.5045 \\
\hline \multicolumn{5}{|c|}{ End of Treatment } \\
\hline Ext-NonExt & 1 & 15821.51 & 0.75 & 0.3900 \\
\hline Sex & 1 & 16140.15 & 0.76 & 0.3853 \\
\hline Age & 1 & 334788.16 & 15.83 & 0.0002 \\
\hline Ext-NonExt-x-Sex & 1 & 82.71 & 0.00 & 0.9503 \\
\hline Ext-NonExt-x-Age & 1 & 6595.19 & 0.31 & 0.5783 \\
\hline Sex-x-Age & 1 & 434.92 & 0.02 & 0.8864 \\
\hline Ext-NonExt-x-Sex-X-Age & 1 & 2846.83 & 0.13 & 0.7148 \\
\hline \multicolumn{5}{|c|}{ In-Treatment Change } \\
\hline Ext-NonExt & 1 & 18661.86 & 1.80 & 0.1847 \\
\hline Sex & 1 & 9207.12 & 0.89 & 0.3498 \\
\hline Age & 1 & 18307.36 & 1.76 & 0.1888 \\
\hline Ext-NonExt-x-Sex & 1 & 63.20 & 0.01 & 0.9381 \\
\hline Ext-NonExt-x-Age & 1 & 3487.00 & 0.34 & 0.5642 \\
\hline Sex-x-Age & 1 & 3345.30 & 0.32 & 0.5723 \\
\hline Ext-NonExt-x-Sex-X-Age & 1 & 2014.50 & 0.19 & 0.6611 \\
\hline
\end{tabular}


Table A-16. ANCOVA results of testing for difference in treatment (extraction versus nonextraction) while controlling for the patient's age and sex: Middle Pharyngeal Plane Width.

\begin{tabular}{|c|c|c|c|c|}
\hline Source & df & SSQ & F ratio & P value \\
\hline \multicolumn{5}{|c|}{ Start of Treatment } \\
\hline Ext-NonExt & 1 & 7.63 & 0.16 & 0.6922 \\
\hline Sex & 1 & 13.00 & 0.27 & 0.6054 \\
\hline Age & 1 & 178.34 & 3.69 & 0.0585 \\
\hline Ext-NonExt-x-Sex & 1 & 0.30 & 0.01 & 0.9378 \\
\hline Ext-NonExt-x-Age & 1 & 118.09 & 2.45 & 0.1222 \\
\hline Sex-x-Age & 1 & 10.91 & 0.23 & 0.6360 \\
\hline Ext-NonExt-x-Sex-x-Age & 1 & 10.87 & 0.23 & 0.6366 \\
\hline \multicolumn{5}{|c|}{ End of Treatment } \\
\hline Ext-NonExt & 1 & 0.08 & 0.00 & 0.9635 \\
\hline Sex & 1 & 15.19 & 0.41 & 0.5247 \\
\hline Age & 1 & 223.40 & 6.01 & 0.0167 \\
\hline Ext-NonExt-x-Sex & 1 & 0.38 & 0.01 & 0.9202 \\
\hline Ext-NonExt-x-Age & 1 & 17.18 & 0.46 & 0.4988 \\
\hline Sex-x-Age & 1 & 10.17 & 0.27 & 0.6026 \\
\hline Ext-NonExt-x-Sex-X-Age & 1 & 4.50 & 0.12 & 0.7289 \\
\hline \multicolumn{5}{|c|}{ In-Treatment Change } \\
\hline Ext-NonExt & 1 & 4.90 & 0.17 & 0.6773 \\
\hline Sex & 1 & 5.16 & 0.18 & 0.6695 \\
\hline Age & 1 & 12.69 & 0.45 & 0.5036 \\
\hline Ext-NonExt-x-Sex & 1 & 3.13 & 0.11 & 0.7393 \\
\hline Ext-NonExt-x-Age & 1 & 46.02 & 1.64 & 0.2047 \\
\hline Sex-X-Age & 1 & 2.82 & 0.10 & 0.7523 \\
\hline Ext-NonExt-x-Sex-x-Age & 1 & 0.54 & 0.02 & 0.8897 \\
\hline
\end{tabular}


Table A-17. ANCOVA results of testing for difference in treatment (extraction versus nonextraction) while controlling for the patient's age and sex: Middle Pharyngeal Plane Area.

\begin{tabular}{|c|c|c|c|c|}
\hline Source & df & SSQ & F ratio & P value \\
\hline \multicolumn{5}{|c|}{ Start of Treatment } \\
\hline Ext-NonExt & 1 & 5537.24 & 0.79 & 0.3755 \\
\hline Sex & 1 & 7187.11 & 1.03 & 0.3131 \\
\hline Age & 1 & 47677.81 & 6.84 & 0.0108 \\
\hline Ext-NonExt-x-Sex & 1 & 1288.76 & 0.19 & 0.6684 \\
\hline Ext-NonExt-x-Age & 1 & 32297.97 & 4.64 & 0.0346 \\
\hline Sex-X-Age & 1 & 10476.93 & 1.50 & 0.2240 \\
\hline Ext-NonExt-x-Sex-X-Age & 1 & 4491.97 & 0.64 & 0.4246 \\
\hline \multicolumn{5}{|c|}{ End of Treatment } \\
\hline Ext-NonExt & 1 & 47.20 & 0.01 & 0.9434 \\
\hline Sex & 1 & 10152.19 & 1.09 & 0.2995 \\
\hline Age & 1 & 71944.41 & 7.74 & 0.0069 \\
\hline Ext-NonExt-x-Sex & 1 & 3147.81 & 0.34 & 0.5624 \\
\hline Ext-NonExt-x-Age & 1 & 23283.46 & 2.51 & 0.1179 \\
\hline Sex-x-Age & 1 & 9884.42 & 1.06 & 0.3059 \\
\hline Ext-NonExt-x-Sex-X-Age & 1 & 9303.10 & 1.00 & 0.3205 \\
\hline \multicolumn{5}{|c|}{ In-Treatment Change } \\
\hline Ext-NonExt & 1 & 3574.42 & 0.59 & 0.4443 \\
\hline Sex & 1 & 3596.45 & 0.60 & 0.4429 \\
\hline Age & 1 & 3323.74 & 0.55 & 0.4606 \\
\hline Ext-NonExt-x-Sex & 1 & 3435.41 & 0.57 & 0.4532 \\
\hline Ext-NonExt-x-Age & 1 & 1140.39 & 0.19 & 0.6652 \\
\hline Sex-x-Age & 1 & 988.51 & 0.16 & 0.6870 \\
\hline Ext-NonExt-x-Sex-X-Age & 1 & 135.67 & 0.02 & 0.8813 \\
\hline
\end{tabular}


Table A-18. ANCOVA results of testing for difference in treatment (extraction versus nonextraction) while controlling for the patient's age and sex: Lower Pharyngeal Plane Width.

\begin{tabular}{|c|c|c|c|c|}
\hline Source & df & SSQ & F ratio & P value \\
\hline \multicolumn{5}{|c|}{ Start of Treatment } \\
\hline Ext-NonExt & 1 & 0.01 & 0.00 & 0.9817 \\
\hline Sex & 1 & 11.23 & 0.68 & 0.4118 \\
\hline Age & 1 & 123.42 & 7.49 & 0.0077 \\
\hline Ext-NonExt-x-Sex & 1 & 3.47 & 0.21 & 0.6475 \\
\hline Ext-NonExt-x-Age & 1 & 6.17 & 0.37 & 0.5423 \\
\hline Sex-x-Age & 1 & 3.66 & 0.22 & 0.6388 \\
\hline Ext-NonExt-x-Sex-x-Age & 1 & 14.77 & 0.90 & 0.3468 \\
\hline \multicolumn{5}{|c|}{ End of Treatment } \\
\hline Ext-NonExt & 1 & 25.03 & 1.30 & 0.3568 \\
\hline Sex & 1 & 61.40 & 3.19 & 0.0994 \\
\hline Age & 1 & 49.22 & 2.56 & 0.0072 \\
\hline Ext-NonExt-x-Sex & 1 & 1.67 & 0.09 & 0.4744 \\
\hline Ext-NonExt-x-Age & 1 & 5.97 & 0.31 & 0.7758 \\
\hline Sex-x-Age & 1 & 46.92 & 2.44 & 0.3891 \\
\hline Ext-NonExt-x-Sex-X-Age & 1 & 72.72 & 3.77 & 0.1958 \\
\hline \multicolumn{5}{|c|}{ In-Treatment Change } \\
\hline Ext-NonExt & 1 & 9.89 & 0.53 & 0.6521 \\
\hline Sex & 1 & 25.85 & 1.39 & 0.3297 \\
\hline Age & 1 & 17.59 & 0.95 & 0.8574 \\
\hline Ext-NonExt-x-Sex & 1 & 6.40 & 0.34 & 0.7767 \\
\hline Ext-NonExt-x-Age & 1 & 0.31 & 0.02 & 0.4200 \\
\hline Sex-X-Age & 1 & 74.55 & 4.01 & 0.1685 \\
\hline Ext-NonExt-x-Sex-X-Age & 1 & 16.71 & 0.90 & 0.8800 \\
\hline
\end{tabular}


Table A-19. ANCOVA results of testing for difference in treatment (extraction versus nonextraction) while controlling for the patient's age and sex: Lower Pharyngeal Plane Area.

\begin{tabular}{|c|c|c|c|c|}
\hline Source & df & SSQ & F ratio & P value \\
\hline \multicolumn{5}{|c|}{ Start of Treatment } \\
\hline Ext-NonExt & 1 & 24940.62 & 2.55 & 0.1145 \\
\hline Sex & 1 & 5903.99 & 0.60 & 0.4397 \\
\hline Age & 1 & 25979.99 & 2.65 & 0.1073 \\
\hline Ext-NonExt-x-Sex & 1 & 1833.56 & 0.19 & 0.6664 \\
\hline Ext-NonExt-x-Age & 1 & 10717.17 & 1.09 & 0.2986 \\
\hline Sex-X-Age & 1 & 87.84 & 0.01 & 0.9248 \\
\hline Ext-NonExt-x-Sex-X-Age & 1 & 1030.77 & 0.11 & 0.7464 \\
\hline \multicolumn{5}{|c|}{ End of Treatment } \\
\hline Ext-NonExt & 1 & 20319.71 & 1.97 & 0.1646 \\
\hline Sex & 1 & 6047.59 & 0.59 & 0.4463 \\
\hline Age & 1 & 51795.87 & 5.02 & 0.0279 \\
\hline Ext-NonExt-x-Sex & 1 & 431.18 & 0.04 & 0.8386 \\
\hline Ext-NonExt-x-Age & 1 & 13523.67 & 1.31 & 0.2559 \\
\hline Sex-x-Age & 1 & 19635.39 & 1.90 & 0.1718 \\
\hline Ext-NonExt-x-Sex-X-Age & 1 & 16292.29 & 1.58 & 0.2128 \\
\hline \multicolumn{5}{|c|}{ In-Treatment Change } \\
\hline Ext-NonExt & 1 & 1579.10 & 0.17 & 0.6856 \\
\hline Sex & 1 & 221.87 & 0.02 & 0.8793 \\
\hline Age & 1 & 4281.14 & 0.45 & 0.5054 \\
\hline Ext-NonExt-x-Sex & 1 & 2523.28 & 0.26 & 0.6090 \\
\hline Ext-NonExt-x-Age & 1 & 377.77 & 0.04 & 0.8430 \\
\hline Sex-x-Age & 1 & 16783.88 & 1.76 & 0.1892 \\
\hline Ext-NonExt-x-Sex-X-Age & 1 & 7899.28 & 0.83 & 0.3663 \\
\hline
\end{tabular}


Table A-20. ANCOVA results of testing for difference in treatment (extraction versus nonextraction) while controlling for the patient's age and sex: Middle Pharyngeal Airway Volume.

\begin{tabular}{|c|c|c|c|c|}
\hline Source & df & SSQ & F ratio & P value \\
\hline \multicolumn{5}{|c|}{ Start of Treatment } \\
\hline Ext-NonExt & 1 & $12,394,440$ & 3.88 & 0.0528 \\
\hline Sex & 1 & $1,432,469$ & 0.45 & 0.5055 \\
\hline Age & 1 & $72,420,308$ & 22.65 & $<0.0001$ \\
\hline Ext-NonExt-x-Sex & 1 & $3,996,200$ & 1.25 & 0.2674 \\
\hline Ext-NonExt-x-Age & 1 & $30,201,461$ & 9.44 & 0.0030 \\
\hline Sex-X-Age & 1 & 4,240 & 0.00 & 0.9711 \\
\hline Ext-NonExt-x-Sex-X-Age & 1 & $11,471,275$ & 3.59 & 0.0623 \\
\hline \multicolumn{5}{|c|}{ End of Treatment } \\
\hline Ext-NonExt & 1 & $14,958,133$ & 3.37 & 0.0707 \\
\hline Sex & 1 & $1,100,720$ & 0.25 & 0.6201 \\
\hline Age & 1 & $49,939,426$ & 11.25 & 0.0013 \\
\hline Ext-NonExt-x-Sex & 1 & $3,731,999$ & 0.84 & 0.3624 \\
\hline Ext-NonExt-x-Age & 1 & $13,804,656$ & 3.11 & 0.0823 \\
\hline Sex-x-Age & 1 & 182,837 & 0.04 & 0.8398 \\
\hline Ext-NonExt-x-Sex-X-Age & 1 & $19,348,254$ & 4.36 & 0.0405 \\
\hline \multicolumn{5}{|c|}{ In-Treatment Change } \\
\hline Ext-NonExt & 1 & 62,338 & 0.02 & 0.9022 \\
\hline Sex & 1 & 239,942 & 0.06 & 0.8095 \\
\hline Age & 1 & $1,411,909$ & 0.34 & 0.5592 \\
\hline Ext-NonExt-x-Sex & 1 & 970,643 & 0.24 & 0.6281 \\
\hline Ext-NonExt-x-Age & 1 & $1,758,016$ & 0.43 & 0.5147 \\
\hline Sex-x-Age & 1 & 714,952 & 0.17 & 0.6775 \\
\hline Ext-NonExt-x-Sex-X-Age & 1 & 216,944 & 0.05 & 0.8187 \\
\hline
\end{tabular}


Table A-21. ANCOVA results of testing for difference in treatment (extraction versus nonextraction) while controlling for the patient's age and sex: Inferior Pharyngeal Airway Volume.

\begin{tabular}{|c|c|c|c|c|}
\hline Source & df & SSQ & F ratio & P value \\
\hline \multicolumn{5}{|c|}{ Start of Treatment } \\
\hline Ext-NonExt & 1 & 229,410 & 0.04 & 0.8521 \\
\hline Sex & 1 & 41,067 & 0.01 & 0.9371 \\
\hline Age & 1 & $62,033,912$ & 9.46 & 0.0030 \\
\hline Ext-NonExt-x-Sex & 1 & 211,785 & 0.03 & 0.8579 \\
\hline Ext-NonExt-x-Age & 1 & $12,637,406$ & 1.93 & 0.1692 \\
\hline Sex-X-Age & 1 & 122,132 & 0.02 & 0.8918 \\
\hline Ext-NonExt-x-Sex-X-Age & 1 & $1,598,597$ & 0.24 & 0.6229 \\
\hline \multicolumn{5}{|c|}{ End of Treatment } \\
\hline Ext-NonExt & 1 & 113,356 & 0.01 & 0.9083 \\
\hline Sex & 1 & $6,351,112$ & 0.75 & 0.3898 \\
\hline Age & 1 & $122,216,461$ & 14.41 & 0.0003 \\
\hline Ext-NonExt-x-Sex & 1 & $3,467,835$ & 0.41 & 0.5246 \\
\hline Ext-NonExt-x-Age & 1 & 60,106 & 0.01 & 0.9331 \\
\hline Sex-x-Age & 1 & 218,975 & 0.03 & 0.8728 \\
\hline Ext-NonExt-x-Sex-X-Age & 1 & $11,408,461$ & 1.35 & 0.2501 \\
\hline \multicolumn{5}{|c|}{ In-Treatment Change } \\
\hline Ext-NonExt & 1 & 21,858 & 0.00 & 0.9526 \\
\hline Sex & 1 & $1,535,519$ & 0.25 & 0.6187 \\
\hline Age & 1 & $10,121,159$ & 1.65 & 0.2037 \\
\hline Ext-NonExt-x-Sex & 1 & $1,942,465$ & 0.32 & 0.5758 \\
\hline Ext-NonExt-x-Age & 1 & $13,312,351$ & 2.17 & 0.1457 \\
\hline Sex-x-Age & 1 & 28,092 & 0.00 & 0.9463 \\
\hline Ext-NonExt-x-Sex-X-Age & 1 & 831,555 & 0.14 & 0.7141 \\
\hline
\end{tabular}


Table A-22. ANCOVA results of testing for difference in treatment (extraction versus nonextraction) while controlling for the patient's age and sex: Total Pharyngeal Airway Volume.

\begin{tabular}{|c|c|c|c|c|}
\hline Source & df & SSQ & F ratio & P value \\
\hline \multicolumn{5}{|c|}{ Start of Treatment } \\
\hline Ext-NonExt & 1 & $8,686,713$ & 0.59 & 0.4432 \\
\hline Sex & 1 & 852,266 & 0.06 & 0.8098 \\
\hline Age & 1 & $269,441,452$ & 18.44 & $<0.0001$ \\
\hline Ext-NonExt-x-Sex & 1 & $2,580,307$ & 0.18 & 0.6755 \\
\hline Ext-NonExt-x-Age & 1 & $81,264,357$ & 5.56 & 0.0211 \\
\hline Sex-X-Age & 1 & 100,922 & 0.01 & 0.9340 \\
\hline Ext-NonExt-x-Sex-X-Age & 1 & $21,940,035$ & 1.50 & 0.2244 \\
\hline \multicolumn{5}{|c|}{ End of Treatment } \\
\hline Ext-NonExt & 1 & $17,675,791$ & 0.90 & 0.3455 \\
\hline Sex & 1 & $2,163,810$ & 0.11 & 0.7407 \\
\hline Age & 1 & $328,404,662$ & 16.76 & 0.0001 \\
\hline Ext-NonExt-x-Sex & 1 & 4,848 & 0.00 & 0.9875 \\
\hline Ext-NonExt-x-Age & 1 & $12,042,954$ & 0.61 & 0.4357 \\
\hline Sex-x-Age & 1 & 1,628 & 0.00 & 0.9928 \\
\hline Ext-NonExt-x-Sex-X-Age & 1 & $60,470,942$ & 3.09 & 0.0834 \\
\hline \multicolumn{5}{|c|}{ In-Treatment Change } \\
\hline Ext-NonExt & 1 & 172,027 & 0.01 & 0.9148 \\
\hline Sex & 1 & 611,900 & 0.04 & 0.8400 \\
\hline Age & 1 & $4,022,470$ & 0.27 & 0.6051 \\
\hline Ext-NonExt-x-Sex & 1 & $5,793,664$ & 0.39 & 0.5351 \\
\hline Ext-NonExt-x-Age & 1 & $24,867,761$ & 1.67 & 0.2009 \\
\hline Sex-x-Age & 1 & $1,054,863$ & 0.07 & 0.7910 \\
\hline Ext-NonExt-x-Sex-X-Age & 1 & $1,935,501$ & 0.13 & 0.7197 \\
\hline
\end{tabular}


APPENDIX B. RESULTS OF ONE-SAMPLE T-TEST TESTING FOR STATISTICALLY SIGNIFICANT TREATMENT 
Table B-1. Descriptive statistics and one-sample (two-tail) t-tests for in-treatment changes of Anterior Facial Height.

\begin{tabular}{lcccc}
\hline \multicolumn{1}{c}{ Statistic } & $\begin{array}{c}\text { Non-X } \\
\text { Girls }\end{array}$ & $\begin{array}{c}\text { Non-X } \\
\text { Boys }\end{array}$ & $\begin{array}{c}\text { Ext } \\
\text { Girls }\end{array}$ & $\begin{array}{c}\text { Ext } \\
\text { Boys }\end{array}$ \\
\hline Mean & 2.21 & 4.27 & 3.26 & 6.47 \\
Std Dev & 1.90 & 2.27 & 2.92 & 3.94 \\
Std Err Mean & 0.34 & 0.42 & 0.75 & 1.25 \\
L1 & 2.91 & 5.14 & 4.87 & 9.29 \\
L2 & 1.51 & 3.41 & 1.65 & 3.65 \\
Sample & 31 & 29 & 15 & 10 \\
t-test & 6.46 & 10.12 & 4.33 & 5.19 \\
P-value & $<0.0001$ & $<0.0001$ & 0.0007 & 0.0006 \\
\hline
\end{tabular}

Table B-2. Descriptive statistics and one-sample (two-tail) t-tests for in-treatment changes of Atlas Vertebra to Posterior Nasal Spine.

\begin{tabular}{lcccc}
\hline \multicolumn{1}{c}{ Statistic } & $\begin{array}{c}\text { Non-X } \\
\text { Girls }\end{array}$ & $\begin{array}{c}\text { Non-X } \\
\text { Boys }\end{array}$ & $\begin{array}{c}\text { Ext } \\
\text { Girls }\end{array}$ & $\begin{array}{c}\text { Ext } \\
\text { Boys }\end{array}$ \\
\hline Mean & 0.20 & 0.68 & -0.26 & 0.15 \\
Std Dev & 1.69 & 2.16 & 1.43 & 1.75 \\
Std Err Mean & 0.30 & 0.39 & 0.36 & 0.53 \\
L1 & 0.82 & 1.49 & 0.50 & 1.33 \\
L2 & -0.42 & -0.12 & -1.02 & -1.02 \\
Sample & 31 & 30 & 16 & 11 \\
t-test & 0.52 & 1.73 & -0.73 & 0.29 \\
P-value & 0.5210 & 0.0942 & 0.4740 & 0.7754 \\
\hline
\end{tabular}


Table B-3. Descriptive statistics and one-sample (two-tail) t-tests for in-treatment changes of Hyoidale to Frankfort Horizontal.

\begin{tabular}{lcccc}
\hline \multicolumn{1}{c}{ Statistic } & $\begin{array}{c}\text { Non-X } \\
\text { Girls }\end{array}$ & $\begin{array}{c}\text { Non-X } \\
\text { Boys }\end{array}$ & $\begin{array}{c}\text { Ext } \\
\text { Girls }\end{array}$ & $\begin{array}{c}\text { Ext } \\
\text { Boys }\end{array}$ \\
\hline Mean & 2.23 & 5.47 & 3.42 & 3.60 \\
Std Dev & 5.06 & 11.18 & 5.85 & 4.67 \\
Std Err Mean & 1.01 & 2.33 & 1.69 & 1.90 \\
L1 & 4.32 & 10.31 & 7.14 & 8.50 \\
L2 & 0.14 & 0.64 & -0.30 & -1.30 \\
Sample & 25 & 23 & 12 & 6 \\
t-test & 2.20 & 2.35 & 2.02 & 1.89 \\
P-value & 0.0376 & 0.0282 & 0.0682 & 0.1173 \\
\hline
\end{tabular}

Table B-4. Descriptive statistics and one-sample (two-tail) t-tests for in-treatment changes of Posterior Soft Palate to Posterior Pharyngeal Wall.

\begin{tabular}{lcccc}
\hline \multicolumn{1}{c}{ Statistic } & $\begin{array}{c}\text { Non-X } \\
\text { Girls }\end{array}$ & $\begin{array}{c}\text { Non-X } \\
\text { Boys }\end{array}$ & $\begin{array}{c}\text { Ext } \\
\text { Girls }\end{array}$ & $\begin{array}{c}\text { Ext } \\
\text { Boys }\end{array}$ \\
\hline Mean & 0.56 & 1.16 & 0.05 & 0.61 \\
Std Dev & 1.91 & 2.43 & 1.85 & 1.58 \\
Std Err Mean & 0.36 & 0.50 & 0.51 & 0.53 \\
L1 & 1.28 & 2.18 & 1.16 & 1.83 \\
L2 & -0.17 & 0.13 & -1.07 & -0.61 \\
Sample & 29 & 24 & 13 & 9 \\
t-test & 1.56 & 2.34 & 0.09 & 1.16 \\
P-value & 0.1294 & 0.0285 & 0.9298 & 0.2805 \\
\hline
\end{tabular}


Table B-5. Descriptive statistics and one-sample (two-tail) t-tests for in-treatment changes of Sella Perpendicular to A Point.

\begin{tabular}{lcccc}
\hline \multicolumn{1}{c}{ Statistic } & $\begin{array}{c}\text { Non-X } \\
\text { Girls }\end{array}$ & $\begin{array}{c}\text { Non-X } \\
\text { Boys }\end{array}$ & $\begin{array}{c}\text { Ext } \\
\text { Girls }\end{array}$ & $\begin{array}{c}\text { Ext } \\
\text { Boys }\end{array}$ \\
\hline Mean & 0.08 & 1.07 & -0.23 & -0.09 \\
Std Dev & 1.21 & 1.61 & 1.55 & 0.76 \\
Std Err Mean & 0.22 & 0.29 & 0.39 & 0.23 \\
L1 & 0.53 & 1.67 & 0.59 & 0.42 \\
L2 & -0.36 & 0.47 & -1.06 & -0.60 \\
Sample & 31 & 30 & 16 & 11 \\
t-test & 0.39 & 3.65 & -0.60 & -0.40 \\
P-value & 0.7016 & 0.0010 & 0.5586 & 0.6987 \\
\hline
\end{tabular}

Table B-6. Descriptive statistics and one-sample (two-tail) t-tests for in-treatment changes of Sella Perpendicular to B Point.

\begin{tabular}{lcccc}
\hline \multicolumn{1}{c}{ Statistic } & $\begin{array}{c}\text { Non-X } \\
\text { Girls }\end{array}$ & $\begin{array}{c}\text { Non-X } \\
\text { Boys }\end{array}$ & $\begin{array}{c}\text { Ext } \\
\text { Girls }\end{array}$ & $\begin{array}{c}\text { Ext } \\
\text { Boys }\end{array}$ \\
\hline Mean & -0.04 & 2.03 & 0.51 & -0.48 \\
Std Dev & 2.34 & 2.34 & 2.09 & 1.43 \\
Std Err Mean & 0.42 & 0.43 & 0.52 & 0.43 \\
L1 & 0.82 & 2.90 & 1.63 & 0.48 \\
L2 & -0.89 & 1.16 & -0.60 & -1.44 \\
Sample & 31 & 30 & 16 & 11 \\
t-test & -0.08 & 4.75 & 0.98 & -1.12 \\
P-value & 0.9332 & $<0.0001$ & 0.3426 & 0.2895 \\
\hline
\end{tabular}


Table B-7. Descriptive statistics and one-sample (two-tail) t-tests for in-treatment changes of Sella Perpendicular to L6 Mesial.

\begin{tabular}{lcccc}
\hline \multicolumn{1}{c}{ Statistic } & $\begin{array}{c}\text { Non-X } \\
\text { Girls }\end{array}$ & $\begin{array}{c}\text { Non-X } \\
\text { Boys }\end{array}$ & $\begin{array}{c}\text { Ext } \\
\text { Girls }\end{array}$ & $\begin{array}{c}\text { Ext } \\
\text { Boys }\end{array}$ \\
\hline Mean & 1.01 & 2.93 & 4.83 & 3.17 \\
Std Dev & 2.04 & 2.35 & 3.31 & 1.63 \\
Std Err Mean & 0.37 & 0.43 & 0.83 & 0.49 \\
L1 & 1.76 & 3.81 & 6.59 & 4.27 \\
L2 & 0.27 & 2.05 & 3.07 & 2.08 \\
Sample & 31 & 30 & 16 & 11 \\
t-test & 2.77 & 6.83 & 5.84 & 6.44 \\
P-value & 0.0095 & $<0.0001$ & $<0.0001$ & $<0.0001$ \\
\hline
\end{tabular}

Table B-8. Descriptive statistics and one-sample (two-tail) t-tests for in-treatment changes of Sella Perpendicular to U6 Mesial.

\begin{tabular}{lcccc}
\hline \multicolumn{1}{c}{ Statistic } & $\begin{array}{c}\text { Non-X } \\
\text { Girls }\end{array}$ & $\begin{array}{c}\text { Non-X } \\
\text { Boys }\end{array}$ & $\begin{array}{c}\text { Ext } \\
\text { Girls }\end{array}$ & $\begin{array}{c}\text { Ext } \\
\text { Boys }\end{array}$ \\
\hline Mean & 0.24 & 2.27 & 3.34 & 2.44 \\
Std Dev & 2.01 & 2.09 & 2.78 & 1.64 \\
Std Err Mean & 0.36 & 0.38 & 0.69 & 0.50 \\
L1 & 0.97 & 3.05 & 4.82 & 3.54 \\
L2 & -0.50 & 1.48 & 1.86 & 1.33 \\
Sample & 31 & 30 & 16 & 11 \\
t-test & 0.66 & 5.93 & 4.81 & 4.91 \\
P-value & 0.5126 & $<0.0001$ & 0.0002 & 0.0006 \\
\hline
\end{tabular}


Table B-9. Descriptive statistics and one-sample (two-tail) t-tests for in-treatment changes of Facial Convexity.

\begin{tabular}{lcccc}
\hline \multicolumn{1}{c}{ Statistic } & $\begin{array}{c}\text { Non-X } \\
\text { Girls }\end{array}$ & $\begin{array}{c}\text { Non-X } \\
\text { Boys }\end{array}$ & $\begin{array}{c}\text { Ext } \\
\text { Girls }\end{array}$ & $\begin{array}{c}\text { Ext } \\
\text { Boys }\end{array}$ \\
\hline Mean & -1.00 & -2.26 & -3.55 & -2.67 \\
Std Dev & 1.84 & 1.98 & 2.92 & 2.22 \\
Std Err Mean & 0.34 & 0.37 & 0.81 & 0.70 \\
L1 & -0.30 & -1.50 & -1.79 & -1.08 \\
L2 & -1.70 & -3.03 & -5.32 & -4.26 \\
Sample & 29 & 28 & 13 & 10 \\
t-test & -2.91 & -6.05 & -4.39 & -3.80 \\
P-value & 0.0070 & $<0.0001$ & 0.0009 & 0.0042 \\
\hline
\end{tabular}

Table B-10. Descriptive statistics and one-sample (two-tail) t-tests for in-treatment changes of SNA.

\begin{tabular}{lcccc}
\hline \multicolumn{1}{c}{ Statistic } & $\begin{array}{c}\text { Non-X } \\
\text { Girls }\end{array}$ & $\begin{array}{c}\text { Non-X } \\
\text { Boys }\end{array}$ & $\begin{array}{c}\text { Ext } \\
\text { Girls }\end{array}$ & $\begin{array}{c}\text { Ext } \\
\text { Boys }\end{array}$ \\
\hline Mean & -0.12 & -0.36 & -1.57 & -1.25 \\
Std Dev & 1.15 & 1.36 & 1.37 & 1.15 \\
Std Err Mean & 0.21 & 0.26 & 0.38 & 0.36 \\
L1 & 0.32 & 0.17 & -0.74 & -0.43 \\
L2 & -0.55 & -0.88 & -2.40 & -2.07 \\
Sample & 29 & 28 & 13 & 10 \\
t-test & -0.55 & -1.39 & -4.13 & -3.43 \\
P-value & 0.5876 & 0.1753 & 0.0014 & 0.0075 \\
\hline
\end{tabular}


Table B-11. Descriptive statistics and one-sample (two-tail) t-tests for in-treatment changes of SNB.

\begin{tabular}{lcccc}
\hline \multicolumn{1}{c}{ Statistic } & $\begin{array}{c}\text { Non-X } \\
\text { Girls }\end{array}$ & $\begin{array}{c}\text { Non-X } \\
\text { Boys }\end{array}$ & $\begin{array}{c}\text { Ext } \\
\text { Girls }\end{array}$ & $\begin{array}{c}\text { Ext } \\
\text { Boys }\end{array}$ \\
\hline Mean & 0.14 & 0.40 & -0.45 & -0.55 \\
Std Dev & 1.43 & 1.28 & 1.17 & 1.14 \\
Std Err Mean & 0.27 & 0.24 & 0.33 & 0.36 \\
L1 & 0.68 & 0.89 & 0.26 & 0.26 \\
L2 & -0.41 & -0.10 & -1.16 & -1.36 \\
Sample & 29 & 28 & 13 & 10 \\
t-test & 0.52 & 1.64 & -1.37 & -1.53 \\
P-value & 0.6078 & 0.1120 & 0.1959 & 0.1609 \\
\hline
\end{tabular}

Table B-12. Descriptive statistics and one-sample (two-tail) t-tests for in-treatment changes of ANB.

\begin{tabular}{lcccc}
\hline \multicolumn{1}{c}{ Statistic } & $\begin{array}{c}\text { Non-X } \\
\text { Girls }\end{array}$ & $\begin{array}{c}\text { Non-X } \\
\text { Boys }\end{array}$ & $\begin{array}{c}\text { Ext } \\
\text { Girls }\end{array}$ & $\begin{array}{c}\text { Ext } \\
\text { Boys }\end{array}$ \\
\hline Mean & -0.26 & -0.75 & -1.12 & -0.70 \\
Std Dev & 1.03 & 1.01 & 1.34 & 0.93 \\
Std Err Mean & 0.19 & 0.19 & 0.37 & 0.29 \\
L1 & 0.14 & -0.36 & -0.31 & -0.04 \\
L2 & -0.65 & -1.15 & -1.93 & -1.36 \\
Sample & 29 & 28 & 13 & 10 \\
t-test & -1.34 & -3.94 & -3.02 & -2.38 \\
P-value & 0.1915 & 0.0005 & 0.0107 & 0.0410 \\
\hline
\end{tabular}


Table B-13. Descriptive statistics and one-sample (two-tail) t-tests for in-treatment changes of Y-Axis.

\begin{tabular}{lcccc}
\hline \multicolumn{1}{c}{ Statistic } & $\begin{array}{c}\text { Non-X } \\
\text { Girls }\end{array}$ & $\begin{array}{c}\text { Non-X } \\
\text { Boys }\end{array}$ & $\begin{array}{c}\text { Ext } \\
\text { Girls }\end{array}$ & $\begin{array}{c}\text { Ext } \\
\text { Boys }\end{array}$ \\
\hline Mean & 0.18 & -0.09 & 0.60 & 1.15 \\
Std Dev & 1.52 & 1.54 & 1.13 & 1.33 \\
Std Err Mean & 0.28 & 0.29 & 0.31 & 0.42 \\
L1 & 0.76 & 0.51 & 1.28 & 2.10 \\
L2 & -0.39 & -0.69 & -0.08 & 0.20 \\
Sample & 29 & 28 & 13 & 10 \\
t-test & 0.65 & -0.31 & 1.91 & 2.73 \\
P-value & 0.5217 & 0.7614 & 0.0797 & 0.0233 \\
\hline
\end{tabular}

Table B-14. Descriptive statistics and one-sample (two-tail) t-tests for in-treatment changes of Upper Pharyngeal Plane Width.

\begin{tabular}{lcccc}
\hline \multicolumn{1}{c}{ Statistic } & $\begin{array}{c}\text { Non-X } \\
\text { Girls }\end{array}$ & $\begin{array}{c}\text { Non-X } \\
\text { Boys }\end{array}$ & $\begin{array}{c}\text { Ext } \\
\text { Girls }\end{array}$ & $\begin{array}{c}\text { Ext } \\
\text { Boys }\end{array}$ \\
\hline Mean & 2.46 & 1.23 & 1.67 & 0.04 \\
Std Dev & 4.35 & 2.20 & 4.62 & 1.54 \\
Std Err Mean & 0.81 & 0.46 & 1.23 & 0.51 \\
L1 & 4.11 & 2.18 & 4.34 & 1.23 \\
L2 & 0.80 & 0.27 & -0.99 & -1.14 \\
Sample & 29 & 23 & 14 & 9 \\
t-test & 3.04 & 2.67 & 1.35 & 0.09 \\
P-value & 0.0051 & 0.0140 & 0.1987 & 0.9333 \\
\hline
\end{tabular}


Table B-15. Descriptive statistics and one-sample (two-tail) t-tests for in-treatment changes of Upper Pharyngeal Plane Area.

\begin{tabular}{lcccc}
\hline \multicolumn{1}{c}{ Statistic } & $\begin{array}{c}\text { Non-X } \\
\text { Girls }\end{array}$ & $\begin{array}{c}\text { Non-X } \\
\text { Boys }\end{array}$ & $\begin{array}{c}\text { Ext } \\
\text { Girls }\end{array}$ & $\begin{array}{c}\text { Ext } \\
\text { Boys }\end{array}$ \\
\hline Mean & 64.12 & 43.18 & 32.62 & 9.93 \\
Std Dev & 127.83 & 78.91 & 90.92 & 53.94 \\
Std Err Mean & 23.74 & 16.45 & 25.22 & 17.98 \\
L1 & 112.74 & 77.31 & 87.57 & 51.40 \\
L2 & 15.50 & 9.06 & -22.32 & -31.53 \\
Sample & 29 & 23 & 13 & 9 \\
t-test & 2.70 & 2.62 & 1.29 & 0.55 \\
P-value & 0.0116 & 0.0155 & 0.2201 & 0.5957 \\
\hline
\end{tabular}

Table B-16. Descriptive statistics and one-sample (two-tail) t-tests for in-treatment changes of Middle Pharyngeal Plane Width.

\begin{tabular}{lcccc}
\hline \multicolumn{1}{c}{ Statistic } & $\begin{array}{c}\text { Non-X } \\
\text { Girls }\end{array}$ & $\begin{array}{c}\text { Non-X } \\
\text { Boys }\end{array}$ & $\begin{array}{c}\text { Ext } \\
\text { Girls }\end{array}$ & $\begin{array}{c}\text { Ext } \\
\text { Boys }\end{array}$ \\
\hline Mean & 3.55 & 2.60 & 2.56 & 2.50 \\
Std Dev & 5.27 & 6.31 & 4.38 & 2.29 \\
Std Err Mean & 0.98 & 1.26 & 1.17 & 0.76 \\
L1 & 5.56 & 5.21 & 5.09 & 4.26 \\
L2 & 1.55 & 0.00 & 0.04 & 0.74 \\
Sample & 29 & 25 & 14 & 9 \\
t-test & 3.63 & 2.06 & 2.19 & 3.28 \\
P-value & 0.0011 & 0.0500 & 0.0473 & 0.0112 \\
\hline
\end{tabular}


Table B-17. Descriptive statistics and one-sample (two-tail) t-tests for in-treatment changes of Middle Pharyngeal Plane Area.

\begin{tabular}{lcccc}
\hline \multicolumn{1}{c}{ Statistic } & $\begin{array}{c}\text { Non-X } \\
\text { Girls }\end{array}$ & $\begin{array}{c}\text { Non-X } \\
\text { Boys }\end{array}$ & $\begin{array}{c}\text { Ext } \\
\text { Girls }\end{array}$ & $\begin{array}{c}\text { Ext } \\
\text { Boys }\end{array}$ \\
\hline Mean & 41.47 & 41.24 & 41.92 & 12.10 \\
Std Dev & 80.38 & 78.50 & 83.59 & 29.69 \\
Std Err Mean & 14.93 & 15.70 & 23.18 & 9.90 \\
L1 & 72.05 & 73.65 & 92.43 & 34.92 \\
L2 & 10.90 & 8.84 & -8.59 & -10.72 \\
Sample & 29 & 25 & 13 & 9 \\
t-test & 2.78 & 2.63 & 1.81 & 1.22 \\
P-value & 0.0096 & 0.0148 & 0.0957 & 0.2563 \\
\hline
\end{tabular}

Table B-18. Descriptive statistics and one-sample (two-tail) t-tests for in-treatment changes of Lower Pharyngeal Plane Width.

\begin{tabular}{lcccc}
\hline \multicolumn{1}{c}{ Statistic } & $\begin{array}{c}\text { Non-X } \\
\text { Girls }\end{array}$ & $\begin{array}{c}\text { Non-X } \\
\text { Boys }\end{array}$ & $\begin{array}{c}\text { Ext } \\
\text { Girls }\end{array}$ & $\begin{array}{c}\text { Ext } \\
\text { Boys }\end{array}$ \\
\hline Mean & 1.65 & 2.73 & 2.22 & 2.91 \\
Std Dev & 2.89 & 4.48 & 3.65 & 3.34 \\
Std Err Mean & 0.52 & 0.85 & 0.91 & 1.06 \\
L1 & 0.59 & 4.47 & 4.17 & 5.30 \\
L2 & 2.71 & 0.99 & 0.27 & 0.52 \\
Sample & 31 & 28 & 16 & 10 \\
t-test & 3.18 & 3.22 & 2.43 & 2.75 \\
P-value & 0.0034 & 0.0033 & 0.0282 & 0.0224 \\
\hline
\end{tabular}


Table B-19. Descriptive statistics and one-sample (two-tail) t-tests for in-treatment changes of Lower Pharyngeal Plane Area.

\begin{tabular}{lcccc}
\hline \multicolumn{1}{c}{ Statistic } & $\begin{array}{c}\text { Non-X } \\
\text { Girls }\end{array}$ & $\begin{array}{c}\text { Non-X } \\
\text { Boys }\end{array}$ & $\begin{array}{c}\text { Ext } \\
\text { Girls }\end{array}$ & $\begin{array}{c}\text { Ext } \\
\text { Boys }\end{array}$ \\
\hline Mean & 49.01 & 63.05 & 51.06 & 43.49 \\
Std Dev & 93.72 & 108.99 & 84.07 & 97.95 \\
Std Err Mean & 16.83 & 20.60 & 21.02 & 30.98 \\
L1 & 83.39 & 105.31 & 95.86 & 113.56 \\
L2 & 14.64 & 20.79 & 6.27 & -26.58 \\
Sample & 31 & 28 & 16 & 10 \\
t-test & 2.91 & 3.06 & 2.43 & 1.40 \\
P-value & 0.0067 & 0.0049 & 0.0281 & 0.1939 \\
\hline
\end{tabular}

Table B-20. Descriptive statistics and one-sample (two-tail) t-tests for in-treatment changes of Middle Pharyngeal Airway Volume.

\begin{tabular}{lcccc}
\hline \multicolumn{1}{c}{ Statistic } & $\begin{array}{c}\text { Non-X } \\
\text { Girls }\end{array}$ & $\begin{array}{c}\text { Non-X } \\
\text { Boys }\end{array}$ & $\begin{array}{c}\text { Ext } \\
\text { Girls }\end{array}$ & $\begin{array}{c}\text { Ext } \\
\text { Boys }\end{array}$ \\
\hline Mean & 952.46 & $1,061.34$ & $1,064.02$ & 698.17 \\
Std Dev & $2,114.27$ & $1,677.03$ & $2,331.05$ & $1,658.32$ \\
Std Err Mean & 392.61 & 357.54 & 646.52 & 552.77 \\
L1 & $1,756.68$ & $1,804.89$ & $2,472.66$ & $1,972.86$ \\
L2 & 148.23 & 317.78 & -344.61 & -576.53 \\
Sample & 29 & 22 & 13 & 9 \\
t-test & 2.43 & 2.97 & 1.65 & 1.26 \\
P-value & 0.0220 & 0.0073 & 0.1257 & 0.2421 \\
\hline
\end{tabular}


Table B-21. Descriptive statistics and one-sample (two-tail) t-tests for in-treatment changes of Inferior Pharyngeal Airway Volume.

\begin{tabular}{lcccc}
\hline \multicolumn{1}{c}{ Statistic } & $\begin{array}{c}\text { Non-X } \\
\text { Girls }\end{array}$ & $\begin{array}{c}\text { Non-X } \\
\text { Boys }\end{array}$ & $\begin{array}{c}\text { Ext } \\
\text { Girls }\end{array}$ & $\begin{array}{c}\text { Ext } \\
\text { Boys }\end{array}$ \\
\hline Mean & $1,371.70$ & $2,138.35$ & $1,788.86$ & $1,718.58$ \\
Std Dev & $2,555.75$ & $2,570.39$ & $2,684.36$ & $1,773.98$ \\
Std Err Mean & 474.59 & 535.96 & 744.51 & 591.33 \\
L1 & $2,343.86$ & $3,249.87$ & $3,411.01$ & $3,082.18$ \\
L2 & 399.55 & $1,026.83$ & 166.72 & 354.98 \\
Sample & 29 & 23 & 13 & 9 \\
t-test & 2.89 & 3.99 & 2.40 & 2.91 \\
P-value & 0.0074 & 0.0006 & 0.0334 & 0.0197 \\
\hline
\end{tabular}

Table B-22. Descriptive statistics and one-sample (two-tail) t-tests for in-treatment changes of Total Pharyngeal Airway Volume.

\begin{tabular}{lcccc}
\hline \multicolumn{1}{c}{ Statistic } & $\begin{array}{c}\text { Non-X } \\
\text { Girls }\end{array}$ & $\begin{array}{c}\text { Non-X } \\
\text { Boys }\end{array}$ & $\begin{array}{c}\text { Ext } \\
\text { Girls }\end{array}$ & $\begin{array}{c}\text { Ext } \\
\text { Boys }\end{array}$ \\
\hline Mean & $2,324.16$ & $3,199.91$ & $2,852.88$ & $2,416.74$ \\
Std Dev & $3,669.85$ & $3,831.92$ & $4,749.46$ & $2,754.00$ \\
Std Err Mean & 681.47 & 816.97 & $1,317.26$ & 918.00 \\
L1 & $3,720.10$ & $4,898.89$ & $5,722.96$ & $4,533.66$ \\
L2 & 928.22 & $1,500.94$ & -17.19 & 299.83 \\
Sample & 29 & 22 & 13 & 9 \\
t-test & 3.41 & 3.92 & 2.17 & 2.63 \\
P-value & 0.0020 & 0.0008 & 0.0512 & 0.0301 \\
\hline
\end{tabular}


APPENDIX C. TREATMENT CHANGES 


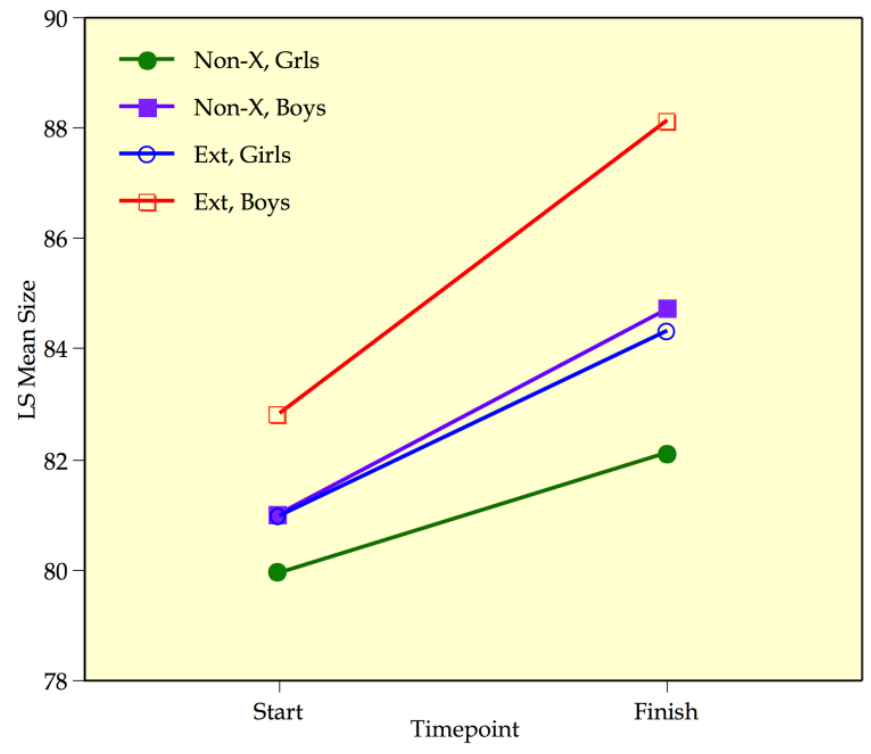

Figure C-1. Plot of the least square means, by sex and extraction pattern, at the start and end of treatment for the variable Anterior Facial Height.

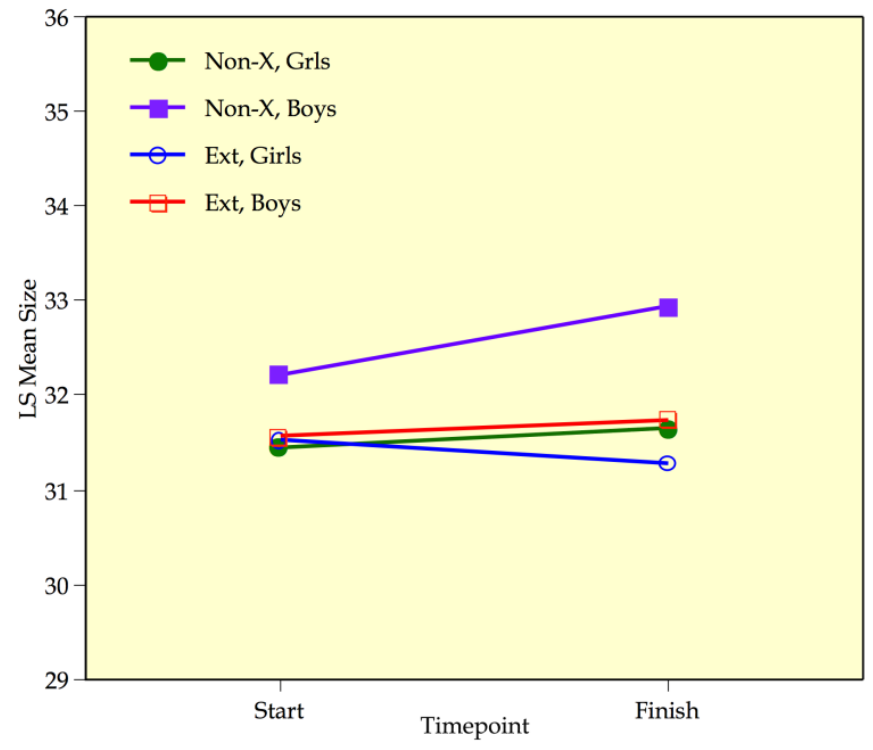

Figure C-2. Plot of the least square means, by sex and extraction pattern at the start and end of treatment for the variable Anterior Vertebra to Posterior Nasal Spine. 


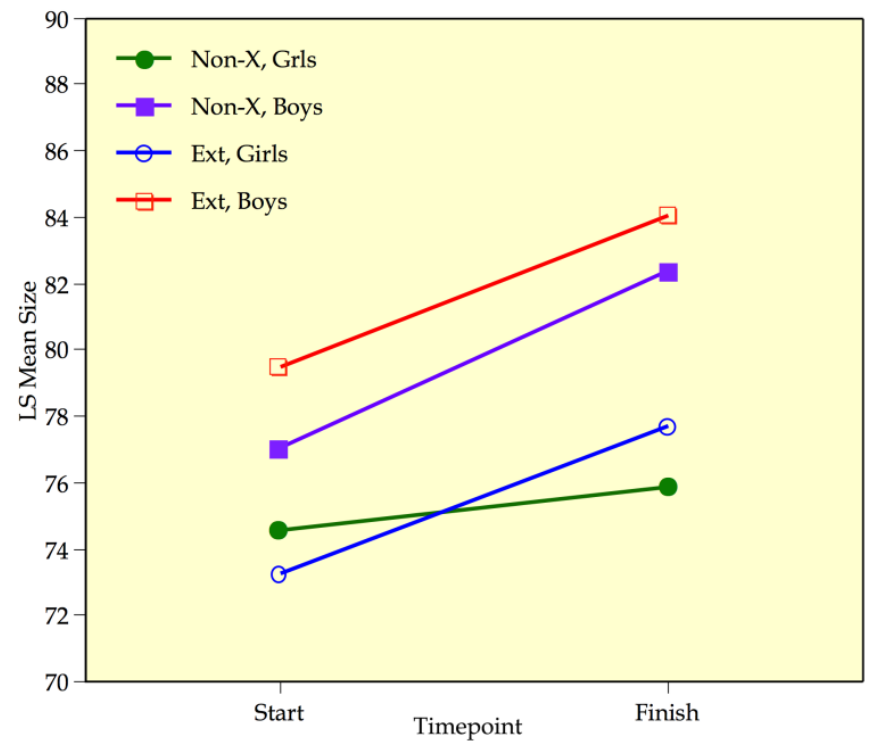

Figure C-3. Plot of the least square means, by sex and extraction pattern at the start and end of treatment for the variable Hyoidale to Frankfort Horizontal.

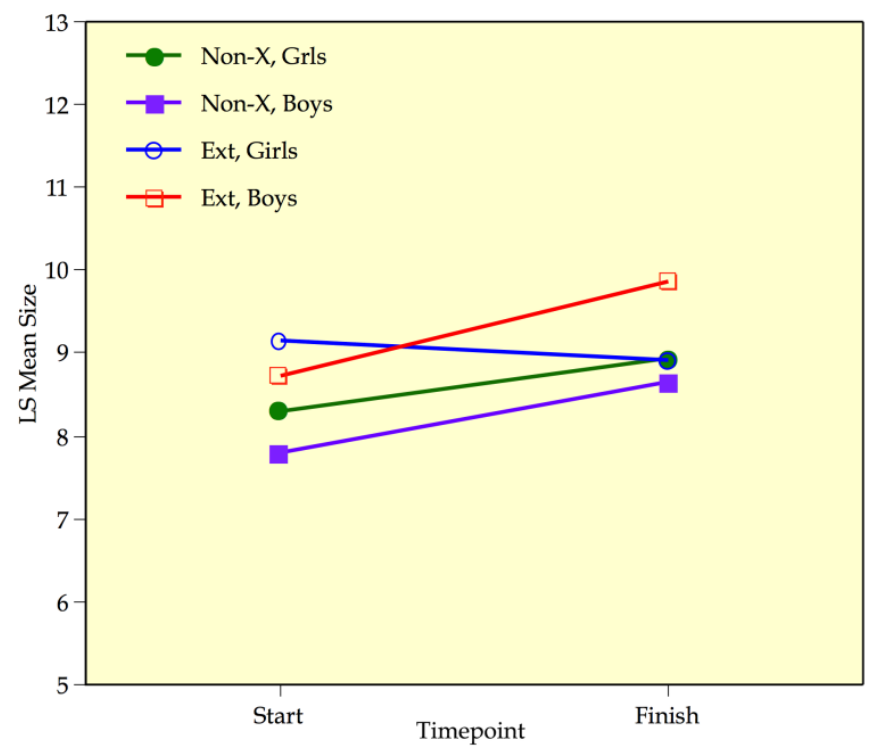

Figure C-4. Plot of the least square means, by sex and extraction pattern at the start and end of treatment for the variable Posterior Soft Palate to Posterior Pharyngeal Wall. 


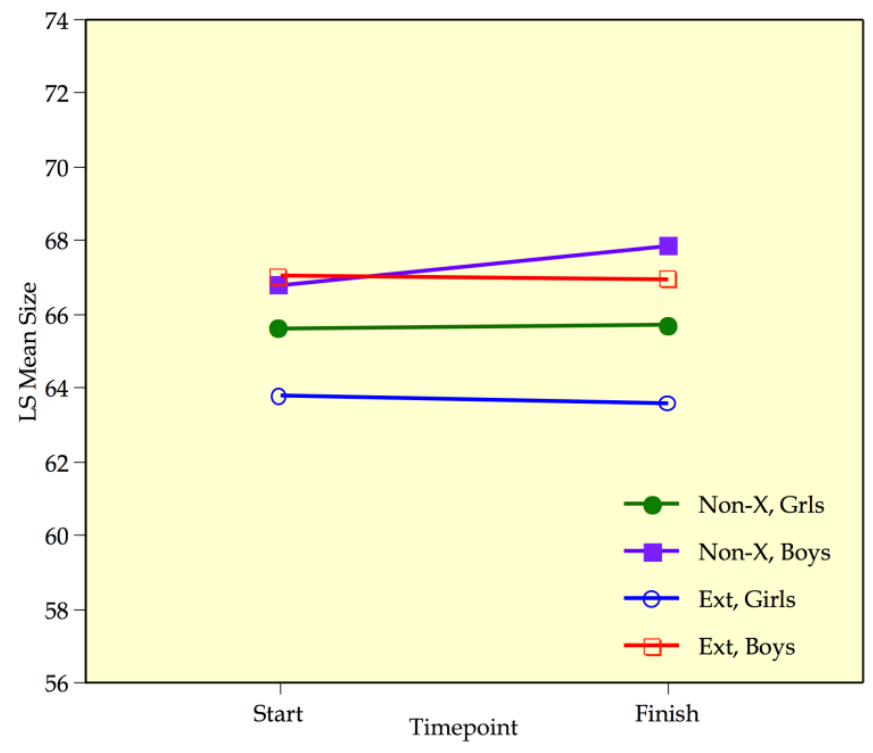

Figure C-5. Plot of the least square means, by sex and extraction pattern at the start and end of treatment for the variable Sella Perpendicular to A Point.

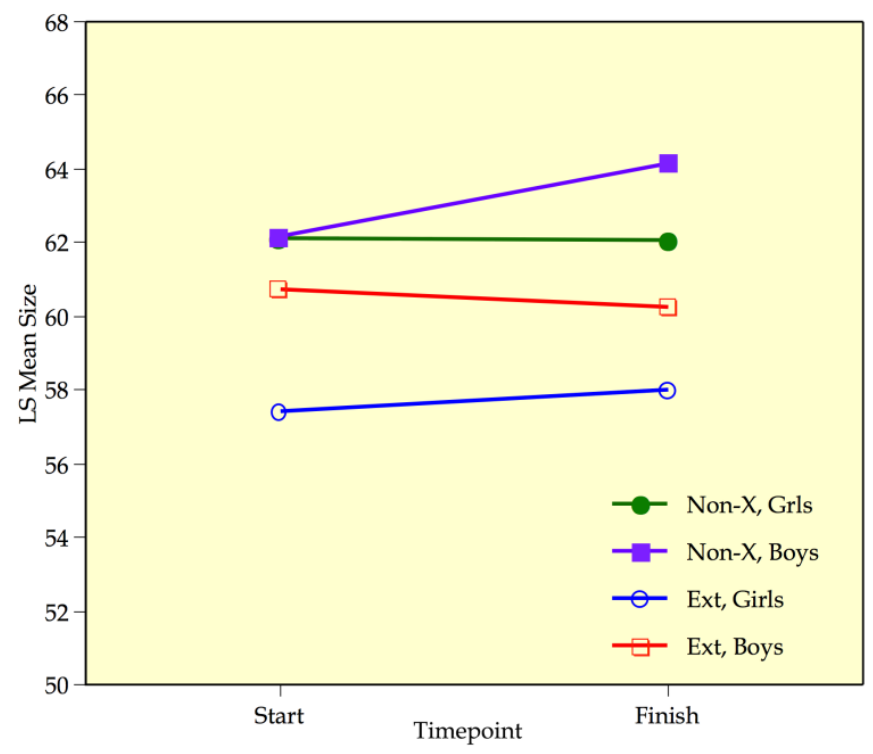

Figure C-6. Plot of the least square means, by sex and extraction pattern at the start and end of treatment for the variable Sella Perpendicular to B Point. 


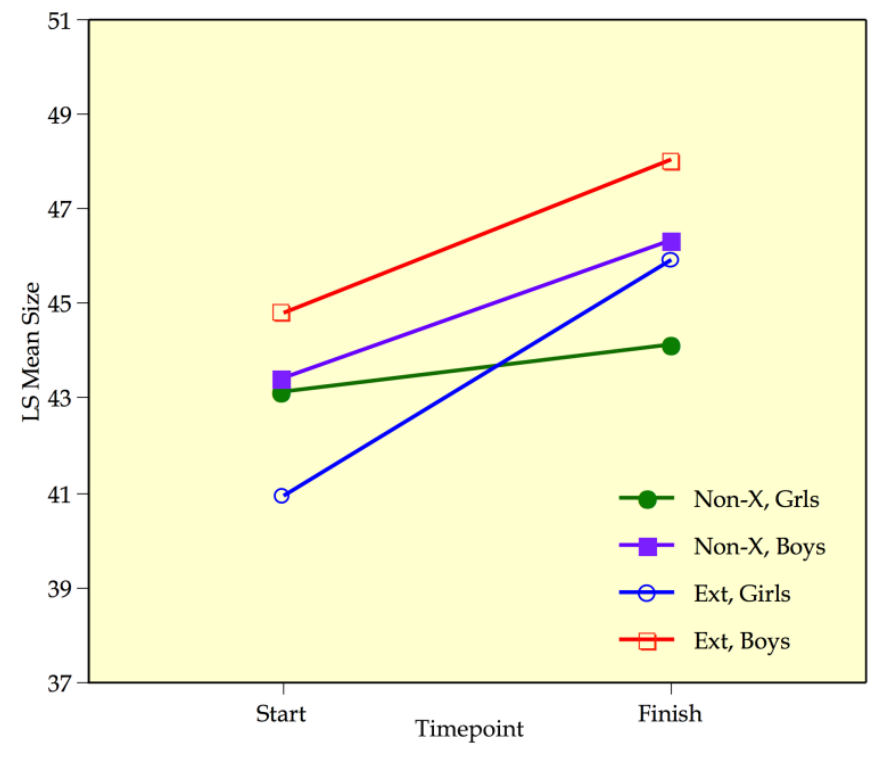

Figure C-7. Plot of the least square means, by sex and extraction pattern at the start and end of treatment for the variable Sella Perpendicular to L6 Mesial.

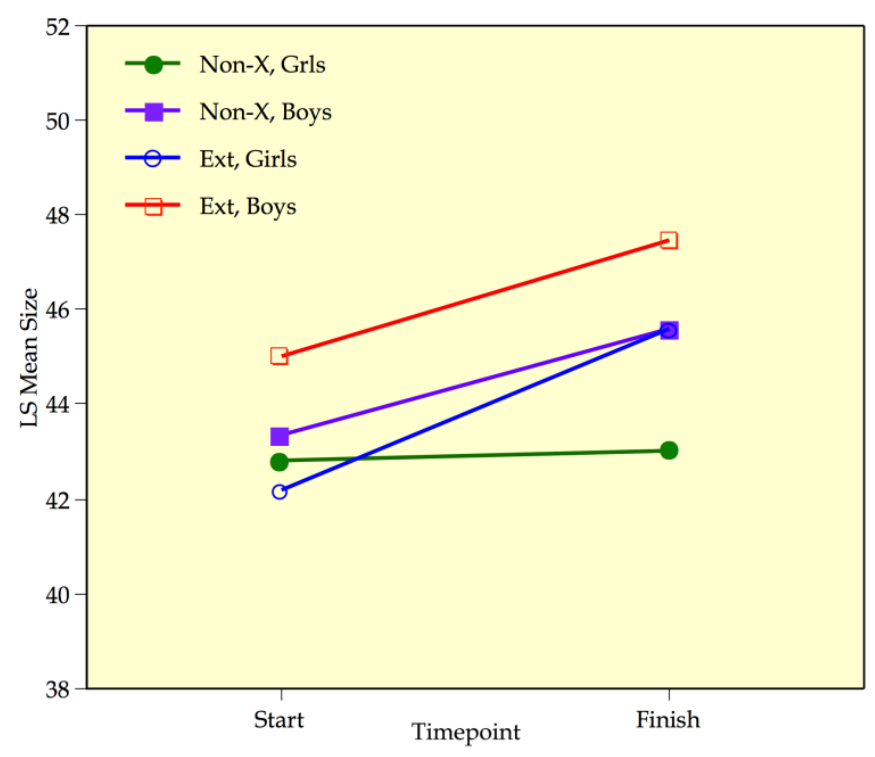

Figure C-8. Plot of the least square means, by sex and extraction pattern at the start and end of treatment for the variable Sella Perpendicular to U6 Mesial. 


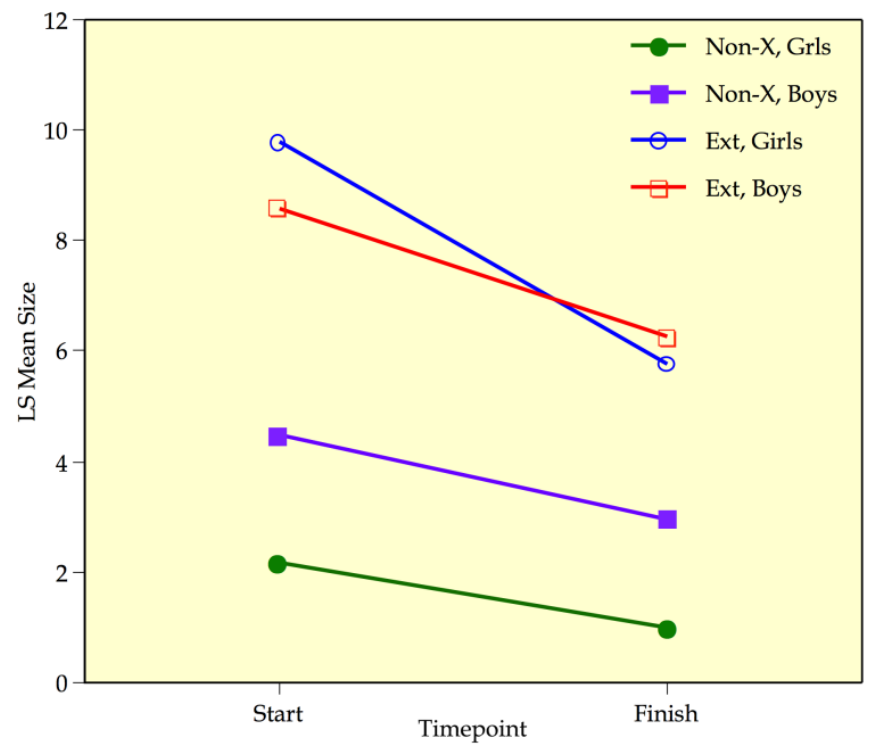

Figure C-9. Plot of the least square means, by sex and extraction pattern at the start and end of treatment for the variable Facial Convexity.

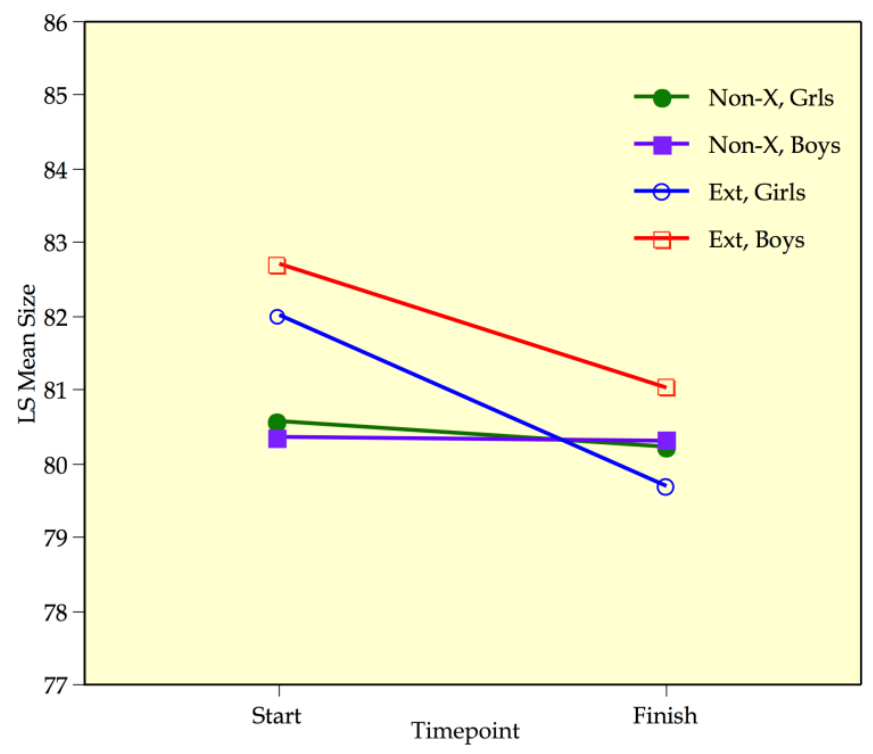

Figure C-10. Plot of the least square means, by sex and extraction pattern at the start and end of treatment for the variable SNA. 


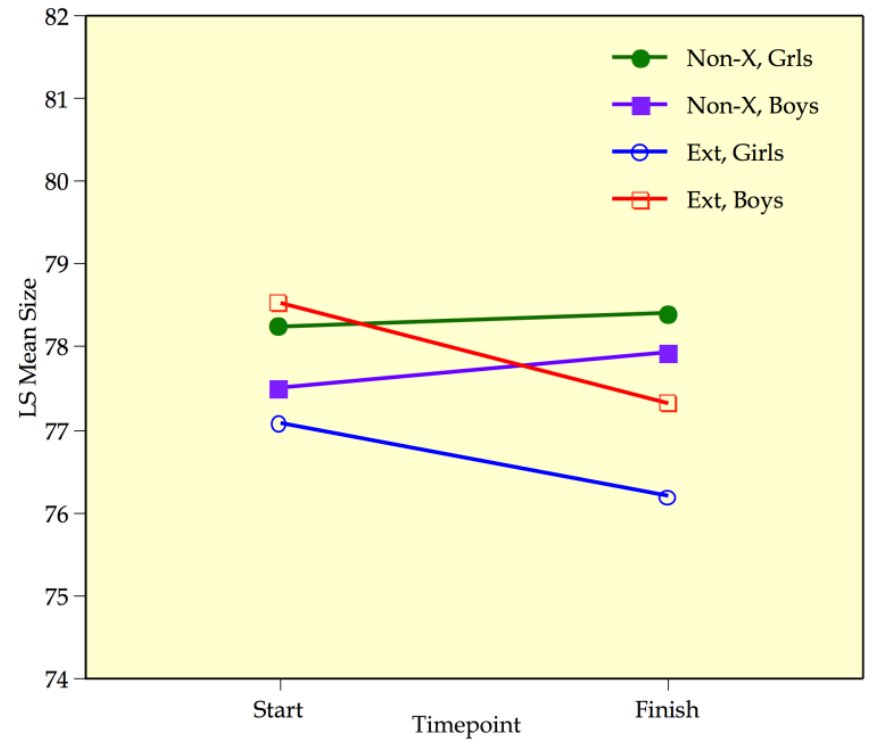

Figure C-11. Plot of the least square means, by sex and extraction pattern at the start and end of treatment for the variable SNB.

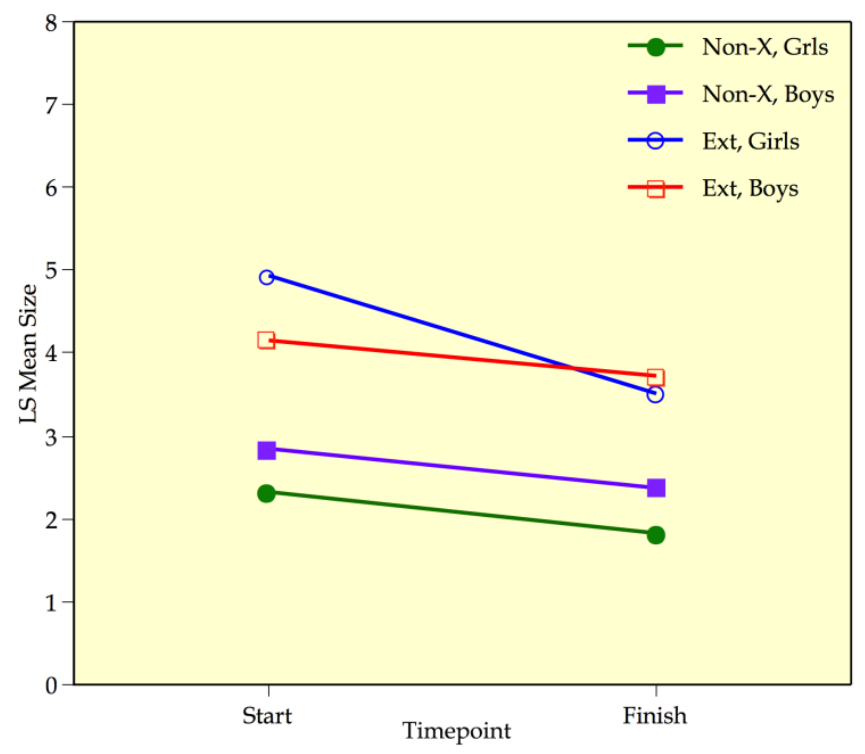

Figure C-12. Plot of the least square means, by sex and extraction pattern at the start and end of treatment for the variable ANB. 


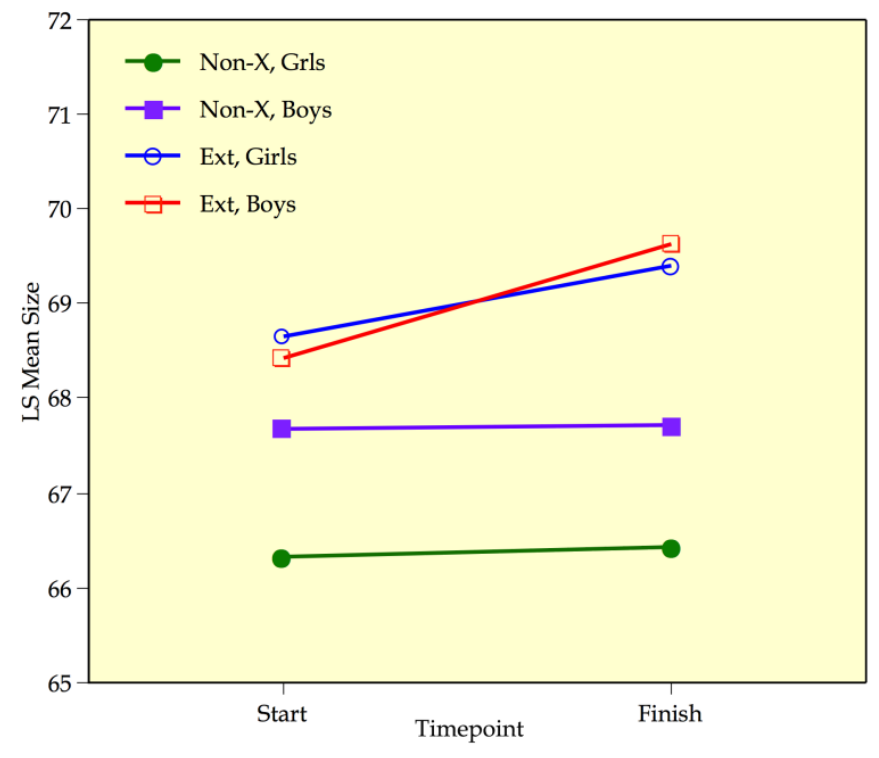

Figure C-13. Plot of the least square means, by sex and extraction pattern at the start and end of treatment for the variable for $\mathrm{Y}$-Axis.

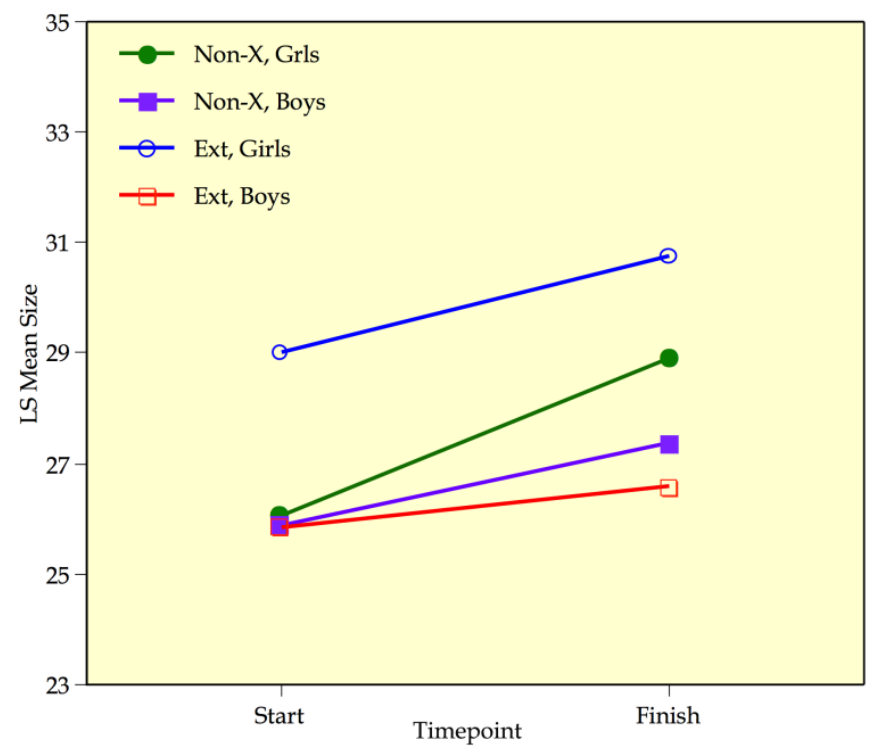

Figure C-14. Plot of the least square means, by sex and extraction pattern at the start and end of treatment for the variable Upper Pharyngeal Plane Width. 


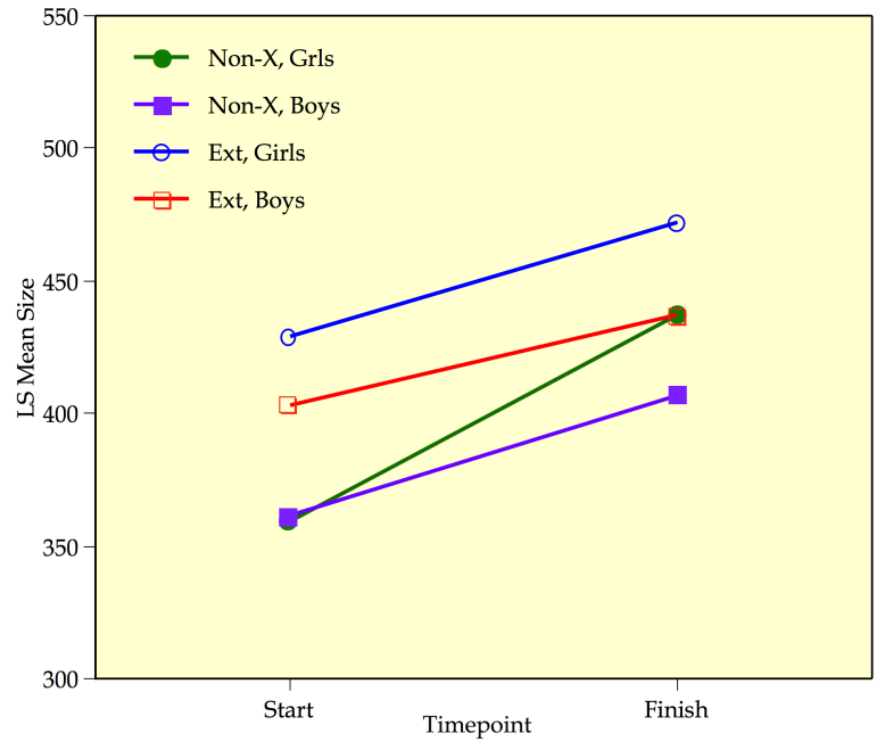

Figure C-15. Plot of the least square means, by sex and extraction pattern at the start and end of treatment for the variable Upper Pharyngeal Plane Area.

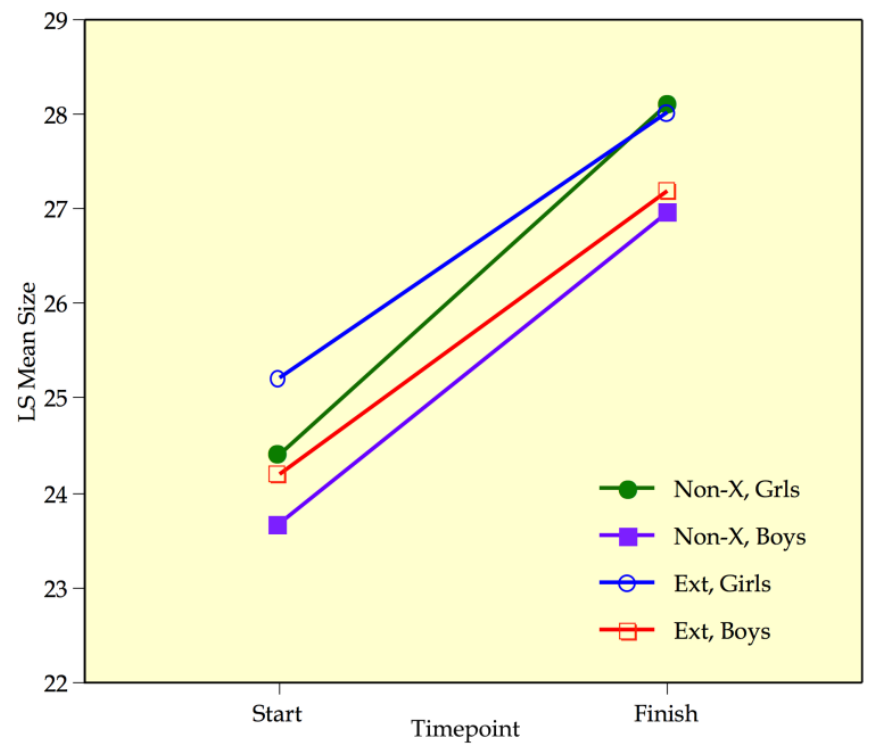

Figure C-16. Plot of the least square means, by sex and extraction pattern at the start and end of treatment for the variable for Middle Pharyngeal Plane Width. 


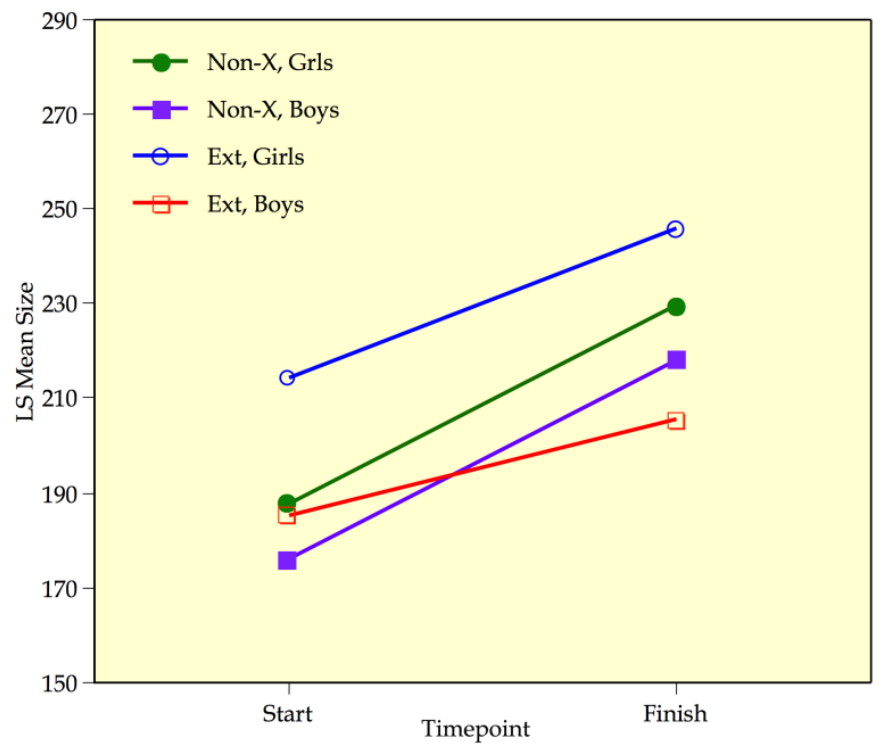

Figure C-17. Plot of the least square means, by sex and extraction pattern at the start and end of treatment for the variable Middle Pharyngeal Plane Area.

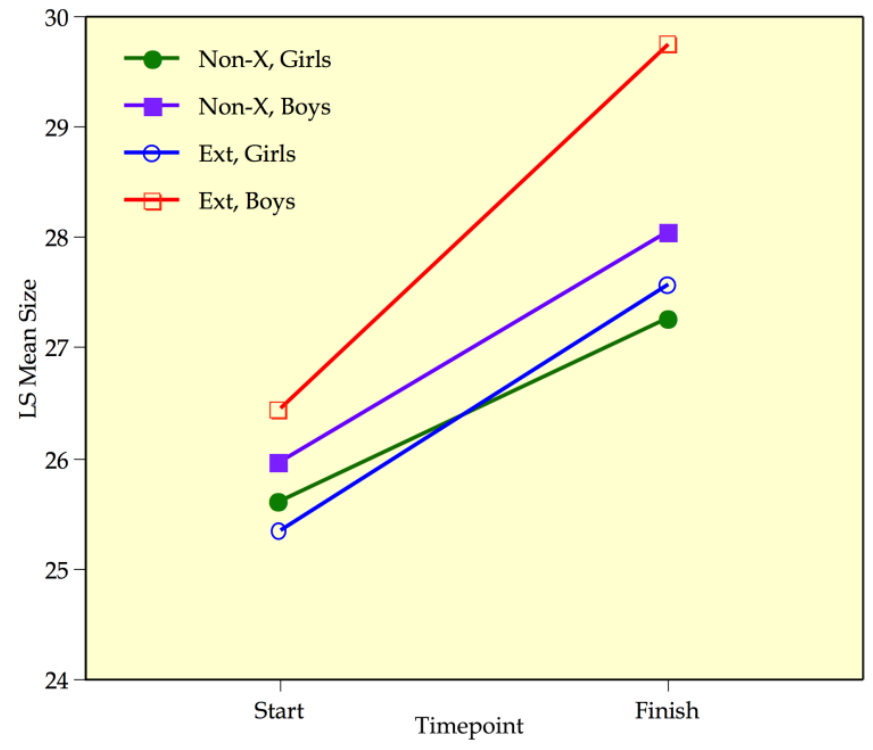

Figure C-18. Plot of the least square means, by sex and extraction pattern at the start and end of treatment for the variable Lower Pharyngeal Plane Width. 


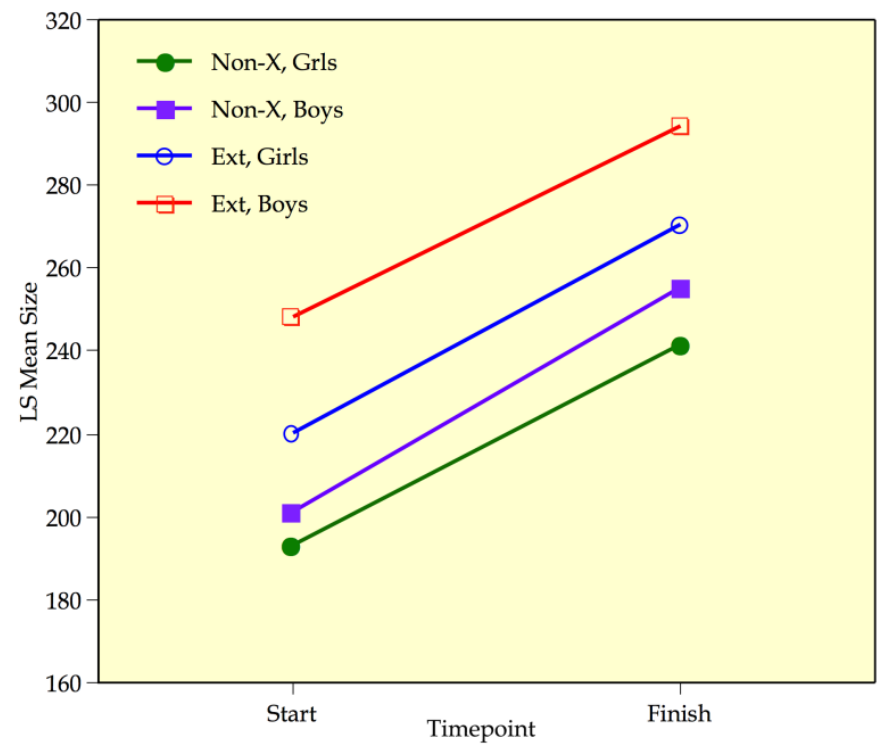

Figure C-19. Plot of the least square means, by sex and extraction pattern at the start and end of treatment for the variable Lower Pharyngeal Plane Area.

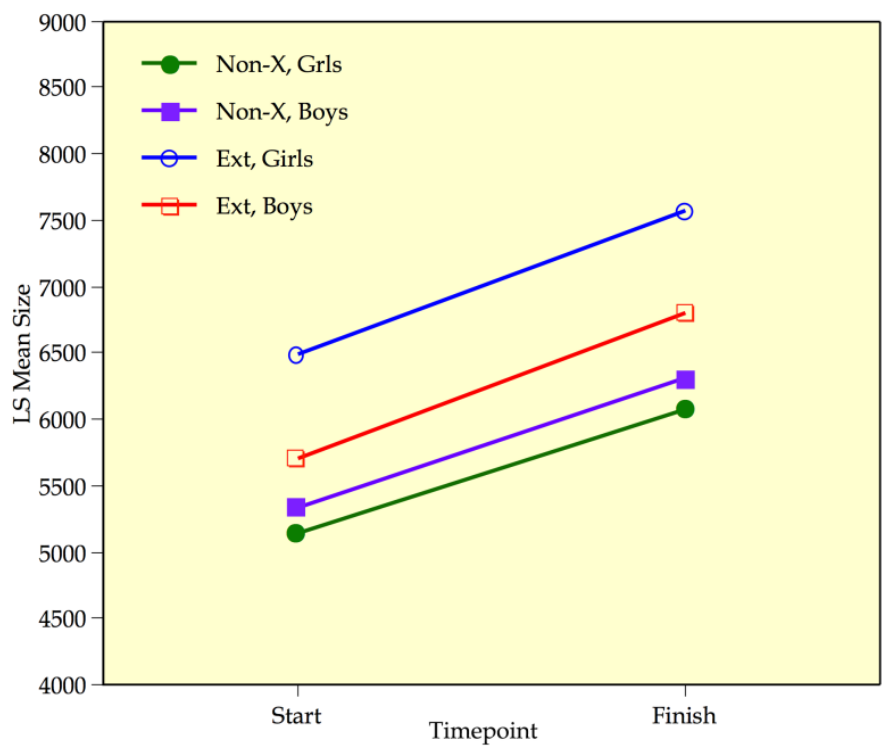

Figure C-20. Plot of the least square means, by sex and extraction pattern at the start and end of treatment for the variable Middle Pharyngeal Airway Volume. 


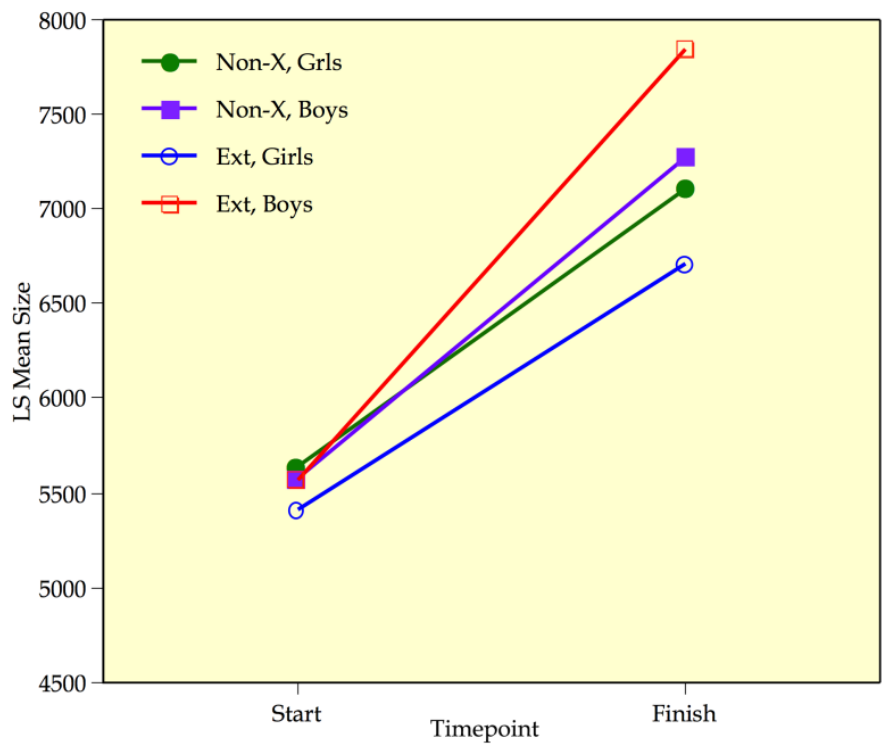

Figure C-21. Plot of the least square means, by sex and extraction pattern at the start and end of treatment for the variable Inferior Pharyngeal Airway Volume.

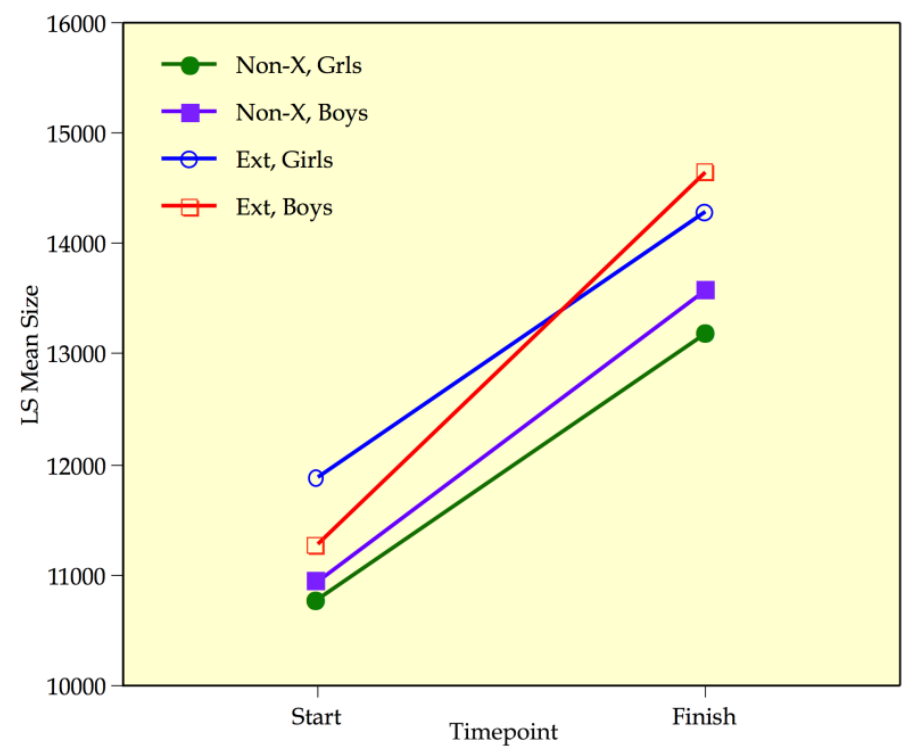

Figure C-22. Plot of the least square means, by sex and extraction pattern at the start and end of treatment for the variable Total Pharyngeal Airway Volume. 
APPENDIX D. DESCRIPTIVE STATISTICS BY GROUP AND SEX 
Table D-1. Descriptive statistics by group and sex for Anterior Facial Height.

\begin{tabular}{|c|c|c|c|c|}
\hline Statistic & $\begin{array}{c}\text { Non-Ext } \\
\text { Girls } \\
\end{array}$ & $\begin{array}{c}\text { Non-Ext } \\
\text { Boys }\end{array}$ & $\begin{array}{c}\text { Extraction } \\
\text { Girls }\end{array}$ & $\begin{array}{c}\text { Extraction } \\
\text { Boys }\end{array}$ \\
\hline \multicolumn{5}{|c|}{ Start of Treatment } \\
\hline Mean & 79.90 & 80.94 & 81.19 & 82.89 \\
\hline Std Dev & 5.13 & 6.10 & 6.02 & 5.31 \\
\hline Std Err Mean & 0.92 & 1.11 & 1.51 & 1.60 \\
\hline $\mathrm{L} 2$ & 81.78 & 83.21 & 84.40 & 86.46 \\
\hline L1 & 78.02 & 78.66 & 77.98 & 79.32 \\
\hline Sample & 31 & 30 & 16 & 11 \\
\hline \multicolumn{5}{|c|}{ End of Treatment } \\
\hline Mean & 82.11 & 84.68 & 84.43 & 88.12 \\
\hline Std Dev & 4.60 & 6.11 & 4.98 & 5.82 \\
\hline Std Err Mean & 0.83 & 1.13 & 1.29 & 1.84 \\
\hline $\mathrm{L} 2$ & 83.80 & 87.01 & 87.19 & 92.29 \\
\hline L1 & 80.42 & 82.36 & 81.67 & 83.95 \\
\hline Sample & 31 & 29 & 15 & 10 \\
\hline \multicolumn{5}{|c|}{ In-Treatment Change } \\
\hline Mean & 2.21 & 4.27 & 3.26 & 6.47 \\
\hline Std Dev & 1.90 & 2.27 & 2.92 & 3.94 \\
\hline Std Err Mean & 0.34 & 0.42 & 0.75 & 1.25 \\
\hline $\mathrm{L} 2$ & 2.91 & 5.14 & 4.87 & 9.29 \\
\hline L1 & 1.51 & 3.41 & 1.65 & 3.65 \\
\hline Sample & 31 & 29 & 15 & 10 \\
\hline
\end{tabular}


Table D-2. Descriptive statistics by group and sex for Atlas Vertebra to Posterior Nasal Spine.

\begin{tabular}{|c|c|c|c|c|}
\hline Statistic & $\begin{array}{c}\text { Non-Ext } \\
\text { Girls } \\
\end{array}$ & $\begin{array}{c}\text { Non-Ext } \\
\text { Boys }\end{array}$ & $\begin{array}{c}\text { Extraction } \\
\text { Girls }\end{array}$ & $\begin{array}{c}\text { Extraction } \\
\text { Boys }\end{array}$ \\
\hline \multicolumn{5}{|c|}{ Start of Treatment } \\
\hline Mean & 31.46 & 32.26 & 31.48 & 31.60 \\
\hline Std Dev & 3.05 & 3.45 & 4.09 & 3.43 \\
\hline Std Err Mean & 0.55 & 0.63 & 1.02 & 1.03 \\
\hline L2 & 32.58 & 33.55 & 33.65 & 33.90 \\
\hline L1 & 30.34 & 30.97 & 29.30 & 29.30 \\
\hline Sample & 31 & 30 & 16 & 11 \\
\hline \multicolumn{5}{|c|}{ End of Treatment } \\
\hline Mean & 31.66 & 32.94 & 31.21 & 31.75 \\
\hline Std Dev & 3.21 & 3.82 & 4.26 & 3.29 \\
\hline Std Err Mean & 0.58 & 0.70 & 1.06 & 0.99 \\
\hline L2 & 32.84 & 34.37 & 33.48 & 33.97 \\
\hline L1 & 30.48 & 31.52 & 28.94 & 29.54 \\
\hline Sample & 31 & 30 & 16 & 11 \\
\hline \multicolumn{5}{|c|}{ In-Treatment Change } \\
\hline Mean & 0.20 & 0.68 & -0.26 & 0.15 \\
\hline Std Dev & 1.69 & 2.16 & 1.43 & 1.75 \\
\hline Std Err Mean & 0.30 & 0.39 & 0.36 & 0.53 \\
\hline $\mathrm{L} 2$ & 0.82 & 1.49 & 0.50 & 1.33 \\
\hline L1 & -0.42 & -0.12 & -1.02 & -1.02 \\
\hline Sample & 31 & 30 & 16 & 11 \\
\hline
\end{tabular}


Table D-3. Descriptive statistics by group and sex for Hyoidale to Frankfort Horizontal.

\begin{tabular}{|c|c|c|c|c|}
\hline Statistic & $\begin{array}{c}\text { Non-Ext } \\
\text { Girls }\end{array}$ & $\begin{array}{c}\text { Non-Ext } \\
\text { Boys }\end{array}$ & $\begin{array}{c}\text { Extraction } \\
\text { Girls }\end{array}$ & $\begin{array}{c}\text { Extraction } \\
\text { Boys }\end{array}$ \\
\hline \multicolumn{5}{|c|}{ Start of Treatment } \\
\hline Mean & 74.57 & 76.46 & 73.78 & 79.66 \\
\hline Std Dev & 6.08 & 7.14 & 8.75 & 6.95 \\
\hline Std Err Mean & 1.11 & 1.35 & 2.43 & 2.09 \\
\hline $\mathrm{L} 2$ & 76.84 & 79.23 & 79.07 & 84.33 \\
\hline L1 & 72.30 & 73.69 & 68.50 & 75.00 \\
\hline Sample & 30 & 28 & 13 & 11 \\
\hline \multicolumn{5}{|c|}{ End of Treatment } \\
\hline Mean & 75.88 & 80.70 & 77.91 & 84.67 \\
\hline Std Dev & 5.05 & 12.47 & 6.66 & 4.49 \\
\hline Std Err Mean & 0.99 & 2.55 & 1.78 & 1.83 \\
\hline $\mathrm{L} 2$ & 77.92 & 85.97 & 81.76 & 89.38 \\
\hline L1 & 73.85 & 75.43 & 74.07 & 79.95 \\
\hline Sample & 26 & 24 & 14 & 6 \\
\hline \multicolumn{5}{|c|}{ In-Treatment Change } \\
\hline Mean & 2.23 & 5.47 & 3.42 & 3.60 \\
\hline Std Dev & 5.06 & 11.18 & 5.85 & 4.67 \\
\hline Std Err Mean & 1.01 & 2.33 & 1.69 & 1.90 \\
\hline $\mathrm{L} 2$ & 4.32 & 10.31 & 7.14 & 8.50 \\
\hline L1 & 0.14 & 0.64 & -0.30 & -1.30 \\
\hline Sample & 25 & 23 & 12 & 6 \\
\hline
\end{tabular}


Table D-4. Descriptive statistics by group and sex for Posterior Soft Palate to Posterior Pharyngeal Wall.

\begin{tabular}{|c|c|c|c|c|}
\hline Statistic & $\begin{array}{c}\text { Non-Ext } \\
\text { Girls }\end{array}$ & $\begin{array}{c}\text { Non-Ext } \\
\text { Boys }\end{array}$ & $\begin{array}{c}\text { Extraction } \\
\text { Girls }\end{array}$ & $\begin{array}{c}\text { Extraction } \\
\text { Boys }\end{array}$ \\
\hline \multicolumn{5}{|c|}{ Start of Treatment } \\
\hline Mean & 8.28 & 7.77 & 9.31 & 8.75 \\
\hline Std Dev & 2.47 & 2.67 & 3.04 & 2.11 \\
\hline Std Err Mean & 0.46 & 0.51 & 0.81 & 0.64 \\
\hline L2 & 9.22 & 8.83 & 11.07 & 10.17 \\
\hline L1 & 7.34 & 6.72 & 7.55 & 7.34 \\
\hline Sample & 29 & 27 & 14 & 11 \\
\hline \multicolumn{5}{|c|}{ End of Treatment } \\
\hline Mean & 8.84 & 8.62 & 9.22 & 9.93 \\
\hline Std Dev & 2.36 & 2.42 & 3.85 & 1.58 \\
\hline Std Err Mean & 0.43 & 0.47 & 1.07 & 0.53 \\
\hline L2 & 9.72 & 9.58 & 11.55 & 11.15 \\
\hline L1 & 7.95 & 7.66 & 6.90 & 8.72 \\
\hline Sample & 30 & 27 & 13 & 9 \\
\hline \multicolumn{5}{|c|}{ In-Treatment Change } \\
\hline Mean & 0.56 & 1.16 & 0.05 & 0.61 \\
\hline Std Dev & 1.91 & 2.43 & 1.85 & 1.58 \\
\hline Std Err Mean & 0.36 & 0.50 & 0.51 & 0.53 \\
\hline $\mathrm{L} 2$ & 1.28 & 2.18 & 1.16 & 1.83 \\
\hline L1 & -0.17 & 0.13 & -1.07 & -0.61 \\
\hline Sample & 29 & 24 & 13 & 9 \\
\hline
\end{tabular}


Table D-5. Descriptive statistics by group and sex for Sella Perpendicular to A Point.

\begin{tabular}{|c|c|c|c|c|}
\hline Statistic & $\begin{array}{c}\text { Non-Ext } \\
\text { Girls }\end{array}$ & $\begin{array}{c}\text { Non-Ext } \\
\text { Boys }\end{array}$ & $\begin{array}{c}\text { Extraction } \\
\text { Girls }\end{array}$ & $\begin{array}{c}\text { Extraction } \\
\text { Boys }\end{array}$ \\
\hline \multicolumn{5}{|c|}{ Start of Treatment } \\
\hline Mean & 65.61 & 66.73 & 63.86 & 67.06 \\
\hline Std Dev & 4.07 & 4.07 & 5.14 & 4.16 \\
\hline Std Err Mean & 0.73 & 0.74 & 1.28 & 1.25 \\
\hline L2 & 67.10 & 68.25 & 66.59 & 69.86 \\
\hline L1 & 64.12 & 65.21 & 61.12 & 64.27 \\
\hline Sample & 31 & 30 & 16 & 11 \\
\hline \multicolumn{5}{|c|}{ End of Treatment } \\
\hline Mean & 65.69 & 67.80 & 63.63 & 66.97 \\
\hline Std Dev & 4.31 & 4.06 & 4.87 & 3.86 \\
\hline Std Err Mean & 0.77 & 0.74 & 1.22 & 1.16 \\
\hline L2 & 67.27 & 69.31 & 66.22 & 69.56 \\
\hline L1 & 64.11 & 66.29 & 61.03 & 64.38 \\
\hline Sample & 31 & 30 & 16 & 11 \\
\hline \multicolumn{5}{|c|}{ In-Treatment Change } \\
\hline Mean & 0.08 & 1.07 & -0.23 & -0.09 \\
\hline Std Dev & 1.21 & 1.61 & 1.55 & 0.76 \\
\hline Std Err Mean & 0.22 & 0.29 & 0.39 & 0.23 \\
\hline $\mathrm{L} 2$ & 0.53 & 1.67 & 0.59 & 0.42 \\
\hline L1 & -0.36 & 0.47 & -1.06 & -0.60 \\
\hline Sample & 31 & 30 & 16 & 11 \\
\hline
\end{tabular}


Table D-6. Descriptive statistics by group and sex for Sella Perpendicular to B Point.

\begin{tabular}{|c|c|c|c|c|}
\hline Statistic & $\begin{array}{c}\text { Non-Ext } \\
\text { Girls }\end{array}$ & $\begin{array}{c}\text { Non-Ext } \\
\text { Boys }\end{array}$ & $\begin{array}{c}\text { Extraction } \\
\text { Girls }\end{array}$ & $\begin{array}{c}\text { Extraction } \\
\text { Boys }\end{array}$ \\
\hline \multicolumn{5}{|c|}{ Start of Treatment } \\
\hline Mean & 62.09 & 62.05 & 57.54 & 60.80 \\
\hline Std Dev & 4.87 & 6.14 & 6.01 & 4.17 \\
\hline Std Err Mean & 0.87 & 1.12 & 1.50 & 1.26 \\
\hline L2 & 63.87 & 64.34 & 60.74 & 63.60 \\
\hline L1 & 60.30 & 59.76 & 54.34 & 58.00 \\
\hline Sample & 31 & 30 & 16 & 11 \\
\hline \multicolumn{5}{|c|}{ End of Treatment } \\
\hline Mean & 62.05 & 64.08 & 58.05 & 60.32 \\
\hline Std Dev & 5.88 & 6.49 & 5.84 & 3.26 \\
\hline Std Err Mean & 1.06 & 1.19 & 1.46 & 0.98 \\
\hline L2 & 64.21 & 66.50 & 61.16 & 62.51 \\
\hline L1 & 59.90 & 61.66 & 54.94 & 58.13 \\
\hline Sample & 31 & 30 & 16 & 11 \\
\hline \multicolumn{5}{|c|}{ In-Treatment Change } \\
\hline Mean & -0.04 & 2.03 & 0.51 & -0.48 \\
\hline Std Dev & 2.34 & 2.34 & 2.09 & 1.43 \\
\hline Std Err Mean & 0.42 & 0.43 & 0.52 & 0.43 \\
\hline $\mathrm{L} 2$ & 0.82 & 2.90 & 1.63 & 0.48 \\
\hline L1 & -0.89 & 1.16 & -0.60 & -1.44 \\
\hline Sample & 31 & 30 & 16 & 11 \\
\hline
\end{tabular}


Table D-7. Descriptive statistics by group and sex for Sella Perpendicular to L6 Mesial.

\begin{tabular}{|c|c|c|c|c|}
\hline Statistic & $\begin{array}{c}\text { Non-Ext } \\
\text { Girls } \\
\end{array}$ & $\begin{array}{c}\text { Non-Ext } \\
\text { Boys }\end{array}$ & $\begin{array}{c}\text { Extraction } \\
\text { Girls }\end{array}$ & $\begin{array}{c}\text { Extraction } \\
\text { Boys }\end{array}$ \\
\hline \multicolumn{5}{|c|}{ Start of Treatment } \\
\hline Mean & 43.11 & 43.32 & 41.16 & 44.91 \\
\hline Std Dev & 4.22 & 5.63 & 6.54 & 3.98 \\
\hline Std Err Mean & 0.76 & 1.03 & 1.63 & 1.20 \\
\hline L2 & 44.66 & 45.43 & 44.65 & 47.58 \\
\hline L1 & 41.56 & 41.22 & 37.68 & 42.24 \\
\hline Sample & 31 & 30 & 16 & 11 \\
\hline \multicolumn{5}{|c|}{ End of Treatment } \\
\hline Mean & 44.12 & 46.26 & 45.99 & 48.08 \\
\hline Std Dev & 4.52 & 5.51 & 4.58 & 3.71 \\
\hline Std Err Mean & 0.81 & 1.01 & 1.15 & 1.12 \\
\hline L2 & 45.78 & 48.31 & 48.44 & 50.57 \\
\hline L1 & 42.46 & 44.20 & 43.55 & 45.59 \\
\hline Sample & 31 & 30 & 16 & 11 \\
\hline \multicolumn{5}{|c|}{ In-Treatment Change } \\
\hline Mean & 1.01 & 2.93 & 4.83 & 3.17 \\
\hline Std Dev & 2.04 & 2.35 & 3.31 & 1.63 \\
\hline Std Err Mean & 0.37 & 0.43 & 0.83 & 0.49 \\
\hline $\mathrm{L} 2$ & 1.76 & 3.81 & 6.59 & 4.27 \\
\hline L1 & 0.27 & 2.05 & 3.07 & 2.08 \\
\hline Sample & 31 & 30 & 16 & 11 \\
\hline
\end{tabular}


Table D-8. Descriptive statistics by group and sex for Sella Perpendicular to U6 Mesial.

\begin{tabular}{|c|c|c|c|c|}
\hline Statistic & $\begin{array}{l}\text { Non-Ext } \\
\text { Girls }\end{array}$ & $\begin{array}{c}\text { Non-Ext } \\
\text { Boys }\end{array}$ & $\begin{array}{l}\text { Extraction } \\
\text { Girls }\end{array}$ & $\begin{array}{l}\text { Extraction } \\
\text { Boys }\end{array}$ \\
\hline \multicolumn{5}{|c|}{ Start of Treatment } \\
\hline Mean & 42.77 & 43.26 & 42.29 & 45.09 \\
\hline Std Dev & 3.62 & 4.44 & 5.89 & 3.66 \\
\hline Std Err Mean & 0.65 & 0.81 & 1.47 & 1.10 \\
\hline L2 & 44.10 & 44.91 & 45.43 & 47.55 \\
\hline L1 & 41.45 & 41.60 & 39.15 & 42.63 \\
\hline Sample & 31 & 30 & 16 & 11 \\
\hline \multicolumn{5}{|c|}{ End of Treatment } \\
\hline Mean & 43.01 & 45.52 & 45.64 & 47.53 \\
\hline Std Dev & 4.31 & 4.96 & 4.55 & 3.24 \\
\hline Std Err Mean & 0.77 & 0.90 & 1.14 & 0.98 \\
\hline L2 & 44.59 & 47.37 & 48.06 & 49.70 \\
\hline L1 & 41.43 & 43.67 & 43.22 & 45.35 \\
\hline Sample & 31 & 30 & 16 & 11 \\
\hline \multicolumn{5}{|c|}{ In-Treatment Change } \\
\hline Mean & 0.24 & 2.27 & 3.34 & 2.44 \\
\hline Std Dev & 2.01 & 2.09 & 2.78 & 1.64 \\
\hline Std Err Mean & 0.36 & 0.38 & 0.69 & 0.50 \\
\hline L2 & 0.97 & 3.05 & 4.82 & 3.54 \\
\hline L1 & -0.50 & 1.48 & 1.86 & 1.33 \\
\hline Sample & 31 & 30 & 16 & 11 \\
\hline
\end{tabular}


Table D-9. Descriptive statistics by group and sex for Facial Convexity.

\begin{tabular}{|c|c|c|c|c|}
\hline Statistic & $\begin{array}{c}\text { Non-Ext } \\
\text { Girls }\end{array}$ & $\begin{array}{c}\text { Non-Ext } \\
\text { Boys }\end{array}$ & $\begin{array}{c}\text { Extraction } \\
\text { Girls }\end{array}$ & $\begin{array}{c}\text { Extraction } \\
\text { Boys }\end{array}$ \\
\hline \multicolumn{5}{|c|}{ Start of Treatment } \\
\hline Mean & 2.15 & 4.52 & 9.77 & 8.47 \\
\hline Std Dev & 5.98 & 6.75 & 6.25 & 7.42 \\
\hline Std Err Mean & 1.09 & 1.23 & 1.67 & 2.35 \\
\hline $\mathrm{L} 2$ & 4.38 & 7.04 & 13.38 & 13.78 \\
\hline L1 & -0.09 & 2.00 & 6.16 & 3.16 \\
\hline Sample & 30 & 30 & 14 & 10 \\
\hline \multicolumn{5}{|c|}{ End of Treatment } \\
\hline Mean & 0.99 & 2.97 & 5.76 & 6.22 \\
\hline Std Dev & 5.60 & 6.38 & 4.75 & 5.55 \\
\hline Std Err Mean & 1.02 & 1.20 & 1.27 & 1.67 \\
\hline $\mathrm{L} 2$ & 3.08 & 5.44 & 8.50 & 9.95 \\
\hline L1 & -1.10 & 0.50 & 3.02 & 2.49 \\
\hline Sample & 30 & 28 & 14 & 11 \\
\hline \multicolumn{5}{|c|}{ In-Treatment Change } \\
\hline Mean & -1.00 & -2.26 & -3.55 & -2.67 \\
\hline Std Dev & 1.84 & 1.98 & 2.92 & 2.22 \\
\hline Std Err Mean & 0.34 & 0.37 & 0.81 & 0.70 \\
\hline $\mathrm{L} 2$ & -0.30 & -1.50 & -1.79 & -1.08 \\
\hline L1 & -1.70 & -3.03 & -5.32 & -4.26 \\
\hline Sample & 29 & 28 & 13 & 10 \\
\hline
\end{tabular}


Table D-10. Descriptive statistics by group and sex for Sella-Nasion-A Point angle.

\begin{tabular}{lcccc}
\hline Statistic & $\begin{array}{c}\text { Non-Ext } \\
\text { Girls }\end{array}$ & $\begin{array}{c}\text { Non-Ext } \\
\text { Boys }\end{array}$ & $\begin{array}{c}\text { Extraction } \\
\text { Girls }\end{array}$ & $\begin{array}{c}\text { Extraction } \\
\text { Boys }\end{array}$ \\
\hline Mean & \multicolumn{4}{c}{ Start of Treatment } \\
Std Dev & 80.54 & 80.35 & 81.99 & 82.86 \\
Std Err Mean & 2.91 & 3.68 & 3.87 & 2.88 \\
L2 & 0.53 & 0.67 & 1.03 & 0.91 \\
L1 & 81.63 & 81.72 & 84.23 & 84.92 \\
Sample & 79.45 & 78.97 & 79.76 & 80.80 \\
& 30 & 30 & 14 & 10 \\
Mean & & & \\
Std Dev & 80.22 & End of Treatment & & \\
Std Err Mean & 2.97 & 30.31 & 79.71 & 81.20 \\
L2 & 0.54 & 0.64 & 4.08 & 3.09 \\
L1 & 81.33 & 81.63 & 82.07 & 0.93 \\
Sample & 79.11 & 79.00 & 77.36 & 79.13 \\
& 30 & 28 & 14 & 11 \\
Mean & & & & \\
Std Dev & & In-Treatment Change & & -1.25 \\
Std Err Mean & -0.12 & -0.36 & -1.57 & 1.15 \\
L2 & 1.15 & 1.36 & 1.37 & 0.36 \\
L1 & 0.21 & 0.26 & 0.38 & -0.43 \\
Sample & 0.32 & 0.17 & -0.74 & 10 \\
\hline
\end{tabular}


Table D-11. Descriptive statistics by group and sex for Sella-Nasion-B Point angle.

\begin{tabular}{|c|c|c|c|c|}
\hline Statistic & $\begin{array}{c}\text { Non-Ext } \\
\text { Girls } \\
\end{array}$ & $\begin{array}{c}\text { Non-Ext } \\
\text { Boys }\end{array}$ & $\begin{array}{c}\text { Extraction } \\
\text { Girls }\end{array}$ & $\begin{array}{c}\text { Extraction } \\
\text { Boys }\end{array}$ \\
\hline \multicolumn{5}{|c|}{ Start of Treatment } \\
\hline Mean & 78.24 & 77.49 & 77.07 & 78.72 \\
\hline Std Dev & 3.24 & 3.52 & 3.64 & 3.99 \\
\hline Std Err Mean & 0.59 & 0.64 & 0.97 & 1.26 \\
\hline $\mathrm{L} 2$ & 79.45 & 78.80 & 79.17 & 81.58 \\
\hline L1 & 77.03 & 76.18 & 74.97 & 75.86 \\
\hline Sample & 30 & 30 & 14 & 10 \\
\hline \multicolumn{5}{|c|}{ End of Treatment } \\
\hline Mean & 78.41 & 77.93 & 76.22 & 77.47 \\
\hline Std Dev & 3.36 & 3.56 & 4.01 & 4.22 \\
\hline Std Err Mean & 0.61 & 0.67 & 1.07 & 1.27 \\
\hline $\mathrm{L} 2$ & 79.66 & 79.31 & 78.54 & 80.31 \\
\hline L1 & 77.15 & 76.55 & 73.90 & 74.64 \\
\hline Sample & 30 & 28 & 14 & 11 \\
\hline \multicolumn{5}{|c|}{ In-Treatment Change } \\
\hline Mean & 0.14 & 0.40 & -0.45 & -0.55 \\
\hline Std Dev & 1.43 & 1.28 & 1.17 & 1.14 \\
\hline Std Err Mean & 0.27 & 0.24 & 0.33 & 0.36 \\
\hline $\mathrm{L} 2$ & 0.68 & 0.89 & 0.26 & 0.26 \\
\hline L1 & -0.41 & -0.10 & -1.16 & -1.36 \\
\hline Sample & 29 & 28 & 13 & 10 \\
\hline
\end{tabular}


Table D-12. Descriptive statistics by group and sex for A Point-Nasion-B Point angle.

\begin{tabular}{|c|c|c|c|c|}
\hline Statistic & $\begin{array}{c}\text { Non-Ext } \\
\text { Girls }\end{array}$ & $\begin{array}{c}\text { Non-Ext } \\
\text { Boys }\end{array}$ & $\begin{array}{c}\text { Extraction } \\
\text { Girls }\end{array}$ & $\begin{array}{c}\text { Extraction } \\
\text { Boys }\end{array}$ \\
\hline \multicolumn{5}{|c|}{ Start of Treatment } \\
\hline Mean & 2.30 & 2.86 & 4.92 & 4.14 \\
\hline Std Dev & 2.46 & 2.35 & 2.67 & 2.79 \\
\hline Std Err Mean & 0.45 & 0.43 & 0.71 & 0.88 \\
\hline L2 & 3.22 & 3.73 & 6.46 & 6.13 \\
\hline L1 & 1.38 & 1.98 & 3.38 & 2.15 \\
\hline Sample & 30 & 30 & 14 & 10 \\
\hline \multicolumn{5}{|c|}{ End of Treatment } \\
\hline Mean & 1.81 & 2.38 & 3.49 & 3.73 \\
\hline Std Dev & 2.10 & 2.24 & 1.75 & 2.48 \\
\hline Std Err Mean & 0.38 & 0.42 & 0.47 & 0.75 \\
\hline L2 & 2.60 & 3.25 & 4.50 & 5.39 \\
\hline L1 & 1.03 & 1.52 & 2.48 & 2.06 \\
\hline Sample & 30 & 28 & 14 & 11 \\
\hline \multicolumn{5}{|c|}{ In-Treatment Change } \\
\hline Mean & -0.26 & -0.75 & -1.12 & -0.70 \\
\hline Std Dev & 1.03 & 1.01 & 1.34 & 0.93 \\
\hline Std Err Mean & 0.19 & 0.19 & 0.37 & 0.29 \\
\hline $\mathrm{L} 2$ & 0.14 & -0.36 & -0.31 & -0.04 \\
\hline L1 & -0.65 & -1.15 & -1.93 & -1.36 \\
\hline Sample & 29 & 28 & 13 & 10 \\
\hline
\end{tabular}


Table D-13. Descriptive statistics by group and sex for Y-Axis.

\begin{tabular}{|c|c|c|c|c|}
\hline Statistic & $\begin{array}{c}\text { Non-Ext } \\
\text { Girls }\end{array}$ & $\begin{array}{c}\text { Non-Ext } \\
\text { Boys }\end{array}$ & $\begin{array}{c}\text { Extraction } \\
\text { Girls }\end{array}$ & $\begin{array}{c}\text { Extraction } \\
\text { Boys }\end{array}$ \\
\hline \multicolumn{5}{|c|}{ Start of Treatment } \\
\hline Mean & 66.31 & 67.71 & 68.66 & 68.26 \\
\hline Std Dev & 3.57 & 4.00 & 2.74 & 3.46 \\
\hline Std Err Mean & 0.65 & 0.73 & 0.73 & 1.09 \\
\hline L2 & 67.64 & 69.20 & 70.25 & 70.73 \\
\hline L1 & 64.98 & 66.22 & 67.08 & 65.79 \\
\hline Sample & 30 & 30 & 14 & 10 \\
\hline \multicolumn{5}{|c|}{ End of Treatment } \\
\hline Mean & 66.43 & 67.72 & 69.40 & 69.51 \\
\hline Std Dev & 3.45 & 3.96 & 3.11 & 3.43 \\
\hline Std Err Mean & 0.63 & 0.75 & 0.83 & 1.03 \\
\hline L2 & 67.71 & 69.25 & 71.20 & 71.81 \\
\hline L1 & 65.14 & 66.18 & 67.60 & 67.21 \\
\hline Sample & 30 & 28 & 14 & 11 \\
\hline \multicolumn{5}{|c|}{ In-Treatment Change } \\
\hline Mean & 0.18 & -0.09 & 0.60 & 1.15 \\
\hline Std Dev & 1.52 & 1.54 & 1.13 & 1.33 \\
\hline Std Err Mean & 0.28 & 0.29 & 0.31 & 0.42 \\
\hline L2 & 0.76 & 0.51 & 1.28 & 2.10 \\
\hline L1 & -0.39 & -0.69 & -0.08 & 0.20 \\
\hline Sample & 29 & 28 & 13 & 10 \\
\hline
\end{tabular}


Table D-14. Descriptive statistics by group and sex for Upper Pharyngeal Plane Width.

\begin{tabular}{|c|c|c|c|c|}
\hline Statistic & $\begin{array}{c}\text { Non-Ext } \\
\text { Girls }\end{array}$ & $\begin{array}{c}\text { Non-Ext } \\
\text { Boys }\end{array}$ & $\begin{array}{c}\text { Extraction } \\
\text { Girls }\end{array}$ & $\begin{array}{c}\text { Extraction } \\
\text { Boys }\end{array}$ \\
\hline \multicolumn{5}{|c|}{ Start of Treatment } \\
\hline Mean & 25.98 & 25.86 & 29.49 & 25.94 \\
\hline Std Dev & 4.79 & 4.14 & 6.12 & 3.37 \\
\hline Std Err Mean & 0.89 & 0.81 & 1.64 & 1.02 \\
\hline $\mathrm{L} 2$ & 27.80 & 27.53 & 33.03 & 28.20 \\
\hline L1 & 24.16 & 24.18 & 25.96 & 23.67 \\
\hline Sample & 29 & 26 & 14 & 11 \\
\hline \multicolumn{5}{|c|}{ End of Treatment } \\
\hline Mean & 28.79 & 27.33 & 31.16 & 26.76 \\
\hline Std Dev & 4.12 & 4.27 & 8.22 & 4.13 \\
\hline Std Err Mean & 0.75 & 0.82 & 2.20 & 1.38 \\
\hline L2 & 30.32 & 29.02 & 35.91 & 29.93 \\
\hline L1 & 27.25 & 25.64 & 26.42 & 23.58 \\
\hline Sample & 30 & 27 & 14 & 9 \\
\hline \multicolumn{5}{|c|}{ In-Treatment Change } \\
\hline Mean & 2.46 & 1.23 & 1.67 & 0.04 \\
\hline Std Dev & 4.35 & 2.20 & 4.62 & 1.54 \\
\hline Std Err Mean & 0.81 & 0.46 & 1.23 & 0.51 \\
\hline L2 & 4.11 & 2.18 & 4.34 & 1.23 \\
\hline L1 & 0.80 & 0.27 & -0.99 & -1.14 \\
\hline Sample & 29 & 23 & 14 & 9 \\
\hline
\end{tabular}


Table D-15. Descriptive statistics by group and sex for Upper Pharyngeal Plane Area.

\begin{tabular}{|c|c|c|c|c|}
\hline Statistic & $\begin{array}{c}\text { Non-Ext } \\
\text { Girls }\end{array}$ & $\begin{array}{c}\text { Non-Ext } \\
\text { Boys }\end{array}$ & $\begin{array}{c}\text { Extraction } \\
\text { Girls }\end{array}$ & $\begin{array}{c}\text { Extraction } \\
\text { Boys }\end{array}$ \\
\hline \multicolumn{5}{|c|}{ Start of Treatment } \\
\hline Mean & 357.63 & 359.41 & 444.39 & 406.06 \\
\hline Std Dev & 115.51 & 154.85 & 199.61 & 144.58 \\
\hline Std Err Mean & 21.45 & 30.37 & 53.35 & 43.59 \\
\hline L2 & 401.57 & 421.95 & 559.65 & 503.19 \\
\hline L1 & 313.69 & 296.86 & 329.14 & 308.94 \\
\hline Sample & 29 & 26 & 14 & 11 \\
\hline \multicolumn{5}{|c|}{ End of Treatment } \\
\hline Mean & 431.36 & 404.97 & 488.88 & 449.81 \\
\hline Std Dev & 127.82 & 153.73 & 224.06 & 173.96 \\
\hline Std Err Mean & 23.34 & 29.58 & 62.14 & 57.99 \\
\hline L2 & 479.09 & 465.78 & 624.29 & 583.53 \\
\hline L1 & 383.63 & 344.15 & 353.48 & 316.09 \\
\hline Sample & 30 & 27 & 13 & 9 \\
\hline \multicolumn{5}{|c|}{ In-Treatment Change } \\
\hline Mean & 64.12 & 43.18 & 32.62 & 9.93 \\
\hline Std Dev & 127.83 & 78.91 & 90.92 & 53.94 \\
\hline Std Err Mean & 23.74 & 16.45 & 25.22 & 17.98 \\
\hline L2 & 112.74 & 77.31 & 87.57 & 51.40 \\
\hline L1 & 15.50 & 9.06 & -22.32 & -31.53 \\
\hline Sample & 29 & 23 & 13 & 9 \\
\hline
\end{tabular}


Table D-16. Descriptive statistics by group and sex for Middle Pharyngeal Plane Width.

\begin{tabular}{|c|c|c|c|c|}
\hline Statistic & $\begin{array}{c}\text { Non-Ext } \\
\text { Girls }\end{array}$ & $\begin{array}{c}\text { Non-Ext } \\
\text { Boys }\end{array}$ & $\begin{array}{c}\text { Extraction } \\
\text { Girls }\end{array}$ & $\begin{array}{c}\text { Extraction } \\
\text { Boys }\end{array}$ \\
\hline \multicolumn{5}{|c|}{ Start of Treatment } \\
\hline Mean & 24.40 & 23.66 & 25.82 & 24.32 \\
\hline Std Dev & 6.27 & 6.96 & 9.32 & 6.68 \\
\hline Std Err Mean & 1.16 & 1.32 & 2.49 & 2.01 \\
\hline $\mathrm{L} 2$ & 26.78 & 26.36 & 31.20 & 28.80 \\
\hline L1 & 22.02 & 20.96 & 20.44 & 19.83 \\
\hline Sample & 29 & 28 & 14 & 11 \\
\hline \multicolumn{5}{|c|}{ End of Treatment } \\
\hline Mean & 27.97 & 26.94 & 28.39 & 27.51 \\
\hline Std Dev & 4.96 & 5.34 & 9.60 & 6.69 \\
\hline Std Err Mean & 0.90 & 1.03 & 2.56 & 2.23 \\
\hline L2 & 29.82 & 29.05 & 33.93 & 32.65 \\
\hline L1 & 26.12 & 24.83 & 22.85 & 22.37 \\
\hline Sample & 30 & 27 & 14 & 9 \\
\hline \multicolumn{5}{|c|}{ In-Treatment Change } \\
\hline Mean & 3.55 & 2.60 & 2.56 & 2.50 \\
\hline Std Dev & 5.27 & 6.31 & 4.38 & 2.29 \\
\hline Std Err Mean & 0.98 & 1.26 & 1.17 & 0.76 \\
\hline L2 & 5.56 & 5.21 & 5.09 & 4.26 \\
\hline L1 & 1.55 & 0.00 & 0.04 & 0.74 \\
\hline Sample & 29 & 25 & 14 & 9 \\
\hline
\end{tabular}


Table D-17. Descriptive statistics by group and sex for Middle Pharyngeal Plane Area.

\begin{tabular}{|c|c|c|c|c|}
\hline Statistic & $\begin{array}{c}\text { Non-Ext } \\
\text { Girls }\end{array}$ & $\begin{array}{c}\text { Non-Ext } \\
\text { Boys }\end{array}$ & $\begin{array}{c}\text { Extraction } \\
\text { Girls }\end{array}$ & $\begin{array}{c}\text { Extraction } \\
\text { Boys }\end{array}$ \\
\hline \multicolumn{5}{|c|}{ Start of Treatment } \\
\hline Mean & 187.38 & 176.00 & 225.69 & 186.72 \\
\hline Std Dev & 72.36 & 88.52 & 135.33 & 69.06 \\
\hline Std Err Mean & 13.44 & 16.73 & 36.17 & 20.82 \\
\hline $\mathrm{L} 2$ & 214.90 & 210.32 & 303.82 & 233.11 \\
\hline L1 & 159.85 & 141.67 & 147.55 & 140.32 \\
\hline Sample & 29 & 28 & 14 & 11 \\
\hline \multicolumn{5}{|c|}{ End of Treatment } \\
\hline Mean & 228.05 & 217.67 & 259.95 & 210.40 \\
\hline Std Dev & 74.93 & 86.73 & 184.84 & 78.42 \\
\hline Std Err Mean & 13.68 & 16.69 & 51.27 & 26.14 \\
\hline L2 & 256.03 & 251.98 & 371.65 & 270.68 \\
\hline L1 & 200.08 & 183.36 & 148.26 & 150.12 \\
\hline Sample & 30 & 27 & 13 & 9 \\
\hline \multicolumn{5}{|c|}{ In-Treatment Change } \\
\hline Mean & 41.47 & 41.24 & 41.92 & 12.10 \\
\hline Std Dev & 80.38 & 78.50 & 83.59 & 29.69 \\
\hline Std Err Mean & 14.93 & 15.70 & 23.18 & 9.90 \\
\hline L2 & 72.05 & 73.65 & 92.43 & 34.92 \\
\hline L1 & 10.90 & 8.84 & -8.59 & -10.72 \\
\hline Sample & 29 & 25 & 13 & 9 \\
\hline
\end{tabular}


Table D-18. Descriptive statistics by group and sex for Lower Pharyngeal Plane Width.

\begin{tabular}{|c|c|c|c|c|}
\hline Statistic & $\begin{array}{l}\text { Non-Ext } \\
\text { Girls }\end{array}$ & $\begin{array}{c}\text { Non-Ext } \\
\text { Boys }\end{array}$ & $\begin{array}{l}\text { Extraction } \\
\text { Girls }\end{array}$ & $\begin{array}{l}\text { Extraction } \\
\text { Boys }\end{array}$ \\
\hline \multicolumn{5}{|c|}{ Start of Treatment } \\
\hline Mean & 25.62 & 25.97 & 25.36 & 26.45 \\
\hline Std Dev & 2.90 & 4.73 & 5.47 & 4.30 \\
\hline Std Err Mean & 0.52 & 0.88 & 1.37 & 1.30 \\
\hline L2 & 26.68 & 27.77 & 28.27 & 29.35 \\
\hline L1 & 24.55 & 24.17 & 22.44 & 23.56 \\
\hline Sample & 31 & 29 & 16 & 11 \\
\hline \multicolumn{5}{|c|}{ End of Treatment } \\
\hline Mean & 27.27 & 28.05 & 27.58 & 29.75 \\
\hline Std Dev & 2.95 & 4.54 & 4.30 & 5.47 \\
\hline Std Err Mean & 0.53 & 0.84 & 1.07 & 1.73 \\
\hline L2 & 28.35 & 29.78 & 29.87 & 33.66 \\
\hline L1 & 26.19 & 26.32 & 25.28 & 25.84 \\
\hline Sample & 31 & 29 & 16 & 10 \\
\hline \multicolumn{5}{|c|}{ In-Treatment Change } \\
\hline Mean & 1.65 & 2.73 & 2.22 & 2.91 \\
\hline Std Dev & 2.89 & 4.48 & 3.65 & 3.34 \\
\hline Std Err Mean & 0.52 & 0.85 & 0.91 & 1.06 \\
\hline L2 & 2.71 & 4.47 & 4.17 & 5.30 \\
\hline L1 & 0.59 & 0.99 & 0.27 & 0.52 \\
\hline Sample & 31 & 28 & 16 & 10 \\
\hline
\end{tabular}


Table D-19. Descriptive statistics by group and sex for Lower Pharyngeal Plane Area.

\begin{tabular}{|c|c|c|c|c|}
\hline Statistic & $\begin{array}{l}\text { Non-Ext } \\
\text { Girls }\end{array}$ & $\begin{array}{c}\text { Non-Ext } \\
\text { Boys }\end{array}$ & $\begin{array}{l}\text { Extraction } \\
\text { Girls }\end{array}$ & $\begin{array}{l}\text { Extraction } \\
\text { Boys }\end{array}$ \\
\hline \multicolumn{5}{|c|}{ Start of Treatment } \\
\hline Mean & 193.05 & 200.84 & 222.70 & 249.65 \\
\hline Std Dev & 78.00 & 91.80 & 95.89 & 162.67 \\
\hline Std Err Mean & 14.01 & 17.05 & 23.97 & 49.05 \\
\hline L2 & 221.66 & 235.76 & 273.80 & 358.94 \\
\hline L1 & 164.43 & 165.92 & 171.60 & 140.37 \\
\hline Sample & 31 & 29 & 16 & 11 \\
\hline \multicolumn{5}{|c|}{ End of Treatment } \\
\hline Mean & 242.06 & 253.25 & 273.76 & 298.36 \\
\hline Std Dev & 86.52 & 113.39 & 103.09 & 148.32 \\
\hline Std Err Mean & 15.54 & 21.06 & 25.77 & 46.90 \\
\hline L2 & 273.79 & 296.38 & 328.70 & 404.46 \\
\hline L1 & 210.32 & 210.12 & 218.83 & 192.26 \\
\hline Sample & 31 & 29 & 16 & 10 \\
\hline \multicolumn{5}{|c|}{ In-Treatment Change } \\
\hline Mean & 49.01 & 63.05 & 51.06 & 43.49 \\
\hline Std Dev & 93.72 & 108.99 & 84.07 & 97.95 \\
\hline Std Err Mean & 16.83 & 20.60 & 21.02 & 30.98 \\
\hline L2 & 83.39 & 105.31 & 95.86 & 113.56 \\
\hline L1 & 14.64 & 20.79 & 6.27 & -26.58 \\
\hline Sample & 31 & 28 & 16 & 10 \\
\hline
\end{tabular}


Table D-20. Descriptive statistics by group and sex for Middle Pharyngeal Airway Volume.

\begin{tabular}{lcccc}
\hline \multicolumn{1}{c}{ Statistic } & $\begin{array}{c}\text { Non-Ext } \\
\text { Girls }\end{array}$ & $\begin{array}{c}\text { Non-Ext } \\
\text { Boys }\end{array}$ & $\begin{array}{c}\text { Extraction } \\
\text { Girls }\end{array}$ & $\begin{array}{c}\text { Extraction } \\
\text { Boys }\end{array}$ \\
\hline \multicolumn{4}{c}{$\begin{array}{c} \\
\text { Start of Treatment }\end{array}$} \\
Mean & 5147.89 & 5306.94 & 6826.12 & 5771.27 \\
Std Dev & 1604.33 & 1928.47 & 3617.57 & 2175.48 \\
Std Err Mean & 297.92 & 378.20 & 966.84 & 655.93 \\
L2 & 5758.14 & 6085.87 & 8914.85 & 7232.78 \\
L1 & 4537.64 & 4528.02 & 4737.40 & 4309.77 \\
Sample & 29 & 26 & 14 & 11 \\
\multicolumn{5}{c}{ End of Treatment } \\
Mean & 6100.34 & 6277.41 & 7911.70 & 6953.80 \\
Std Dev & 1452.76 & 2063.91 & 4320.50 & 2154.95 \\
Std Err Mean & 269.77 & 404.77 & 1198.29 & 718.32 \\
L2 & 6652.94 & 7111.04 & 10522.55 & 8610.24 \\
L1 & 5547.74 & 5443.78 & 5300.85 & 5297.36 \\
Sample & 29 & 26 & 13 & 9 \\
\multicolumn{4}{c}{ In-Treatment Change } \\
Mean & 952.46 & 1061.34 & 1064.02 & 698.17 \\
Std Dev & 2114.28 & 1677.03 & 2331.05 & 1658.32 \\
Std Err Mean & 392.61 & 357.54 & 646.52 & 552.77 \\
L2 & 1756.68 & 1804.89 & 2472.66 & 1972.86 \\
L1 & 148.23 & 317.78 & -344.61 & -576.53 \\
Sample & 29 & 22 & 13 & 9 \\
\hline
\end{tabular}


Table D-21. Descriptive statistics by group and sex for Inferior Pharyngeal Airway Volume.

\begin{tabular}{lcccc}
\hline \multicolumn{1}{c}{ Statistic } & $\begin{array}{c}\text { Non-Ext } \\
\text { Girls }\end{array}$ & $\begin{array}{c}\text { Non-Ext } \\
\text { Boys }\end{array}$ & $\begin{array}{c}\text { Extraction } \\
\text { Girls }\end{array}$ & $\begin{array}{c}\text { Extraction } \\
\text { Boys }\end{array}$ \\
\hline \multicolumn{4}{c}{$\begin{array}{c} \\
\text { Start of Treatment }\end{array}$} \\
Mean & 5620.26 & 5556.06 & 5641.62 & 5625.18 \\
Std Dev & 2147.19 & 2712.76 & 3146.17 & 3537.01 \\
Std Err Mean & 398.72 & 522.07 & 840.85 & 1066.45 \\
L2 & 6437.00 & 6629.19 & 7458.16 & 8001.37 \\
L1 & 4803.51 & 4482.93 & 3825.08 & 3248.99 \\
Sample & 29 & 27 & 14 & 11 \\
\multicolumn{5}{c}{ End of Treatment } \\
Mean & 6991.96 & 7222.17 & 7046.06 & 7992.26 \\
Std Dev & 2580.86 & 3111.94 & 4110.65 & 4300.46 \\
Std Err Mean & 479.25 & 610.30 & 1140.09 & 1433.49 \\
L2 & 7973.67 & 8479.11 & 9530.10 & 11297.88 \\
L1 & 6010.25 & 5965.23 & 4562.02 & 4686.63 \\
Sample & 29 & 26 & 13 & 9 \\
\multicolumn{5}{c}{ In-Treatment Change } \\
Mean & 1371.70 & 2138.35 & 1788.86 & 1718.58 \\
Std Dev & 2555.75 & 2570.39 & 2684.36 & 1773.98 \\
Std Err Mean & 474.59 & 535.96 & 744.51 & 591.33 \\
L2 & 2343.86 & 3249.87 & 3411.01 & 3082.18 \\
L1 & 399.55 & 1026.83 & 166.72 & 354.98 \\
Sample & 29 & 23 & 13 & 9 \\
\hline
\end{tabular}


Table D-22. Descriptive statistics by group and sex for Total Pharyngeal Airway Volume.

\begin{tabular}{|c|c|c|c|c|}
\hline Statistic & $\begin{array}{c}\text { Non-Ext } \\
\text { Girls }\end{array}$ & $\begin{array}{c}\text { Non-Ext } \\
\text { Boys }\end{array}$ & $\begin{array}{c}\text { Extraction } \\
\text { Girls }\end{array}$ & $\begin{array}{c}\text { Extraction } \\
\text { Boys }\end{array}$ \\
\hline \multicolumn{5}{|c|}{ Start of Treatment } \\
\hline Mean & 10768.15 & 10883.64 & 12467.74 & 11396.46 \\
\hline Std Dev & 2990.27 & 4344.04 & 6442.43 & 5254.28 \\
\hline Std Err Mean & 555.28 & 851.94 & 1721.81 & 1584.22 \\
\hline L2 & 11905.58 & 12638.23 & 16187.49 & 14926.33 \\
\hline L1 & 9630.71 & 9129.04 & 8747.99 & 7866.58 \\
\hline Sample & 29 & 26 & 14 & 11 \\
\hline \multicolumn{5}{|c|}{ End of Treatment } \\
\hline Mean & 13092.30 & 13499.58 & 14957.76 & 14946.06 \\
\hline Std Dev & 2967.24 & 4806.86 & 8169.61 & 6352.24 \\
\hline Std Err Mean & 551.00 & 942.70 & 2265.84 & 2117.41 \\
\hline L2 & 14220.98 & 15441.11 & 19894.61 & 19828.82 \\
\hline L1 & 11963.63 & 11558.05 & 10020.91 & 10063.29 \\
\hline Sample & 29 & 26 & 13 & 9 \\
\hline \multicolumn{5}{|c|}{ In-Treatment Change } \\
\hline Mean & 2324.16 & 3199.91 & 2852.88 & 2416.74 \\
\hline Std Dev & 3669.85 & 3831.92 & 4749.46 & 2754.00 \\
\hline Std Err Mean & 681.47 & 816.97 & 1317.26 & 918.00 \\
\hline L2 & 3720.10 & 4898.89 & 5722.96 & 4533.66 \\
\hline L1 & 928.22 & 1500.94 & -17.19 & 299.83 \\
\hline Sample & 29 & 22 & 13 & 9 \\
\hline
\end{tabular}


APPENDIX E. DESCRIPTIVE STATISTICS BY GROUP 
Table E-1. Descriptive statistics by group for Anterior Facial Height.

\begin{tabular}{lcc}
\hline \multicolumn{1}{c}{ Statistic } & Non-Ext & Extraction \\
\hline & Start of Treatment & \\
Mean & 80.41 & 81.88 \\
Std Dev & 5.60 & 5.70 \\
Std Err Mean & 0.72 & 1.10 \\
L2 & 81.85 & 84.14 \\
L1 & 78.98 & 79.63 \\
Sample & 61 & 27 \\
& & \\
Mean & End of Treatment & \\
Std Dev & 83.35 & 85.90 \\
Std Err Mean & 5.49 & 5.53 \\
L2 & 0.71 & 1.11 \\
L1 & 84.77 & 88.19 \\
Sample & 81.94 & 83.62 \\
& 60 & 25 \\
Mean & & \\
Std Dev & In-Treatment Change & \\
Std Err Mean & 3.20 & 4.54 \\
L2 & 2.32 & 3.66 \\
L1 & 0.30 & 0.73 \\
Sample & 3.81 & 6.05 \\
& 2.61 & 3.03 \\
\hline
\end{tabular}


Table E-2. Descriptive statistics by group for Atlas Vertebra to Posterior Nasal Spine.

\begin{tabular}{lcc}
\hline \multicolumn{1}{c}{ Statistic } & Non-Ext & Extraction \\
\hline & Start of Treatment & \\
Mean & 31.85 & 31.53 \\
Std Dev & 3.25 & 3.76 \\
Std Err Mean & 0.42 & 0.72 \\
L2 & 32.69 & 33.01 \\
L1 & 31.02 & 30.03 \\
Sample & 61 & 27 \\
& & \\
Mean & End of Treatment & \\
Std Dev & 32.29 & 31.43 \\
Std Err Mean & 3.55 & 3.83 \\
L2 & 0.46 & 0.74 \\
L1 & 33.20 & 32.95 \\
Sample & 31.38 & 29.92 \\
& 61 & 27 \\
Mean & & \\
Std Dev & In-Treatment Change & -0.09 \\
Std Err Mean & 0.43 & 1.55 \\
L2 & 1.94 & 0.30 \\
L1 & 0.25 & 0.52 \\
Sample & 0.93 & -0.71 \\
\hline
\end{tabular}


Table E-3. Descriptive statistics by group for Hyoidale to Frankfort Horizontal.

\begin{tabular}{lcc}
\hline \multicolumn{1}{c}{ Statistic } & Non-Ext & Extraction \\
\hline & Start of Treatment & \\
Mean & 75.48 & 76.48 \\
Std Dev & 6.62 & 8.36 \\
Std Err Mean & 0.87 & 1.71 \\
L2 & 77.22 & 80.01 \\
L1 & 73.74 & 72.95 \\
Sample & 58 & 24 \\
& & \\
Mean & End of Treatment & \\
Std Dev & 78.20 & 79.94 \\
Std Err Mean & 9.59 & 6.76 \\
L2 & 1.36 & 1.51 \\
L1 & 80.92 & 83.11 \\
Sample & 75.47 & 76.78 \\
& 50 & 20 \\
Mean & & \\
Std Dev & In-Treatment Change & 3.48 \\
Std Err Mean & 3.78 & 5.35 \\
L2 & 8.62 & 1.26 \\
L1 & 1.24 & 6.14 \\
Sample & 6.29 & 0.82 \\
\hline
\end{tabular}


Table E-4. Descriptive statistics by group for Posterior Soft Palate to Posterior Pharyngeal Wall.

\begin{tabular}{lcc}
\hline \multicolumn{1}{c}{ Statistic } & Non-Ext & Extraction \\
\hline & Start of Treatment & \\
Mean & 8.04 & \\
Std Dev & 2.56 & .06 \\
Std Err Mean & 0.34 & 2.64 \\
L2 & 8.72 & 0.53 \\
L1 & 7.35 & 10.15 \\
Sample & 56 & 7.98 \\
& & 25 \\
Mean & End of Treatment & \\
Std Dev & 8.74 & \\
Std Err Mean & 2.37 & 9.51 \\
L2 & 0.31 & 3.09 \\
L1 & 9.36 & 0.66 \\
Sample & 8.11 & 10.88 \\
& 57 & 8.14 \\
Mean & & 22 \\
Std Dev & In-Treatment Change & \\
Std Err Mean & 0.83 & 0.28 \\
L2 & 2.16 & 1.73 \\
L1 & 0.30 & 0.37 \\
Sample & 1.42 & 1.04 \\
& 0.23 & -0.49 \\
& 53 & 22 \\
\hline
\end{tabular}


Table E-5. Descriptive statistics by group for Sella Perpendicular to A Point.

\begin{tabular}{lcc}
\hline \multicolumn{1}{c}{ Statistic } & Non-Ext & Extraction \\
\hline & Start of Treatment & \\
Mean & 66.16 & 65.16 \\
Std Dev & 4.08 & 4.95 \\
Std Err Mean & 0.52 & 0.95 \\
L2 & 67.21 & 67.12 \\
L1 & 65.12 & 63.21 \\
Sample & 61 & 27 \\
& & \\
Mean & End of Treatment & \\
Std Dev & 66.73 & 64.99 \\
Std Err Mean & 4.29 & 4.72 \\
L2 & 0.55 & 0.91 \\
L1 & 67.83 & 66.85 \\
Sample & 65.63 & 63.12 \\
& 61 & 27 \\
Mean & & \\
Std Dev & In-Treatment Change & -0.17 \\
Std Err Mean & 0.57 & 1.27 \\
L2 & 1.49 & 0.24 \\
L1 & 0.19 & 0.33 \\
Sample & 0.95 & -0.68 \\
\hline
\end{tabular}


Table E-6. Descriptive statistics by group for Sella Perpendicular to B Point.

\begin{tabular}{lcc}
\hline \multicolumn{1}{c}{ Statistic } & Non-Ext & Extraction \\
\hline \multicolumn{3}{c}{ Start of Treatment } \\
Mean & 62.07 & \\
Std Dev & 5.48 & 58.87 \\
Std Err Mean & 0.70 & 5.49 \\
L2 & 63.47 & 1.06 \\
L1 & 60.67 & 61.04 \\
Sample & 61 & 56.70 \\
& & 27 \\
Mean & End of Treatment & \\
Std Dev & 63.05 & 58.97 \\
Std Err Mean & 6.22 & 5.01 \\
L2 & 0.80 & 0.96 \\
L1 & 64.64 & 60.96 \\
Sample & 61.46 & 56.99 \\
& 61 & 27 \\
Mean & & \\
Std Dev & In-Treatment Change & 0.11 \\
Std Err Mean & 0.98 & 1.89 \\
L2 & 2.54 & 0.36 \\
L1 & 0.33 & 0.85 \\
Sample & 1.63 & -0.64 \\
\hline
\end{tabular}


Table E-7. Descriptive statistics by group for Sella Perpendicular to L6 Mesial.

\begin{tabular}{lcc}
\hline \multicolumn{1}{c}{ Statistic } & Non-Ext & Extraction \\
\hline & & \\
Mean & Start of Treatment & \\
Std Dev & 43.21 & 42.69 \\
Std Err Mean & 4.92 & 5.85 \\
L2 & 0.63 & 1.13 \\
L1 & 44.47 & 45.01 \\
Sample & 41.95 & 40.37 \\
& 61 & 27 \\
Mean & & \\
Std Dev & End of Treatment & \\
Std Err Mean & 45.17 & 46.84 \\
L2 & 5.10 & 4.30 \\
L1 & 0.65 & 0.83 \\
Sample & 46.48 & 48.55 \\
& 43.86 & 45.14 \\
Mean & 61 & 27 \\
Std Dev & & \\
Std Err Mean & In-Treatment Change & 4.16 \\
L2 & 1.96 & 2.83 \\
L1 & 2.38 & 0.55 \\
Sample & 0.31 & 5.28 \\
& 2.57 & 3.03 \\
\end{tabular}


Table E-8. Descriptive statistics by group for Sella Perpendicular to U6 Mesial.

\begin{tabular}{lcc}
\hline \multicolumn{1}{c}{ Statistic } & Non-Ext & Extraction \\
\hline & Start of Treatment & \\
Mean & 43.01 & 43.43 \\
Std Dev & 4.02 & 5.21 \\
Std Err Mean & 0.51 & 1.00 \\
L2 & 44.04 & 45.50 \\
L1 & 41.98 & 41.37 \\
Sample & 61 & 27 \\
& & \\
Mean & End of Treatment & \\
Std Dev & 44.25 & 46.41 \\
Std Err Mean & 4.77 & 4.10 \\
L2 & 0.61 & 0.79 \\
L1 & 43.03 & 48.03 \\
Sample & 45.47 & 44.78 \\
& 61 & 27 \\
Mean & & \\
Std Dev & In-Treatment Change & 2.97 \\
Std Err Mean & 1.24 & 2.39 \\
L2 & 2.28 & 0.46 \\
L1 & 0.29 & 3.92 \\
Sample & 1.82 & 2.03 \\
\hline
\end{tabular}


Table E-9. Descriptive statistics by group for Facial Convexity.

\begin{tabular}{lcc}
\hline \multicolumn{1}{c}{ Statistic } & Non-Ext & Extraction \\
\hline & Start of Treatment & \\
Mean & 3.33 & 9.23 \\
Std Dev & 6.44 & 6.64 \\
Std Err Mean & 0.83 & 1.35 \\
L2 & 5.00 & 12.03 \\
L1 & 1.67 & 6.43 \\
Sample & 60 & 24 \\
& & \\
Mean & End of Treatment & \\
Std Dev & 1.94 & 5.96 \\
Std Err Mean & 6.02 & 5.01 \\
L2 & 0.79 & 1.00 \\
L1 & 3.53 & 8.03 \\
Sample & 0.36 & 3.89 \\
& 58 & 25 \\
Mean & & \\
Std Dev & In-Treatment Change & \\
Std Err Mean & -1.62 & -3.17 \\
L2 & 2.00 & 2.62 \\
L1 & 0.26 & 0.55 \\
Sample & -1.09 & -2.04 \\
& -2.15 & -4.30 \\
\hline
\end{tabular}


Table E-10. Descriptive statistics by group for Sella-Nasion-A Point angle.

\begin{tabular}{lcc}
\hline \multicolumn{1}{c}{ Statistic } & Non-Ext & Extraction \\
\hline & Start of Treatment & \\
Mean & 80.44 & 82.35 \\
Std Dev & 3.29 & 3.45 \\
Std Err Mean & 0.43 & 0.70 \\
L2 & 81.29 & 83.81 \\
L1 & 79.59 & 80.90 \\
Sample & 60 & 24 \\
& & \\
Mean & End of Treatment & \\
Std Dev & 80.27 & 80.37 \\
Std Err Mean & 3.15 & 3.68 \\
L2 & 0.41 & 0.74 \\
L1 & 81.10 & 81.89 \\
Sample & 79.44 & 78.85 \\
& 58 & 25 \\
Mean & & \\
Std Dev & In-Treatment Change & -1.43 \\
Std Err Mean & -0.24 & 1.26 \\
L2 & 1.25 & 0.26 \\
L1 & 0.17 & -0.88 \\
Sample & 0.01 & -1.98 \\
\hline
\end{tabular}


Table E-11. Descriptive statistics by group for Sella-Nasion-B Point angle.

\begin{tabular}{lcc}
\hline \multicolumn{1}{c}{ Statistic } & Non-Ext & Extraction \\
\hline & Start of Treatment & \\
Mean & 77.87 & 77.76 \\
Std Dev & 3.38 & 3.80 \\
Std Err Mean & 0.44 & 0.78 \\
L2 & 78.74 & 79.36 \\
L1 & 76.99 & 76.16 \\
Sample & 60 & 24 \\
& & \\
Mean & End of Treatment & \\
Std Dev & 78.18 & 76.77 \\
Std Err Mean & 3.43 & 4.07 \\
L2 & 0.45 & 0.81 \\
L1 & 79.08 & 78.45 \\
Sample & 79.28 & 75.09 \\
& 58 & 25 \\
Mean & & \\
Std Dev & In-Treatment Change & -0.49 \\
Std Err Mean & 0.26 & 1.13 \\
L2 & 1.35 & 0.24 \\
L1 & 0.18 & -0.98 \\
Sample & 0.62 & 0.00 \\
\hline
\end{tabular}


Table E-12. Descriptive statistics by group for A Point-Nasion-B Point angle.

\begin{tabular}{lcc}
\hline Statistic & Non-Ext & Extraction \\
\hline & Start of Treatment & \\
Mean & 2.58 & 4.60 \\
Std Dev & 2.40 & 2.69 \\
Std Err Mean & 0.31 & 0.55 \\
L2 & 3.20 & 5.73 \\
L1 & 1.96 & 3.46 \\
Sample & 60 & 24 \\
& & \\
Mean & End of Treatment & \\
Std Dev & 2.09 & 3.60 \\
Std Err Mean & 2.16 & 2.06 \\
L2 & 0.28 & 0.41 \\
L1 & 2.66 & 4.45 \\
Sample & 1.52 & 2.75 \\
& 58 & 25 \\
Mean & & \\
Std Dev & In-Treatment Change & -0.94 \\
Std Err Mean & -0.50 & 1.18 \\
L2 & 1.04 & 0.25 \\
L1 & 0.14 & -0.43 \\
Sample & -0.22 & -1.45 \\
\hline
\end{tabular}


Table E-13. Descriptive statistics by group for Y-Axis.

\begin{tabular}{lcc}
\hline \multicolumn{1}{c}{ Statistic } & Non-Ext & Extraction \\
\hline & Start of Treatment & \\
Mean & 67.01 & 68.50 \\
Std Dev & 3.83 & 3.00 \\
Std Err Mean & 0.49 & 0.61 \\
L2 & 68.00 & 69.76 \\
L1 & 66.02 & 67.23 \\
Sample & 60 & 24 \\
& & \\
Mean & End of Treatment & \\
Std Dev & 67.05 & 69.45 \\
Std Err Mean & 3.73 & 3.18 \\
L2 & 0.49 & 0.64 \\
L1 & 68.03 & 70.76 \\
Sample & 66.07 & 68.13 \\
& 58 & 25 \\
Mean & & \\
Std Dev & In-Treatment Change & \\
Std Err Mean & 0.05 & 0.84 \\
L2 & 1.52 & 1.23 \\
L1 & 0.20 & 0.26 \\
Sample & 0.45 & 1.37 \\
\hline
\end{tabular}


Table E-14. Descriptive statistics by group for Upper Pharyngeal Plane Width.

\begin{tabular}{lcc}
\hline \multicolumn{1}{c}{ Statistic } & Non-Ext & Extraction \\
\hline & Start of Treatment & \\
Mean & 25.92 & 27.93 \\
Std Dev & 4.45 & 5.32 \\
Std Err Mean & 0.60 & 1.06 \\
L2 & 27.13 & 30.12 \\
L1 & 24.72 & 25.73 \\
Sample & 55 & 25 \\
& & \\
Mean & End of Treatment & \\
Std Dev & 28.09 & 29.44 \\
Std Err Mean & 4.22 & 7.14 \\
L2 & 0.56 & 1.49 \\
L1 & 29.21 & 32.53 \\
Sample & 26.98 & 26.35 \\
& 57 & 23 \\
Mean & & \\
Std Dev & In-Treatment Change & 1.03 \\
Std Err Mean & 1.91 & 3.76 \\
L2 & 3.59 & 0.78 \\
L1 & 0.50 & 2.66 \\
Sample & 2.91 & -0.59 \\
\hline
\end{tabular}


Table E-15. Descriptive statistics by group for Upper Pharyngeal Plane Area.

\begin{tabular}{lcc}
\hline Statistic & Non-Ext & Extraction \\
\hline & Start of Treatment & \\
Mean & 358.47 & 427.53 \\
Std Dev & 134.24 & 175.13 \\
Std Err Mean & 18.10 & 35.03 \\
L2 & 394.76 & 499.82 \\
L1 & 355.24 & 355.24 \\
Sample & 55 & 25 \\
& & \\
Mean & End of Treatment & \\
Std Dev & 418.86 & 472.90 \\
Std Err Mean & 140.04 & 201.50 \\
L2 & 18.55 & 42.96 \\
L1 & 456.01 & 562.24 \\
Sample & 381.70 & 383.56 \\
& 57 & 22 \\
Mean & & \\
Std Dev & In-Treatment Change & 23.34 \\
Std Err Mean & 54.86 & 77.22 \\
L2 & 108.48 & 16.46 \\
L1 & 15.04 & 57.58 \\
Sample & 85.06 & -10.90 \\
\hline
\end{tabular}


Table E-16. Descriptive statistics by group for Middle Pharyngeal Plane Width.

\begin{tabular}{lcc}
\hline \multicolumn{1}{c}{ Statistic } & Non-Ext & Extraction \\
\hline & Start of Treatment & \\
Mean & 24.04 & 25.16 \\
Std Dev & 6.57 & 8.14 \\
Std Err Mean & 0.87 & 1.63 \\
L2 & 25.78 & 28.52 \\
L1 & 22.29 & 21.80 \\
Sample & 57 & 25 \\
& & \\
Mean & End of Treatment & \\
Std Dev & 27.48 & 28.04 \\
Std Err Mean & 5.12 & 8.42 \\
L2 & 0.68 & 1.76 \\
L1 & 28.84 & 31.68 \\
Sample & 26.13 & 24.40 \\
& 57 & 23 \\
Mean & & \\
Std Dev & In-Treatment Change & 2.54 \\
Std Err Mean & 3.11 & 3.64 \\
L2 & 5.74 & 0.76 \\
L1 & 0.78 & 4.11 \\
Sample & 4.68 & 0.97 \\
\hline
\end{tabular}


Table E-17. Descriptive statistics by group for Middle Pharyngeal Plane Area.

\begin{tabular}{lcc}
\hline \multicolumn{1}{c}{ Statistic } & Non-Ext & Extraction \\
\hline & Start of Treatment & \\
Mean & 181.79 & 208.54 \\
Std Dev & 80.18 & 110.89 \\
Std Err Mean & 10.62 & 22.18 \\
L2 & 203.06 & 254.31 \\
L1 & 160.51 & 162.77 \\
Sample & 57 & 25 \\
& & \\
Mean & End of Treatment & \\
Std Dev & 223.14 & 239.68 \\
Std Err Mean & 80.17 & 149.96 \\
L2 & 10.62 & 31.97 \\
L1 & 244.41 & 306.17 \\
Sample & 201.87 & 173.19 \\
& 57 & 22 \\
Mean & & \\
Std Dev & In-Treatment Change & 29.72 \\
Std Err Mean & 41.37 & 67.48 \\
L2 & 78.76 & 14.39 \\
L1 & 10.72 & 59.64 \\
Sample & 62.87 & -0.20 \\
\hline
\end{tabular}


Table E-18. Descriptive statistics by group for Lower Pharyngeal Plane Width.

\begin{tabular}{lcc}
\hline \multicolumn{1}{c}{ Statistic } & Non-Ext & Extraction \\
\hline & Start of Treatment & \\
Mean & 25.79 & 25.80 \\
Std Dev & 3.86 & 4.97 \\
Std Err Mean & 0.50 & 0.96 \\
L2 & 26.78 & 27.77 \\
L1 & 24.79 & 23.84 \\
Sample & 60 & 27 \\
& & \\
Mean & End of Treatment & \\
Std Dev & 27.65 & 28.41 \\
Std Err Mean & 3.79 & 4.80 \\
L2 & 0.49 & 0.94 \\
L1 & 28.63 & 30.35 \\
Sample & 26.67 & 26.47 \\
& 60 & 26 \\
Mean & & \\
Std Dev & In-Treatment Change & \\
Std Err Mean & 2.16 & 2.48 \\
L2 & 3.74 & 3.49 \\
L1 & 0.49 & 0.68 \\
Sample & 3.14 & 3.89 \\
\hline
\end{tabular}


Table E-19. Descriptive statistics by group for Lower Pharyngeal Plane Area.

\begin{tabular}{lcc}
\hline \multicolumn{1}{c}{ Statistic } & Non-Ext & Extraction \\
\hline & Start of Treatment & \\
Mean & 196.81 & 233.68 \\
Std Dev & 84.31 & 125.16 \\
Std Err Mean & 10.89 & 24.09 \\
L2 & 218.59 & 283.19 \\
L1 & 175.03 & 184.17 \\
Sample & 60 & 27 \\
& & \\
Mean & End of Treatment & \\
Std Dev & 247.47 & 283.22 \\
Std Err Mean & 99.70 & 120.19 \\
L2 & 12.87 & 23.57 \\
L1 & 273.22 & 331.77 \\
Sample & 221.71 & 234.68 \\
& 60 & 26 \\
Mean & & \\
Std Dev & In-Treatment Change & \\
Std Err Mean & 55.67 & 48.15 \\
L2 & 100.61 & 87.80 \\
L1 & 13.10 & 17.22 \\
Sample & 81.89 & 83.61 \\
& 29.45 & 12.69 \\
\hline
\end{tabular}


Table E-20. Descriptive statistics by group for Middle Pharyngeal Airway Volume.

\begin{tabular}{lcc}
\hline Statistic & Non-Ext & Extraction \\
\hline & & \\
Mean & Start of Treatment & \\
Std Dev & 5223.08 & 6361.99 \\
Std Err Mean & 1750.08 & 3057.16 \\
L2 & 235.98 & 611.43 \\
L1 & 5696.20 & 7623.90 \\
Sample & 4750.00 & 5100.10 \\
& 55 & 25 \\
Mean & & \\
Std Dev & End of Treatment & 7519.83 \\
Std Err Mean & 6184.05 & 3559.23 \\
L2 & 1753.39 & 758.83 \\
L1 & 236.43 & 9097.90 \\
Sample & 6658.10 & 5941.80 \\
& 5710.00 & 22 \\
Mean & 55 & \\
Std Dev & & 914.36 \\
Std Err Mean & In-Treatment Change & 2046.10 \\
L2 & 999.43 & 436.23 \\
L1 & 1920.28 & 7821.50 \\
Sample & 28.89 & 7.16 \\
\hline
\end{tabular}


Table E-21. Descriptive statistics by group for Inferior Pharyngeal Airway Volume.

\begin{tabular}{lcc}
\hline \multicolumn{1}{c}{ Statistic } & Non-Ext & Extraction \\
\hline & Start of Treatment & \\
Mean & 5589.30 & 5634.39 \\
Std Dev & 2413.92 & 3251.82 \\
Std Err Mean & 322.57 & 650.36 \\
L2 & 6235.80 & 6976.70 \\
L1 & 4942.90 & 4292.10 \\
Sample & 56 & 25 \\
& & \\
Mean & End of Treatment & 7433.14 \\
Std Dev & 7100.79 & 4114.33 \\
Std Err Mean & 2819.69 & 877.18 \\
L2 & 380.21 & 9257.30 \\
L1 & 7863.10 & 5608.90 \\
Sample & 6338.50 & 22 \\
& 55 & \\
Mean & & 1760.11 \\
Std Dev & In-Treatment Change & 2306.02 \\
Std Err Mean & 1710.80 & 491.64 \\
L2 & 2565.92 & 2425.20 \\
L1 & 355.83 & 22 \\
Sample & 2425.2 & \\
\hline
\end{tabular}


Table E-22. Descriptive statistics by group for Total Pharyngeal Airway Volume.

\begin{tabular}{lcc}
\hline \multicolumn{1}{c}{ Statistic } & Non-Ext & Extraction \\
\hline & Start of Treatment & \\
Mean & 10822.70 & 11996.40 \\
Std Dev & 3657.36 & 5854.87 \\
Std Err Mean & 493.20 & 1171.00 \\
L2 & 11811.00 & 14413.00 \\
L1 & 9834.00 & 9579.60 \\
Sample & 55 & 25 \\
& & \\
Mean & End of Treatment & 14953.00 \\
Std Dev & 13284.80 & 7315.08 \\
Std Err Mean & 3912.10 & 1559.60 \\
L2 & 527.50 & 18196.00 \\
L1 & 14342.00 & 11710.00 \\
Sample & 12227.00 & 22 \\
& 55 & \\
Mean & & 2674.46 \\
Std Dev & In-Treatment Change & 3978.37 \\
Std Err Mean & 2701.94 & 4438.40 \\
L2 & 3728.40 & 910.60 \\
L1 & 522.08 & 22 \\
Sample & 3750.60 & \\
\hline
\end{tabular}




\section{VITA}

Thomas Patrick Shannon was born in 1981 in Sault Sainte Marie, Ontario, Canada. Thomas was raised in Sault Sainte Marie, Michigan and graduated from Sault Area High School in 2000. He attended Hillsdale College and then the University of Michigan School of Dentistry, graduating with a Doctor of Dental Surgery degree in May 2007. He then completed an AEGD residency at the University of North Carolina in Chapel Hill and spent one year in private general practice in Beaufort, SC. He is currently completing a residency in orthodontics at the University of Tennessee Health Science Center and plans to graduate with a Master of Dental Science degree in May 2012. 